Aus dem Institut für Pathologie

(Prof. Dr. med. P. Ströbel)

der Medizinischen Fakultät der Universität Göttingen

\title{
Zur Rolle von N-Cadherin in der Proliferation, Migration und Invasion maligner Keimzelltumoren des Hodens
}

\author{
INAUGURAL-DISSERTATION \\ zur Erlangung des Doktorgrades \\ der Medizinischen Fakultät der \\ Georg-August-Universität zu Göttingen
}

vorgelegt von

Simon Schallenberg

aus

Lengerich (Westfalen)

Göttingen 2019 
Dekan:

Referent:

Ko-Referentin:

Drittreferent:
Prof. Dr. rer. nat. H. K. Kroemer

PD. Dr. F. Bremmer

Prof. Dr. Margarete Schön

Prof. Dr. Thomas Meyer

Datum der mündlichen Prüfung: 12.12.2019 
Hiermit erkläre ich, die Dissertation mit dem Titel " Zur Rolle von N-Cadherin in der Proliferation, Migration und Invasion maligner Keimzelltumoren des Hodens " eigenständig angefertigt und keine anderen als die von mir angegebenen Quellen und Hilfsmittel verwendet zu haben.

Berlin, den 12.11.2019 


\section{Inhaltsverzeichnis}

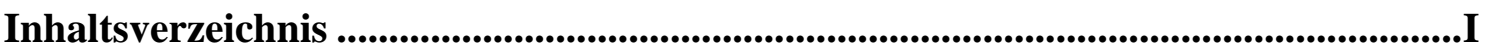

Abbildungsverzeichnis..................................................................................................... III

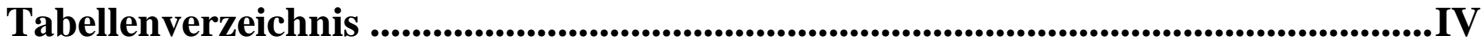

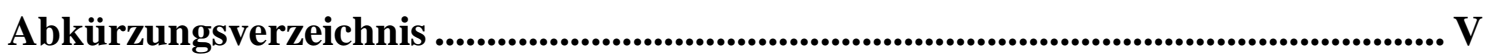

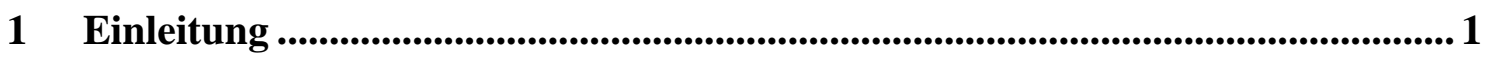

1.1 Maligne Keimzelltumoren des Hodens........................................................ 1

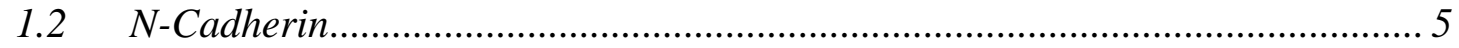

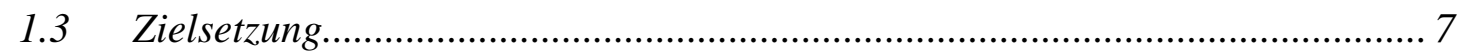

2 Material und Methoden .......................................................................................8 8

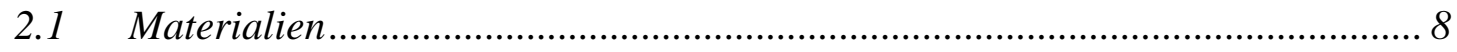

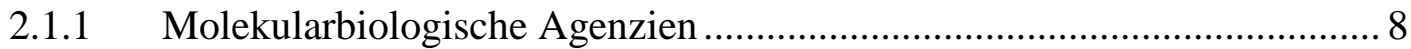

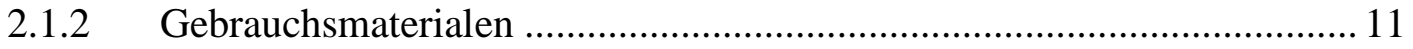

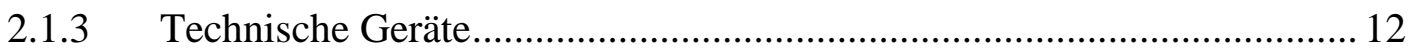

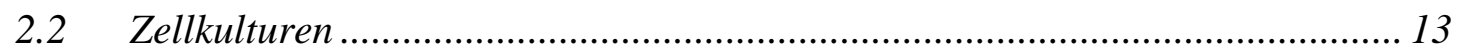

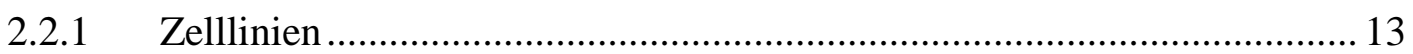

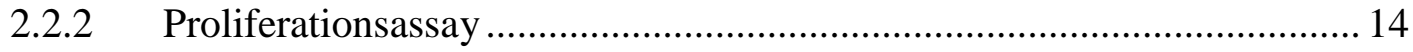

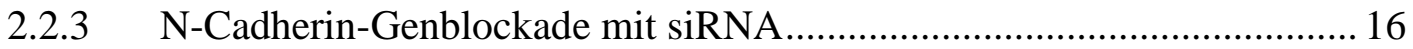

2.2.4 N-Cadherin-Blockade mit Antikörper ................................................. 17

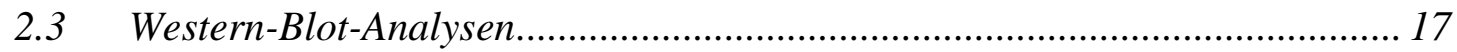

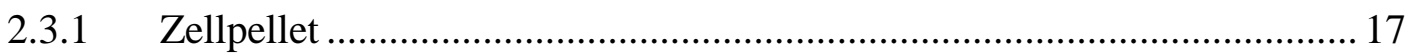

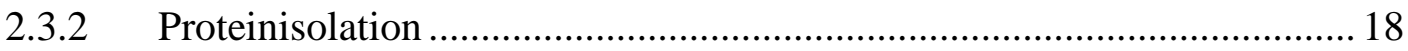

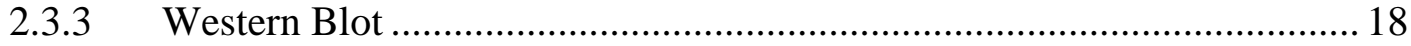

2.3.4 Proteindetektion und Lichtmessung.................................................... 20

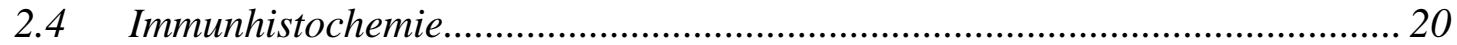

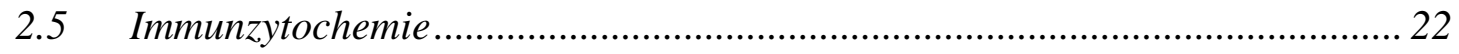

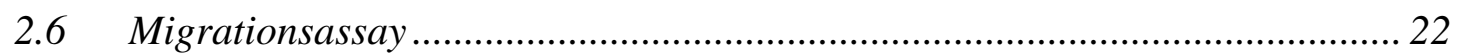

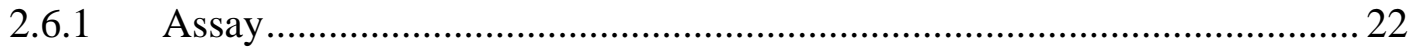

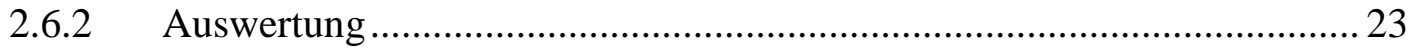

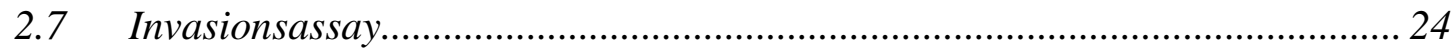

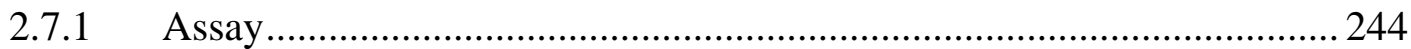

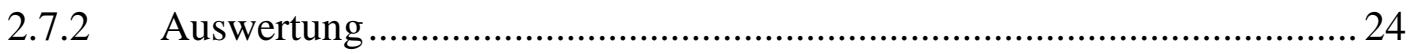

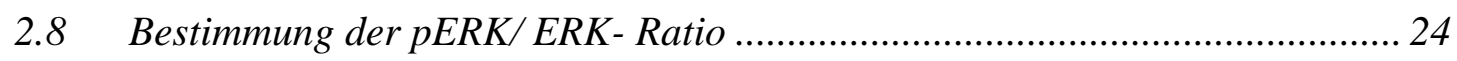




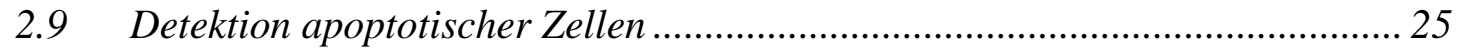

2.10 Bestimmung der pAKT/ AKT- Ratio …….................................................... 266

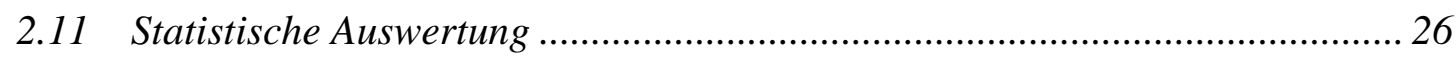

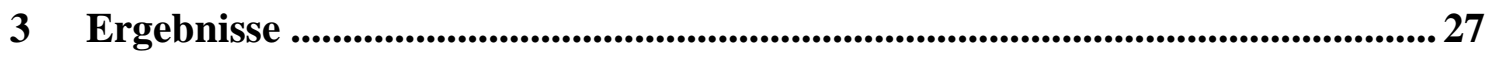

$3.1 \quad N$-Cadherin-Expression in Keimzelltumoren ................................................. 27

$3.2 \quad N$-Cadherin-Expression nach siRNA-Transfektion ....................................... 27

$3.3 \quad \mathrm{~N}$-Cadherin-Expression in Keimzelltumormetastasen .................................... 27

$3.4 \quad$ Proliferationsanalyse in GCT-Zelllinien....................................................... 28

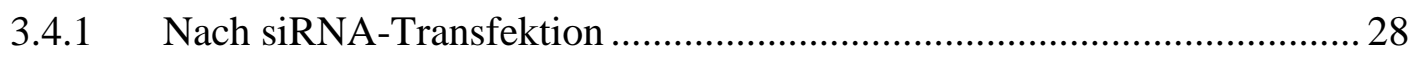

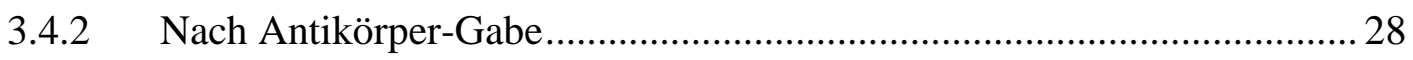

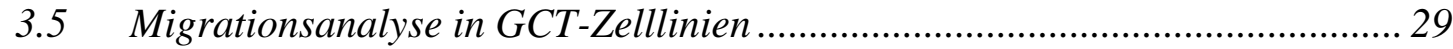

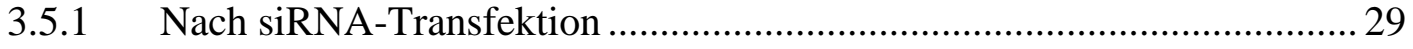

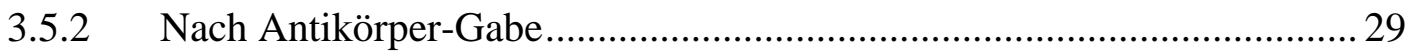

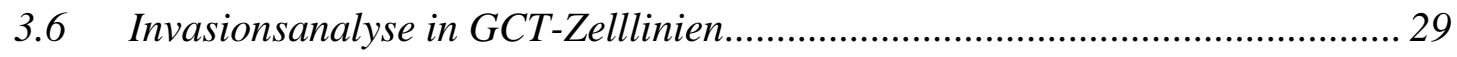

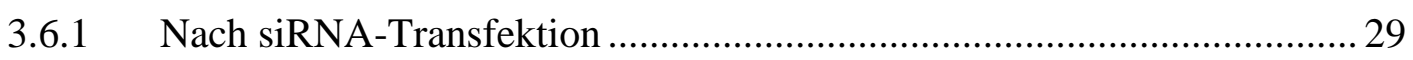

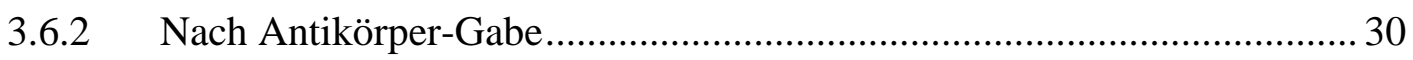

$3.7 \quad$ pERK/ ERK-Ratio nach siRNA-Transfektion .................................................. 30

3.8 Caspase-3-Aktivität nach Antikörper-Gabe .................................................... 30

3.9 pAKT/ AKT-Ratio nach siRNA-Transfektion ................................................. 30

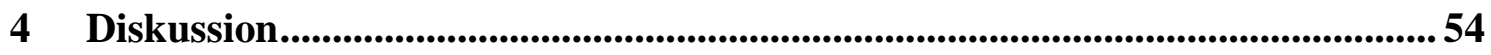

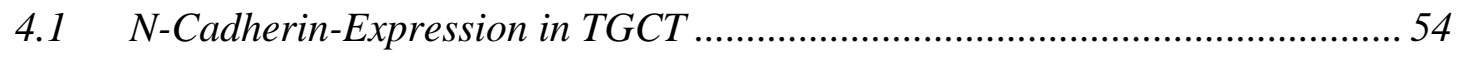

4.2 Proliferationsverhalten von GCT-Zelllinien nach N-Cadherin-Blockade ....... 57

4.3 Migrations- und Invasionsverhalten von GCT-Zelllinien nach N-CadherinBlockade

4.4 Molekulare Mechanismen der N-Cadherin-vermittelten Proliferation in

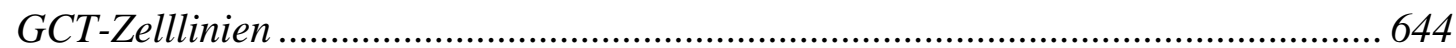

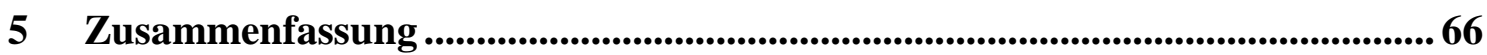

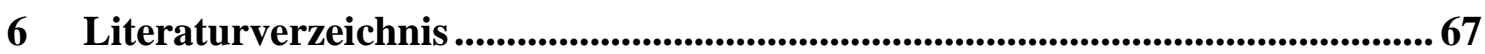




\section{Abbildungsverzeichnis}

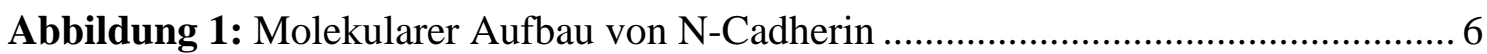

Abbildung 2: Zellprofil nach durchflusszytometrischer Messung .............................. 15

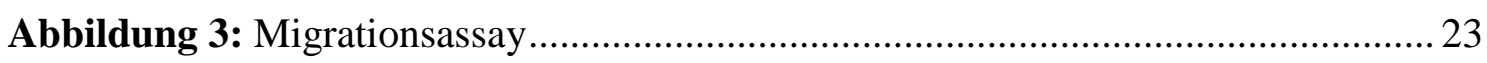

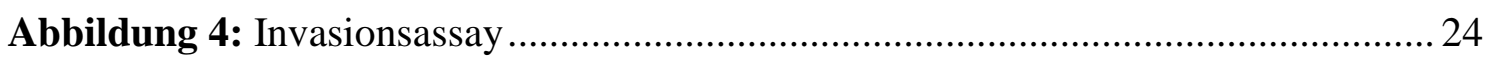

Abbildung 5: N-Cadherin-Expression in Cisplatin-sensitiven GCT-Zellllinien ............ 31

Abbildung 6: N-Cadherin-Expression in Cisplatin-resistenten GCT-Zellllinien ........... 31

Abbildung 7: N-Cadherin-Expression in Cisplatin-sensitiven GCT-Zelllinien nach siRNA-Transfektion

Abbildung 8: N-Cadherin-Expression in Cisplatin-resistenten GCT-Zelllinien nach siRNA-Transfektion

Abbildung 9: N-Cadherin-Expression in der Metastase eines Seminoms..................... 34

Abbildung 10: N-Cadherin-Expression in der Metastase eines Dottersacktumors ....... 35

Abbildung 11: N-Cadherin-Expression in primitivem neuroektodermalem Gewebe ... 36

Abbildung 12: N-Cadherin-Expression in der Metastase eines embryonalen

Karzinoms

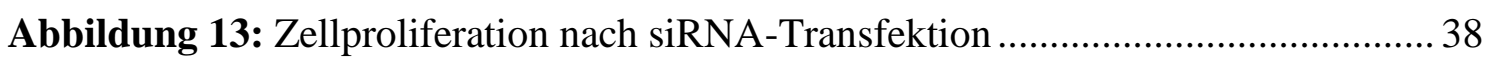

Abbildung 14: Zellproliferation nach Antikörper-Gabe........................................... 40

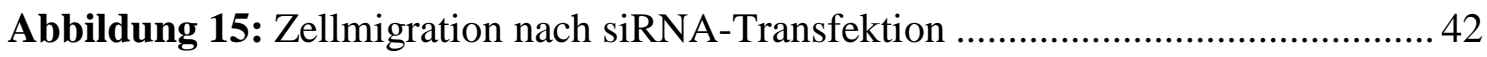

Abbildung 16: Zellmigration nach Antikörper-Gabe ................................................ 44

Abbildung 17: Zellinvasion nach siRNA-Transfektion ............................................. 45

Abbildung 18: Zellinvasion nach Antikörper-Gabe .................................................... 47

Abbildung 19: pERK/ ERK-Ratio nach siRNA-Transfektion ........................................ 48

Abbildung 20: Caspase-3-Aktivität nach Antikörper-Gabe ........................................... 50

Abbildung 21: pAKT/ AKT-Ratio nach siRNA-Transfektion ..................................... 52 


\section{Tabellenverzeichnis}

Tabelle 1: Zusammensetzung des Nährmediums ................................................... 14

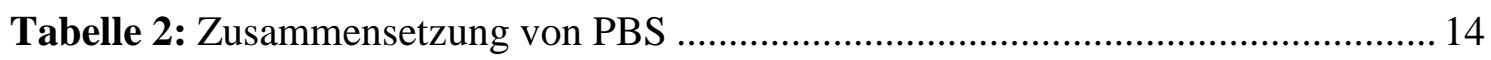

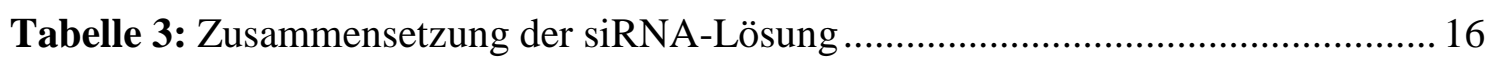

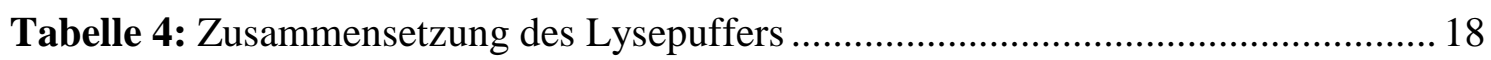

Tabelle 5: Zusammensetzung des TBS-Tween-Waschpuffer...................................... 19

Tabelle 6: Prozentsatz positiv gefärbter Zellen ........................................................ 21

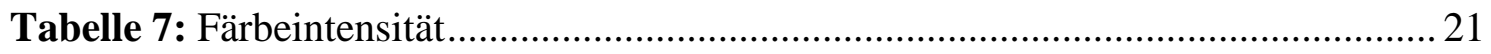

Tabelle 8: Immunhistochemischer Auswertungs-Score .......................................... 21

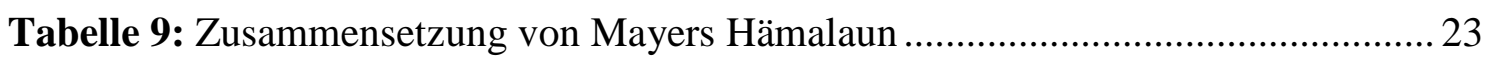

Tabelle 10: Histologische Subtypen der untersuchten Metastasen ................................ 28 


\section{Abkürzungsverzeichnis}

A

AFP

AK

AKT

Bad

$\beta$-HCG

bidest.

$\mathrm{Ca}^{2+}$

CD 30

CD 117

CDDP

$\mathrm{CDH} 2$

CK 19

c-Kit

$\mathrm{CO}_{2}$

CRPC

CT

dest.

D2-40

DNA

E-Cadherin

EMT

ERK

FACs

FISH

FCS

GCNIS

GCT

HDCT

$\mathrm{H}_{2} \mathrm{O}_{2}$
Ampere

$\alpha$-Fetoprotein

Antikörper

Proteinkinase B

Bcl-2-associated death promoter

$\beta$-humanes Choriongonadotropin

zweimal destilliert

Kalzium

Tumornekrose- Faktor- Rezeptor 8

Tyrosinkinase KIT

Cisdiamminedichloroplatinum

$\mathrm{N}-\mathrm{Cadherin}$

Zytokeratin 19

Tyrosinkinase KIT

Kohlenstoffdioxid

kastrationsresistente Prostatakrebszellen

Computertomographie

destilliert

Podoplanin

Deoxyribonucleic acid (Desoxyribonukleinsäure)

epitheliales Cadherin

epitheliale-mesenchymale Transition

Extracellular signal-regulated kinase

Fluorescence-activated cell sorting

Fluoreszenz-in-situ-Hybridisierung

fötales Kälberserum

Germ cell neoplasia in situ

Germ cell tumor

Hochdosischemotherapie

Wasserstoffperoxid 
HEPES

$\mathrm{i}(12 \mathrm{p})$

$\operatorname{IgG}$

IRS

IU

$\mathrm{K} \mathrm{Al}\left(\mathrm{SO}_{4}\right) 12 \mathrm{H}_{2} \mathrm{O}$

$\mathrm{KCl}$

$\mathrm{KH}_{2} \mathrm{PO}_{4}$

$\mathrm{LDH}$

L-Glutamin

MAPK

MAPKK

MAPKKK

MET

mRNA

MRT

$\mathrm{NaCl}$

N-Cadherin

$\mathrm{Na}_{2} \mathrm{HPO}_{4}$

Oct-3/4

PBS

P-Cadherin

pERK

PI3K

PLAP

RNA

RPMI

RT

SALL4

siRNA
2-(4-(2-Hydroxyethyl)-1-piperazinyl)-ethansulfonsäure

Isochromosom $12 \mathrm{p}$

Immunglobulin $\mathrm{G}$

Immunoreactive staining score

International unit (internationale Einheit)

Kalialaun

Kaliumchlorid

Kaliumdihydrogenphosphat

Laktatdehydrogenase

L-Enantiomer der Glutaminsäure

Mitogen-activated protein kinase

Mitogen-activated protein kinase-kinase (MAP2K)

Mitogen-activated protein kinase-kinase-kinase (MAP3K)

Mesenchymale-epitheliale Transition

Messenger ribonucleic acid

Magnetresonanztomographie

Natriumchlorid

neurales Cadherin

Dinatriumhydrogenphosphat

Octamer-binding transcription factor 4

Phosphate-buffered saline (Phosphat-gepufferte Saline)

plazentares Cadherin

Phosphorylated extracellular signal-regulated kinase

Phosphoinositid-3-Kinasen

plazentare alkalische Phosphatase

Ribonucleic acid (Ribonukleinsäure)

Benennung durch G. E. Moore und Kollegen am Roswell Park

Memorial Institute.

Raumtemperatur

Sal-like protein 4

Small interfering ribonucleic acid 
SOX-2

SOX-17

PMSF

TBS

TDS

TGCT

UICC

UpM

ZNS
Sex determining region Y-box 2

Sex determining region Y-box 17

Phenylmethylsulfonylfluorid

Tris-buffered saline (Trisgepufferte Saline)

Testikuläres Dysgenesie- Syndrom

Testicular germ cell tumors (testikuläre Keimzelltumore)

Union internationale contre le cancer (Internationale Vereinigung gegen Krebs)

Umdrehungen pro Minute

Zentrales Nervensystem 


\section{Einleitung}

\subsection{Maligne Keimzelltumoren des Hodens}

Die malignen Keimzelltumoren des Hodens (Testicular germ cell tumors, TGCT) bilden nahezu weltweit die größte Gruppe solider und maligner Tumoren bei jungen Männern zwischen dem 15. und 40. Lebensjahr (Beyer et al. 2013; Chia et al. 2002; Enewold et al. 2011; National Cancer Institute 2014). Des Weiteren machen sie mehr als 95\% aller Neubildungen des Hodens aus, sodass die Begriffe Hodenkrebs und TGCT in der Nomenklatur häufig synonym verwendet werden (Ekbom und Akre 1998; McGlynn und Trabert 2012). Männer aus den skandinavischen Ländern - dies gilt insbesondere für Dänemark und Norwegen - und der Schweiz weisen dabei die höchste Inzidenz mit einer Rate von mehr als 12 Neuerkrankungsfällen je 100.000 Einwohner und einem Lebenszeitrisiko von ca. 1\% auf (Chia et al. 2002; Dalgaard et al. 2012; Enewold et al. 2011; Rosen et al. 2011). Die Inzidenzrate in Deutschland ist mit etwa 9 Neuerkrankungsfällen je 100.000 Einwohner ebenfalls hoch und stieg wie in allen anderen Industrienationen in den letzten vier Dekaden stetig an (Hanna und Einhorn 2014; Krege et al. 2008a, 2008b). Mit einem Prozentsatz von 1-2\% aller Tumorerkrankungen weltweit stellen die malignen Keimzelltumoren des Hodens dennoch eine vergleichsweise seltenere Tumorentität dar (Bokemeyer et al. 1992; Chia et al. 2002; Enewold et al. 2011; Krege et al. 2008a, 2008b; National Cancer Institute 2014).

Bekannte Risikofaktoren für das Auftreten von TGCT sind der Kryptorchismus, ein früherer kontralateral aufgetretener Hodentumor und eine familiäre Vorbelastung sowohl seitens des Vaters als auch des Bruders (Cook et al. 2010; Fosså et al. 2005; Hemminki et al. 2006; Westergaard et al. 1996). Der größte Anstieg des relativen Risikos resultiert dabei aus einer Vorbelastung durch den Bruder - das individuelle Risiko steigt hier um etwa das 10-Fache (Hemminki et al. 2006). Einen wichtigen Anhaltspunkt zur Pathogenese gab dann eine Publikation aus dem Jahre 1989. Sie zeigte, dass Männer, die während der Zeit des Zweiten Weltkrieges geboren wurden, ein geringeres Risiko für TGCT in allen Altersklassen aufwiesen als alle anderen Männer, die vorher oder nachher zur Welt kamen (Møller 1989). Schließlich wurde durch eine zeitlich variierende Analyse von Inzidenzraten in mehreren Ländern, unter Einbeziehung der oben genannten Beobachtungen, die Hypothese aufgestellt, dass das Erkrankungsrisiko bereits während der Fetalperiode in utero durch eine Differenzierungsstörung der Gonozyten determiniert wird 
(Bergstrom et al. 1996; Ekbom und Akre 1998; McGlynn et al. 2003; McGlynn und Trabert 2012). Diese These stütze sich zum einen auf die Vielzahl kongenitaler Anomalien und perinataler Faktoren, die mit einem erhöhten Risiko für TGCT einhergehen neben dem oben genannten Kryptorchismus können hier als weitere Beispiele die angeborene Inguinalhernie und die Zwillingsschwangerschaft angeführt werden -, zum anderen auf die signifikante Verbindung zur männlichen Infertilität, vor allem aber auf die Korrelation zwischen Hodenkrebs und der Geburtsjahrgangskohorte (Bergstrom et al. 1996; Cook et al. 2010; Ekbom und Akre 1998; Jacobsen et al. 2000).

Die Vorstellung, dass eine Beziehung zwischen kongenitalen Anomalien, perinatalen Faktoren, männlicher Infertilität und Geburtenjahrgängen auf der einen und der erhöhten Erkrankungswahrscheinlichkeit für TGCT auf der anderen Seite besteht, wurde durch das Hyperonym eines testikulären Dysgenesie-Syndroms (TDS) weiterentwickelt (HoeiHansen et al. 2003; Skakkebaek et al. 2001). Bei dem TDS handelt es sich per definitionem um eine testikuläre Grunderkrankung, die funktionelle Läsionen wie eine beeinträchtigte Spermatogenese, Entwicklungsstörungen wie eine Hypospadie und den Kryptorchismus beinhaltet und diese in pathogenetischen Zusammenhang mit TGCT setzt (Hoei-Hansen et al. 2003; McGlynn und Trabert 2012; Skakkebaek et al. 2001). Die Abbildung der exakten Ätiologie und Pathogenese bleibt dennoch - auch nach heutigen Forschungsstand - weitgehend unvollständig (McGlynn und Trabert 2012).

Bei der Entstehung von TGCT stellt die testikuläre intratubuläre Keimzellneoplasie (Germ cell neoplasia in situ, GCNIS) in nahezu 90\% der Fälle die nicht invasive Vorläuferläsion dar (Hanna und Einhorn 2014; Moch et al. 2016). Während der Entwicklung eines invasiven Karzinoms kommt es dann bei einem Großteil der Tumoren zu einer strukturellen Veränderung im Chromosom 12 (Rodriguez et al. 1992). Das Isochromosom 12p (i(12p)), welches eine Verdopplung des kurzen Armes von Chromosom 12 kennzeichnet, ist dabei mit ca. 80\% die häufigste genetische Alteration (Atkin und Baker 1983; Samaniego et al. 1990). TGCT ohne i(12p), auch als i(12p) negative TGCT bekannt, weisen ebenfalls strukturelle Veränderungen des Chromosoms 12 auf, die mittels FISH nachgewiesen werden konnten. Beides unterstreicht die Bedeutung des Chromosoms für die Invasivität maligner Keimzelltumoren (Rodriguez et al. 1993; Samaniego et al. 1990).

Die WHO unterteilt die Keimzelltumoren des Hodens in zwei Gruppen: Die Keimzelltumoren, die von einer GCNIS ausgehen, und solche ohne Beziehung zur GCNIS. Erstere werden wiederum sowohl histologisch als auch klinisch-therapeutisch in die zwei großen 
Gruppen der Seminome und Nicht-Seminome gegliedert. Weitere Subtypen sind die Seminome mit synzytiotrophoblastären Riesenzellen und die gemischten Keimzelltumoren. Die Nicht-Seminome werden histomorphologisch weiter in das embryonale Karzinom, den Dottersacktumor, trophoblastische Tumoren wie das Chorionkarzinom und Teratome (postpubertär oder mit somatischer Malignität) unterteilt (Moch et al. 2016).

Das Seminom ist mit ca. 56\% die größte Subentität der TGCT (McGlynn und Trabert 2012). Das histologische Bild wird durch in Gruppen oder Strängen angeordnete große runde Zellen mit glykogenreichem hellen bis klaren Zytoplasma geprägt. In den hyperchromatischen Zellkernen mit feingranuliertem Chromatin sind deutliche Nukleolen erkennbar (Shen und Ro 2016b). Die einzelnen Tumorzellverbände sind charakteristischerweise von Bindegewebssepten mit variablem lymphozytären Infiltrat umgeben (Shen und Ro 2016). Immunhistochemische Marker sind Oct3/4, SOX-17, Podoplanin (D2-40), cKit (CD 117), Vimentin, SALL4, NANOG und die plazentare alkalische Phosphatase (PLAP) (Shen und Ro 2016b). Seminome mit synzytiotrophoblastären Riesenzellen beinhalten die namensgebenden $\beta$-HCG produzierenden synzytiotrophoblastären Riesenzellen (Shen und Ro 2016b).

Nicht-Seminome zeigen eine große morphologische Vielfalt. Das embryonale Karzinom ist der zweithäufigste TGCT nach dem Seminom und tritt zudem sehr häufig (80\%) als Komponente eines Mischtumors auf (Shen und Ro 2016c). Mikroskopisch kennzeichnend sind große, kohäsiv wachsende Zellen mit ausgeprägter Pleomorphie und eine hohe mitotische Aktivität. Begleitend zeigen sich meistens eingeblutete oder nekrotische Gewebsareale (Shen und Ro 2016c). Immunhistochemische Marker sind hier Pancytokeratin, die Transkriptionsfaktoren Oct-3/ -4, SALL4, Nanog, SOX-2 und CD30 (Shen und Ro 2016c). Der Dottersacktumor ist nach dem Teratom der zweithäufigste Keimzelltumor des Kindesalters (Bremmer et al. 2014). Er bietet ein buntes histologisches Bild in Form vielfältiger Wachstumsmuster (Bremmer et al. 2014). Pathognomonisch sind die sogenannten Schiller-Duval-Körperchen (Bremmer et al. 2014). Immunhistochemisch sind die Tumorzellen positiv für AFP, Glypican-3 und CK19 (Bremmer et al. 2015b). In der Regel ist das AFP auch im Serum erhöht und kann somit als Tumormarker genutzt werden (Böcker et al. 2012). Bei dem Chorionkarzinom handelt es sich um einen trophoblastär differenzierten hochmalignen Tumor. Er bildet häufig metastatische Absiedlungen in der Leber, der Lunge oder dem ZNS (Bremmer et al. 2014). Neben den immunhistochemischen Markern $\beta$-HCG und GATA-3 sind stark erhöhte $\beta$-HCG-Werte im Serum 
(>100000 IU/l) charakteristisch (Banet et al. 2015; Moch et al. 2016). Das Teratom ist ein Tumor, der Bestandteile aller drei Keimblätter, also Ektoderm, Mesoderm und Entoderm, enthalten kann. Man unterscheidet zwischen präpubertären-, postpubertären Teratomen und Teratomen mit somatischer Malignität (Moch et al. 2016). Epidermoidund Dermoidzysten, die Subtypen des präpubertären Teratoms, werden als benigne angesehen (Zhang et al. 2013).

Das Leitsymptom bei malignen Keimzelltumoren ist die schmerzlose Schwellung des Hodens (Shen und Ro 2016a). Ein Schweregefühl und Schmerzen treten ebenfalls gehäuft auf (Shen und Ro 2016a). Die klinische Klassifikation erfolgt nach der UICC TNM-Klassifikation (Krege et al. 2008a). Diagnostisch stehen die körperliche Untersuchung, bildgebende Verfahren (Sonographie, CT, MRT) und laborchemische Parameter ( $\beta$-HCG, AFP, LDH) im Mittelpunkt (Krege et al. 2008a). Therapeutisch erfolgen je nach Tumorstadium variable Kombinationen aus operativen Maßnahmen und Radio-/ Chemotherapien (Krege et al. 2008a, 2008b).

Die Prognose der malignen Keimzelltumoren hat sich in den letzten fünf Dekaden rapide verbessert. Noch vor 50 Jahren lag die Sterblichkeit eines Neuerkrankten bei ca. $90 \%$ im ersten Jahr (Hanna und Einhorn 2014). Bedingt durch die überlegeneren Chemotherapien sanken die Mortalitätsraten seit 1970 kontinuierlich (Bosl und Motzer 1997). In den USA lag die relative 5-Jahresüberlebensrate für Hodenkrebs zwischen 2001 und 2007 bei 96,4\% (McGlynn und Trabert 2012). Sogar bei Patienten mit einem metastasierten TGCT konnte eine Heilung in 80\% der Fälle erreicht werden (Beyer et al. 2013; Feldman et al. 2008; Hanna und Einhorn 2014). Bei metastasierten Tumoren mit mehrfachen Rezidiven besteht jedoch weiterhin eine sehr schlechte Prognose mit einem Langzeitüberleben von nur $10-15 \%$ (Einhorn, et al. 2007). 


\subsection{N-Cadherin}

Bei Cadherinen handelt es sich um $\mathrm{Ca}^{2+}$-abhängige, transmembranäre Glykoproteine, die in den Plasmazellmembranen der meisten soliden Geweben lokalisiert sind und zur Gruppe der Adhäsionsproteine gezählt werden (Angst et al. 2001).

In den frühen 1980er Jahren wurde Uvomorulin, heutzutage besser bekannt unter dem Namen E-Cadherin, als erstes Cadherin entdeckt. Beschrieben wurde es als Glykoprotein der Zelloberfläche, welches eine Rolle bei der Gewebsverdichtung spielt (Hyafil et al. 1981). In der Zwischenzeit wurden zahlreiche weitere Cadherine charakterisiert. Neben den drei klassischen Cadherinen E-Cadherin (epitheliales Cadherin), N-Cadherin (neurales Cadherin) und P-Cadherin (plazentares Cadherin) sind zum jetzigen Zeitpunkt eine große Vielzahl weiterer Proteine, wie zum Beispiel T-Cadherin oder Desmoglein, bekannt. Insgesamt umfasst die Cadherin-Superfamilie mehr als 80 verschiedene Moleküle (Angst et al. 2001).

Die drei klassischen Cadherine finden sich bevorzugt an Adhäsionspunkten und vermitteln $\mathrm{Ca}^{2+}$-abhängige Zell-Zell-Verbindungen (Angst et al. 2001; Pötter et al. 1999). Entscheidend sind die Proteine auch an der embryonalen Organentwicklung beteiligt. Cadherine kontrollieren hier u.a. die Trennung verschiedener Gewebeschichten, die Verschmelzung von Gewebeabschnitten und die Ausbildung von Gewebegrenzen (Kim et al. 2000; Takeichi 1995). Die Beobachtung, dass Cadherine das Metastasierungsverhalten von Tumorzellen beeinflussen - eine geringere Zahl der Proteine ging mit einer gesteigerten Metastasierungsrate des Tumors einher - unterstreicht zudem ihre Rolle in der Tumorbiologie (Stemmler 2008).

Das neurale Cadherin (N-Cadherin) ist ein $140 \mathrm{kDa}$ schweres Protein aus der CadherinSuperfamilie und wurde erstmals im Gehirn von Mäusen identifiziert. Strukturell handelt es sich um ein Homodimer mit extra- und intrazellulärer Domäne. Über die extrazelluläre Domäne, welche aus fünf durch Kalziumionen verbundenen identischen EC's (extrazelluläre Cadherin-Domänen) zusammensetzt ist, vermittelt das Glykoprotein adhäsive ZellZell-Kontakte (Gumbiner 2005). Intrazellulär ist es über Interaktionen zwischen seiner C-terminalen Region und den zytoplasmatisch gelegenen Cateninen ( $\beta$-Catenin, $\alpha$ Catenin und p120) mit dem Aktin-Zytoskelett verbunden (Abb. 1) (Gumbiner 2005). 


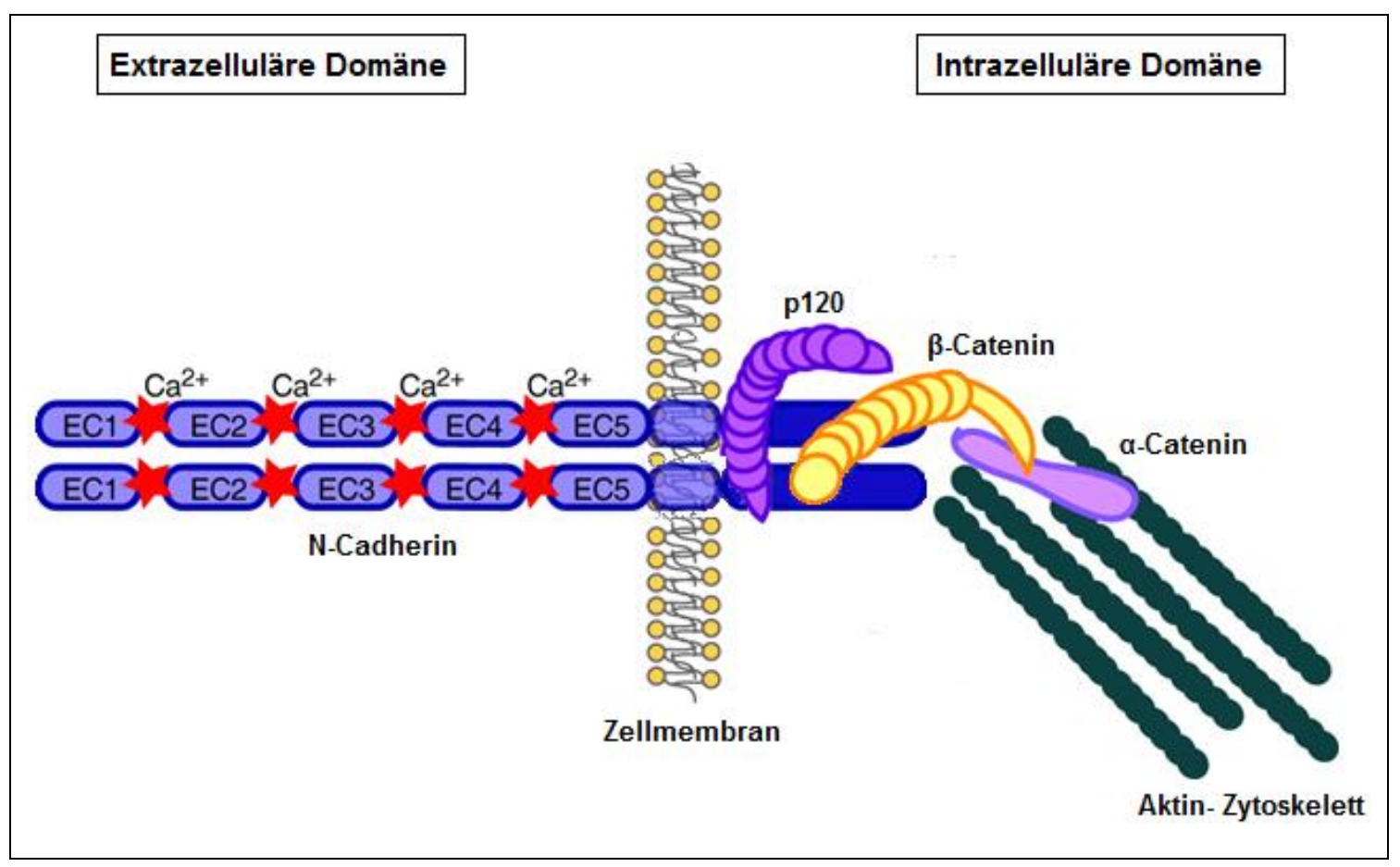

\section{Abbildung 1: Molekularer Aufbau von N-Cadherin; modifiziert nach Gumbiner,} 2005; Wheelock et al. 2008

Das Molekül erfüllt eine Vielzahl an Funktionen, nicht nur im ausgereiften soliden Gewebe, sondern auch bei der embryonalen Entwicklung. Es spielt u. a. eine entscheidende Rolle bei der Zell-Zell-Adhäsion und Zellmigration (Akitaya und Bronner-Fraser 1992). Außerdem konnte seine Beteiligung an Wundheilungsprozessen nachgewiesen werden (De Wever et al. 2004). Dass eine Mutation des proteinkodierenden Gens während der frühen Herzentwicklung einen Adhäsionsdefekt der Myozyten, einhergehend mit einer defizitären Entwicklung des Herzschlauches, zur Folge hat, unterstreicht die Bedeutung des Proteins in der Embryogenese (Radice et al. 1997). Darüber hinaus zeigten zahlreiche Publikationen, dass N-Cadherin auch beim Metastasierungsverhalten von Tumoren eine wichtige Funktion einnimmt (Kashima et al. 2003; Li et al. 2001; Tanaka et al. 2010).

N-Cadherin wird von verschiedenen epithelialen und mesenchymalen Tumoren exprimiert. Es wurde bei Untersuchungen in 78\% der Pleuramesotheliome und 26\% der pulmonalen Adenokarzinome nachgewiesen (Abutaily et al. 2002). Außerdem wurde es in serösen und endometrioiden epithelialen Tumoren des Ovars beobachtet (Peralta Soler et al. 1997). Papilläre Nierenzellkarzinome Typ II zeigten ebenfalls eine durchgängige Expression des Proteins (Behnes et al. 2012). Im Jahr 2012 wurde die N-Cadherin-Expression dann sowohl in normalem Hodengewebe als auch in der testikulären intratubulären 
Keimzellneoplasie (GCNIS) und in malignen Keimzelltumoren nachgewiesen. Die verschiedenen Subtypen der TGCT zeigten dabei eine unterschiedliche Expression des Proteins (Bremmer et al. 2012a).

\subsection{Zielsetzung}

Die Expression von N-Cadherin konnte in den Subtypen maligner Keimzelltumoren des Hodens und deren Vorläuferläsion nachgewiesen werden (Felix Bremmer et al. 2012a). Das Adhäsionsmolekül wiederum spielt eine entscheidende Rolle bei der Proliferation und Metastasierung von Tumorzellen (El Sayegh et al. 2007; Tanaka et al. 2010).

Darauf aufbauend waren die Ziele der vorliegenden Arbeit:

(I) Die Expressionsanalyse von N-Cadherin in TGCT und Keimzelltumor-Zelllinien (GCT-Zelllinien) mittels immunzytochemischen, immunhistochemischen und Western-Blot-Analysen.

(II) Der Einfluss von N-Cadherin auf die Proliferation, Migration und Invasion in Cisplatin-sensitiven GCT-Zelllinien.

(III) Der Einfluss von N-Cadherin auf die Proliferation, Migration und Invasion in Cisplatin-resistenten GCT-Zelllinien.

(IV) Die Untersuchung möglicher zugrundeliegender molekularer Mechanismen der N-Cadherin-vermittelten Proliferation in GCT-Zelllinien. 


\section{Material und Methoden}

\subsection{Materialien}

\subsubsection{Molekularbiologische Agenzien}

\begin{tabular}{|c|c|}
\hline Agens & Hersteller \\
\hline Aqua bidest. & Carl Roth, Karlsruhe, Deutschland \\
\hline Aqua dest. & $\begin{array}{l}\text { Universitätsmedizin, Göttingen, Deutsch- } \\
\text { land }\end{array}$ \\
\hline Aquamount Aquatex & Merck, Darmstadt, Deutschland \\
\hline Anti-Akt-Antikörper & Millipore, Billerica, Massachusetts, USA \\
\hline Anti-beta-Actin-Antikörper & $\begin{array}{l}\text { Monoclonal mouse, Sigma-Aldrich, } \\
\text { Taufkirchen, Deutschland }\end{array}$ \\
\hline Anti-Caspase-3-Antikörper & $\begin{array}{l}\text { Zytomed Systems GmbH, Berlin, } \\
\text { Deutschland }\end{array}$ \\
\hline Anti-Maus-Antikörper & Dako, Hamburg, Deutschland \\
\hline Anti-N-Cadherin-Antikörper & $\begin{array}{l}\text { Monoclonal mouse, Sigma-Aldrich, } \\
\text { Taufkirchen, Deutschland }\end{array}$ \\
\hline Anti-ERK1/2-Antikörper & Millipore, Billerica, Massachusetts, USA \\
\hline Anti-phospho-Akt-Antikörper & Millipore, Billerica, Massachusetts, USA \\
\hline Anti-phospho-ERK1/2-Antikörper & Millipore, Billerica, Massachusetts, USA \\
\hline Assay Buffer & Millipore, Billerica, Massachusetts, USA \\
\hline Chloralhydrat & Merck, Darmstadt, Deutschland \\
\hline DAB chromogen & Dako, Hamburg, Deutschland \\
\hline FCS, $10 \%$ & CC Pro, Neustadt, Deutschland \\
\hline Fixation Buffer & Millipore, Billerica, Massachusetts, USA \\
\hline Hämatoxylin & Merck, Darmstadt, Deutschland \\
\hline HiPerFect Transfection Reagent & Qiagen, Hilden, Deutschland \\
\hline
\end{tabular}




\begin{tabular}{|c|c|}
\hline Hepes-buffer & Carl Roth, Karlsruhe, Deutschland \\
\hline Kaliumaluminiumsulfat-Dodecahydrat & Merck, Darmstadt, Deutschland \\
\hline L-Glutamin & Biochrom, Berlin, Deutschland \\
\hline Lösung A, Bio-Rad DC Protein Assay & Bio-Rad, Hercules, Kalifornien, USA \\
\hline Lösung B, Bio-Rad DC Protein Assay & Bio-Rad, Hercules, Kalifornien, USA \\
\hline Lösung S, Bio-Rad DC Protein Assay & Bio-Rad, Hercules, Kalifornien, USA \\
\hline Magermilchpulver & Carl Roth, Karlsruhe, Deutschland \\
\hline Matrigel & $\begin{array}{l}\text { Becton Dickinson GmbH, Heidelberg, } \\
\text { Deutschland }\end{array}$ \\
\hline Methanol & Merck, Darmstadt, Deutschland \\
\hline Mayers Haematoxylin & Dako, Hamburg, Deutschland \\
\hline Muse Count\&Viability Kit & Millipore, Billerica, Massachusetts, USA \\
\hline $\mathrm{NaCl}$ (Natriumchlorid) & Carl Roth, Karlsruhe, Deutschland \\
\hline Natriumjodat & Merck, Darmstadt, Deutschland \\
\hline NCCIT-Zelllinie & $\begin{array}{l}\text { American Type Culture Collection, Ma- } \\
\text { nassas, Virginia, USA }\end{array}$ \\
\hline NCCIT-R-Zelllinie & $\begin{array}{l}\text { PD Dr. Dr. F. Honecker, AG experimen- } \\
\text { telle Onkologie, Universitäts-klinik Ham- } \\
\text { burg-Eppendorf, Deutschland }\end{array}$ \\
\hline $\begin{array}{l}\text { Novex Tris-Glycine SDS Running Buffer } \\
(10 \mathrm{X})\end{array}$ & $\begin{array}{l}\text { Thermo Fisher Scientific Inc., Waltham, } \\
\text { Massachusetts, USA }\end{array}$ \\
\hline NTERA-2-Zelllinie & $\begin{array}{l}\text { American Type Culture Collection, Ma- } \\
\text { nassas, Virginia, USA }\end{array}$ \\
\hline NTERA-2R-Zelllinie & $\begin{array}{l}\text { PD Dr. Dr. F. Honecker, AG experimen- } \\
\text { telle Onkologie, Universitäts-klinik Ham- } \\
\text { burg-Eppendorf, Deutschland }\end{array}$ \\
\hline Ortho Vanadat & Sigma-Aldrich, München, Deutschland \\
\hline PBS & Biochrom, Berlin, Deutschland \\
\hline
\end{tabular}




\begin{tabular}{|c|c|}
\hline Penicillin & Sigma-Aldrich, München, Deutschland \\
\hline Permeabilization buffer & Millipore, Billerica, Massachusetts, USA \\
\hline PMSF & Sigma, München, Deutschland \\
\hline RIPA Puffer mit Protease Inhibitoren & Roche, Mannheim, Deutschland \\
\hline RNase free water & Quiagen, Hilden, Deutschland \\
\hline Roti $®$-Load 1 & Carl Roth, Karlsruhe, Deutschland \\
\hline RPMI-1640 & Biochrom, Berlin, Deutschland \\
\hline siRNA-CDH2 & Qiagen, Hilden, Deutschland \\
\hline siRNA-fluoreszierend & Qiagen, Hilden, Deutschland \\
\hline siRNA-Kontrolle & Qiagen, Hilden, Deutschland \\
\hline Streptomycin & Sigma-Aldrich, München, Deutschland \\
\hline TCam-2-Zelllinie & $\begin{array}{l}\text { H. Schorle, Abteilung für Pathologie, } \\
\text { Universitätsklinikum Bonn, Deutschland }\end{array}$ \\
\hline 3-in-1 Procedure buffer & Dako, Glostrup, Dänemark \\
\hline Triton X100 & Sigma, München, Deutschland \\
\hline Trypsin/ EDTA Solution 10x & Biochrom, Berlin, Deutschland \\
\hline Tween 20-Detergent & $\begin{array}{l}\text { Sigma-Aldrich, Taufkirchen, Deutsch- } \\
\text { land }\end{array}$ \\
\hline Wasserstoffperoxid & Merck, Darmstadt, Deutschland \\
\hline Western Lightning Plus ECL & $\begin{array}{l}\text { Perkin Elmer, Waltham, Massachusetts, } \\
\text { USA }\end{array}$ \\
\hline Zitronensäure-Monohydrat & Merck, Darmstadt, Deutschland \\
\hline
\end{tabular}




\subsubsection{Gebrauchsmaterialen}

\begin{tabular}{|c|c|}
\hline Material & Hersteller \\
\hline Auslaufpipette (5ml, $10 \mathrm{ml}, 15 \mathrm{ml})$ & Sarstedt, Nümbrecht, Deutschland \\
\hline BioCoat Matrigel Invasion Chambers & $\begin{array}{l}\text { BD Pharmingen }{ }^{\mathrm{TM}} \text {, San Diego, Kalifor- } \\
\text { nien, USA }\end{array}$ \\
\hline Deckgläser & $\begin{array}{l}\text { Menzel-Gläser, Braunschweig, Deutsch- } \\
\text { land }\end{array}$ \\
\hline ECL System & $\begin{array}{l}\text { Amersham Bioscience, Freiburg, } \\
\text { Deutschland }\end{array}$ \\
\hline Falcon-Tubes, $50 \mathrm{ml}$ & Sarstedt, Nümbrecht, Deutschland \\
\hline Kanüle, $50 \mu \mathrm{m}$ & Braun, Melsungen, Deutschland \\
\hline $\begin{array}{l}\text { Klebefolie I-Cycler IQ Optical Quality } \\
\text { Sealing tape }\end{array}$ & $\begin{array}{l}\text { BioRad Laboratories, München, Deutsch- } \\
\text { land }\end{array}$ \\
\hline $\begin{array}{l}\text { Kolbenhub-Pipetten }(0,1-2,5 \mu 1,0,5-10 \\
\mu 1,10-100 \mu 1,100-1000 \mu 1)\end{array}$ & Eppendorf, Hamburg, Deutschland \\
\hline Millicell $8.0 \mu \mathrm{m}$ hanging PET inserts & Millipore, Billerica, Massachusetts, USA \\
\hline Mikrotiterplatte 96 & $\begin{array}{l}\text { Greiner Bio-One, Kremsmünster, Öster- } \\
\text { reich }\end{array}$ \\
\hline Mini PROTEAN Gele 4-15\% & $\begin{array}{l}\text { BioRad Laboratories, München, Deutsch- } \\
\text { land }\end{array}$ \\
\hline Mini PROTEAN Gelkammer & $\begin{array}{l}\text { BioRad Laboratories, München, Deutsch- } \\
\text { land }\end{array}$ \\
\hline Pipettenspitzen $(10 \mu \mathrm{l}, 100 \mu \mathrm{l}, 1000 \mu \mathrm{l})$ & Sarstedt, Nümbrecht, Deutschland \\
\hline Pipettenspitzen $(2,5 \mu \mathrm{l})$ & $\begin{array}{l}\text { Biozym Diagnostik, Hess. Oldendorf, } \\
\text { Deutschland }\end{array}$ \\
\hline $\begin{array}{l}\text { Standard-Reaktionsgefäße }(0,5 \mathrm{ml}, 1.5 \\
\mathrm{ml})\end{array}$ & Eppendorf, Hamburg, Deutschland \\
\hline TransTurboBlot Kit Nitrocellulose & Bio-Rad, Hercules, Kalifornien, USA \\
\hline
\end{tabular}




\begin{tabular}{|l|l|}
\hline 6-Well-Platte & Sarstedt, Nümbrecht, Deutschland \\
\hline Zählkammer & Neubauer Brand, Wertheim, Deutschland \\
\hline Zellkulturflaschen (25T, 75T) & Sarstedt, Nümbrecht, Deutschland \\
\hline
\end{tabular}

\subsubsection{Technische Geräte}

\begin{tabular}{|c|c|}
\hline Gerät & Hersteller \\
\hline Brutschrank $\left(+37^{\circ} \mathrm{C}\right)$ & Heraeus, Düsseldorf, Deutschland \\
\hline Eismaschine, Scotsman AF 80 & Scotsman Ice Systems, Mailand, Italien \\
\hline Feinwaage & Sartorius, Göttingen, Deutschland \\
\hline Gefrierschrank $\left(-20^{\circ} \mathrm{C}\right)$ & Liebherr, Biberach, Deutschland \\
\hline Gefrierschrank $\left(-80^{\circ} \mathrm{C}\right)$ & GFL, Burgwedel, Deutschland \\
\hline Kühlschrank, Silkafrost comfort & Siemens, München, Deutschland \\
\hline Kulturbank, Hera Safe & Heraeus, Düsseldorf, Deutschland \\
\hline Mikroskop ID 03 & Zeiss, Jena, Deutschland \\
\hline Muse ${ }^{\circledR}$ Cell Analyzer & Millipore, Billerica, Massachusetts, USA \\
\hline Objektträger $67 \times 26 \mathrm{~mm}$ & Knittel- Gläser, Bielefeld, Deutschland \\
\hline pH-Meter InoLab ph 720 & WTW, Weilheim, Deutschland \\
\hline Präzitherm Typ PZ 28-2 (Heizplatte) & Gestigkeit, Düsseldorf, Deutschland \\
\hline Schlittenmikrotom Hn 40 & $\begin{array}{l}\text { Reichert \& Jung, Heidelberg, Deutsch- } \\
\text { land }\end{array}$ \\
\hline Schüttler, Modell 3016 & GFL, Burgwedel, Deutschland \\
\hline Spannungsgerät LKB GPS 200/400 & $\begin{array}{l}\text { Amersham Pharmacia Biotech, Freiburg, } \\
\text { Deutschland }\end{array}$ \\
\hline Tecan reader & Tecan Group Ltd., Männedorf, Schweiz \\
\hline Vortex Genie 2 & Bänder u. Hobein AG, Zürich, Schweiz \\
\hline Wärmeschrank OV 5 & Biometra, Göttingen, Deutschland \\
\hline
\end{tabular}




\begin{tabular}{|l|l|}
\hline Zentrifuge, Biofuge Stratos & Heraeus, Düsseldorf, Deutschland \\
\hline Zentrifuge, Megafuge 1.0 R & Heraeus, Düsseldorf, Deutschland \\
\hline
\end{tabular}

\subsection{Zellkulturen}

\subsubsection{Zelllinien}

In der vorliegenden Doktorarbeit wurden die Cisplatin-sensitiven Zelllinien NCCIT, NTERA-2, TCam-2 und die Cisplatin-resistenten Varianten NCCIT-R und NTERA-2R verwendet. Die pluripotente Stammzelle von NCCIT (CRL 2073, American Type Culture Collection, Manassas, Virginia, USA) und NCCIT-R (bereitgestellt von PD Dr. Dr. F. Honecker, AG experimentelle Onkologie, Universitätsklinikum Hamburg-Eppendorf, Deutschland) stammte von einem Teratokarzinom, die von NTERA-2 (CRL 1973, American Type Culture Collection, Manassas, Virginia, USA) und NTERA-2R (bereitgestellt von PD Dr. Dr. F. Honecker, AG experimentelle Onkologie, Universitätsklinikum Hamburg-Eppendorf, Deutschland) von einem embryonalen Karzinom und die von TCam-2 (bereitgestellt von H. Schorle, Abteilung für Pathologie, Universitätsklinikum Bonn, Deutschland) von einem Seminom. Die Aufzucht der Zelllinien fand unter sterilen Bedingungen an einer Kulturbank statt.

Die anfangs eingefrorenen Zellen wurden im Zuge der Rekultivierung in einem Wasserbad bei $37^{\circ} \mathrm{C}$ aufgetaut und in eine neue Tube mit $5 \mathrm{ml}$ Nährmedium resuspendiert. Anschließend wurden sie bei Raumtemperatur für 5 min bei $1100 \mathrm{UpM}$ zentrifugiert. Im Anschluss ließ sich nun der Überschuss oberhalb der Zellpellets abpipettieren. Danach wurde das Pellet mit $5 \mathrm{ml}$ Medium wiederum resuspendiert. Hiernach wurden die Zelllinien in Kulturflaschen mit einer Grundfläche von $75 \mathrm{~cm}^{2}$ und $15 \mathrm{ml}$ Nährmedium in einem Brutschrank bei $37^{\circ} \mathrm{C}$ Umgebungstemperatur und $5 \% \mathrm{CO}_{2}$ kultiviert. Anhand eines charakteristischen Farbumschlags des Mediums von Rot (frisch) nach Gelb (aufgebraucht) konnte während der Anzucht der Zeitpunkt für einen Nährmediumwechsel erkannt werden.

Vor dem Ablösen der Zellen wurde das alte Medium mit einer sterilen Pipette abgesaugt. Anschließend wurden die Ziellinien mit 3 ml PBS gewaschen und dieses danach entfernt. Nach Zugabe von $1 \mathrm{ml}$ Trypsin wurden die Zellkulturen 3-5 min im Brutschrank inkubiert. Das Ablösen der Zellen wurde daraufhin mikroskopisch kontrolliert, der Vorgang 
dann mit $9 \mathrm{ml}$ Nährmedium gestoppt, sodass man im Ergebnis $10 \mathrm{ml}$ Zellsuspension erhielt. Abschließend wurde die Zellzahl mittels Durchflusszytometrie bestimmt. Jeweils $1 \times 10^{6}$ Zellen wurden in eine neue Kulturflasche für weitere Versuche überführt.

\begin{tabular}{|c|c|c|}
\hline \multicolumn{3}{|l|}{ Nährmedium (500 ml) } \\
\hline Agens & Menge & Anteil \\
\hline RPMI 1640 & $425 \mathrm{ml}$ & $85 \%$ \\
\hline FCS & $50 \mathrm{ml}$ & $10 \%$ \\
\hline L-Glutamin & $6,25 \mathrm{ml}$ & $1,25 \%$ \\
\hline $\begin{array}{l}\text { Penicillin }(100 \mathrm{IU} / \mathrm{ml}) \text {, } \\
\text { Streptomycin }(100 \mu \mathrm{g} / \mathrm{ml})\end{array}$ & $6,25 \mathrm{ml}$ & $1,25 \%$ \\
\hline Hepes buffer & $12,5 \mathrm{ml}$ & $2,5 \%$ \\
\hline
\end{tabular}

Tabelle 1: Zusammensetzung des Nährmediums

\begin{tabular}{|c|c|}
\hline \multicolumn{2}{|c|}{ Phosphat-gepufferte Saline (PBS) } \\
\hline Agens & Menge \\
\hline $\mathrm{Na}_{2} \mathrm{HPO}_{4}$ & $5,75 \mathrm{~g}$ \\
\hline $\mathrm{KH}_{2} \mathrm{PO}_{4}$ & $1 \mathrm{~g}$ \\
\hline $\mathrm{NaCl}$ & $40 \mathrm{~g}$ \\
\hline $\mathrm{KCl}$ & $1 \mathrm{~g}$ \\
\hline Aqua dest. & $500 \mathrm{ml}$ \\
\hline
\end{tabular}

\section{Tabelle 2: Zusammensetzung von PBS}

\subsubsection{Proliferationsassay}

Für diesen Versuch wurden 6-Well-Platten verwendet. $1 \times 10^{5}$ oder $3 \times 10^{5}$ Zellen wurden je nach Ziellinie pro Well ausgesät und mit Nährmedium auf $2 \mathrm{ml} /$ Well verdünnt. Im Anschluss ließ man die Zellen im Brutschrank über $24 \mathrm{~h}$ anwachsen. Danach wurde das Nährmedium entweder durch siRNA- (2,3 ml Nährmedium + $100 \mu 1$ siRNA-Lösung) oder 
durch Antikörper-Medium (2 ml Nährmedium + $20 \mu$ l N-Cadherin- oder Kontrollantikörper) ersetzt und für jeweils 12-, 24-, 48- und 72 h, oder 1-, 12-, 24- und 48 h inkubiert. $\mathrm{Zu}$ den jeweiligen Zeitpunkten wurden dann die lebenden Zellen je Well ausgezählt.

Die Zellzahl wurde mit dem Muse Cell Analyzer bestimmt. Dazu mussten die vorher adhärenten Tumorzellen mit Trypsin abgelöst und in Nährmedium gelöst werden. Danach wurden $50 \mu 1$ der gut gemischten Suspension mit $450 \mu 1$ Muse Count and Viability Kit im Verhältnis 1:10 verdünnt. Das Gemisch inkubierte 5 min bei Raumtemperatur (RT), bis im Anschluss die Zellzahl durchflusszytometrisch bestimmt wurde (Abb. 2).

Das Prinzip der Messung beruhte dabei auf einem spezifisch DNA-bindenden Farbstoff im Muse Count and Viability Kit. Dieser Farbstoff ist nicht zellmembrangängig und färbt somit die DNA gesunder und lebender Zellen nicht an. Stark geschädigte, oder aber abgestorbene Zellen verlieren ihre Membranintegrität und werden somit angefärbt und von dem Gerät als tot erkannt.

Das Gerät errechnete am Ende die absolute Zellzahl pro ml, die absolute Zahl lebender Zellen pro ml, genauso wie den prozentuellen Anteil lebender und toter Zellen. Mittels der absoluten Zahl lebender Zellen/ml konnte die Proliferation der Tumorzelllinien, unter Antikörper- und siRNA-Einfluss genau analysiert werden.

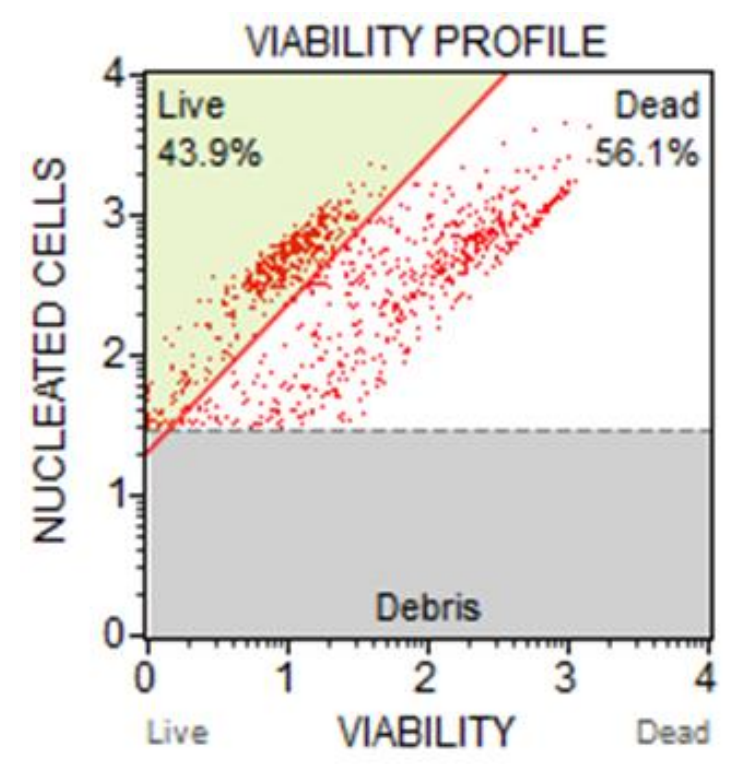

Abbildung 2: Zellprofil nach durchflusszytometrischer Messung 


\subsubsection{N-Cadherin-Genblockade mit siRNA}

Die Kultivierung der Zellen erfolgte wie unter 2.2.1 beschrieben. Um statistisch verwertbare Ergebnisse zu erhalten, musste die Zellzahl mittels Durchflusszytometrie exakt bestimmt werden (siehe 2.2.2). Für den weiteren Versuch wurden 6-Well-Platten verwendet. 100000 oder 300000 Zellen wurden je nach Ziellinie pro Well ausgesät und mit Nährmedium auf 2 ml/Well verdünnt. Im Anschluss ließ man die Zellen im Brutschrank über $24 \mathrm{~h}$ anwachsen.

Bei der benutzten siRNA handelte es sich um Hs_CDH2_6, cat. nr. SI02757335 (Qiagen, Hilden, Deutschland). Die siRNA lag ursprünglich als Pulver vor. $20 \mathrm{nmol}$ wurden mit $1000 \mu 1$ RNase-free water verdünnt, um eine $20 \mu \mathrm{M}$ Lösung zu erhalten. Um ein Zerfall der siRNA zu verhindern, musste der ganze Vorgang auf Eis durchgeführt werden. Danach wurde aus siRNA, HiPerFect Transfection Reagent und RPMI die endgültige siRNA-Versuchslösung hergestellt und mittels Vortexer ausreichend vermengt. Parallel dazu wurden eine siRNA-Vergleichslösung aus Kontroll-siRNA, HiPerFect und RPMI und eine Lösung aus fluoreszierender RNA, HiPerFect und RPMI selbigen Mischungsverhältnisses angesetzt. Letztere diente zur Messung der siRNA-Aggregation in den Zellen mittels FACs-Analyse. Die Lösungen inkubierten 20 min bei RT.

Als Nächstes erfolgte die behutsame Abpippetierung des Nährmediums aus den 6-WellPlatten, um die angewachsenen Zellen nicht zu lösen. Am Schluss wurde jedes Well mit 2,3 ml Nährlösung und $100 \mu \mathrm{l}$ Versuchslösung befüllt (3 Wells mit siRNA, 3 Wells mit Kontroll-siRNA), sodass eine siRNA-Verdünnung von 1:1000 erzielt wurde. Die Zellen wurden dann entsprechend Versuch 12-, 24-, 48- oder 72 h lang inkubiert.

\begin{tabular}{|l|r|}
\hline \multicolumn{2}{|c|}{ siRNA-Versuchslösung für $\mathbf{1}$ Well $(\mathbf{1 0 0} \mu \mathrm{l})$} \\
\hline \multicolumn{1}{|c|}{ Agens } & Menge \\
\hline siRNA, Kontroll-siRNA oder fluoreszierende siRNA & $2,4 \mu \mathrm{l}$ \\
\hline HiPerFect & $12 \mu \mathrm{l}$ \\
\hline RPMI & $86,6 \mu \mathrm{l}$ \\
\hline
\end{tabular}

\section{Tabelle 3: Zusammensetzung der siRNA-Lösung}




\subsubsection{N-Cadherin-Blockade mit Antikörper}

Die Kultivierung der Zellen erfolgte wie unter 2.2.1 beschrieben. Um statistisch verwertbare Ergebnisse zu erhalten musste die Zellzahl durchflusszytometrisch exakt bestimmt werden (siehe 2.2.2). Für den weiteren Versuch wurden 6-Well-Platten verwendet. $1 \times 10^{5}$ oder $3 \times 10^{5}$ Zellen wurden je nach Ziellinie pro Well ausgesät und mit Nährmedium auf 2ml/Well verdünnt. Im Anschluss ließ man die Zellen im Brutschrank über $24 \mathrm{~h}$ anwachsen.

Bei dem verwendeten Blockadeantikörper handelte es sich um einen monoklonalen AntiN-Cadherin Antikörper, der in der Maus produziert wurde (Sigma-Aldrich, Taufkirchen, Deutschland). Um die empfohlene Arbeitskonzentration $(10 \mu \mathrm{g} / \mathrm{ml}) \mathrm{zu}$ erreichen, wurden $20 \mu$ l Antikörper (IgG Konzentration: 2-2.5 mg/ml) mit 2 ml Nährmedium gemischt. Zur Herstellung der Vergleichslösung wurde anstelle des Blockadeantikörpers ein Kontrollantikörper verwendet.

Anschließend wurde das Nährmedium vorsichtig aus den 6-Well-Platten entfernt, um die angewachsenen Zellen nicht zu lösen und das Ergebnis damit zu verfälschen. Drei Wells wurden daraufhin mit $2 \mathrm{ml}$ Medium (Antikörperkonzentration: $10 \mu \mathrm{g} / \mathrm{ml}$ ) befüllt, die andere Hälfte mit 2 ml Kontrollmedium. Die Zellen wurden dann entsprechend Versuch 1, 12-, 24- und $48 \mathrm{~h}$ inkubiert.

\subsection{Western-Blot-Analysen}

\subsubsection{Zellpellet}

Als Erstes mussten Zellen pelletiert werden. Dabei wurden zum einen Pellets aus Zellkulturen unter normalen Wachstumsbedingungen, zum anderen aus Zellkulturen nach vorangegangener Blockade mit siRNA-CDH2 gewonnen. Die Kultivierung der Zellen erfolgte wie unter 2.2.1 beschrieben. Die Zellen wurden mittels Trypsin abgelöst und mit Nährmedium zu einer Zellsuspension vermischt. Daraufhin erfolgte die Zentrifugation bei 1200 UpM für 4 min. Der Überstand an Medium wurde vorsichtig abpippetiert und das entstandene Zellpellet für die nachfolgende Proteinisolation bei $-80{ }^{\circ} \mathrm{C}$ eingefroren. 


\subsubsection{Proteinisolation}

Zur Proteinisolation wurde ein Lysepuffer mit Protease-Inhibitoren verwendet. Jedes Zellpellet wurde mit $60 \mu 1$ Lysepuffer versetzt und $30 \mathrm{~min}$ auf Eis gelagert. Anschließend folgte die Zentrifugation des Ansatzes über 30 min bei $4{ }^{\circ} \mathrm{C}$. Der Überstand, der die Proteine enthielt, wurde in ein neues Tube überführt und bei $-20{ }^{\circ} \mathrm{C}$ kryokonserviert.

\begin{tabular}{|l|r|}
\hline \multicolumn{2}{|c|}{ Lysepuffer $(\mathbf{1} \mathbf{~ m l})$} \\
\hline \multicolumn{1}{|c|}{ Agens } & Menge \\
\hline Ripa- Buffer & $940 \mu \mathrm{l}$ \\
\hline 25 complete $\mathrm{x}$ & $40 \mu \mathrm{l}$ \\
\hline PMSF & $10 \mu \mathrm{l}$ \\
\hline Ortho Vanadat & $10 \mu \mathrm{l}$ \\
\hline
\end{tabular}

\section{Tabelle 4: Zusammensetzung des Lysepuffers}

Als nächster Schritt erfolgte die Messung der Proteinkonzentration mit dem Tecan-Reader (Tecan Group Ltd., Männedorf, Schweiz). Neben den Proteinproben benötigte man dazu das DC Protein Assay (Bio-Rad, Hercules, Kalifornien, USA), welches aus drei verschiedene Lösungen (A, B, S) bestand, die man dann auf Mikrotiterplatten in Triplikaten vorlegte. Dazu wurde zu Anfang Lösung S in einem Verhältnis von 1:50 mit Lösung A verdünnt. Jedes Well wurde mit $20 \mu 1$ dieser Mischung befüllt. Danach wurden $2 \mu 1$ Protein in Triplikaten je Proteinprobe hinzugegeben. Zuletzt erfolgte die Zugabe von $200 \mu 1$ der Lösung B je Well. Dieses Gemisch wurde 10 min bei RT gelagert. Dann wurde die Proteinkonzentration absorptionsspektrometrisch im Tecan-Reader gemessen. Außerdem errechnete das Gerät die Menge an benötigtem Roti-Load-Puffer je Probe für den nachfolgenden Western Blot.

\subsubsection{Western Blot}

Die jeweils $15 \mu$ g großen Proteinproben wurden auf Eis aufgetaut und mit entsprechend errechneter Menge (siehe 2.3.2) Roti-Load-Puffer versetzt. Dadurch sollten die Proteine angefärbt, eine molekulare Interaktion vermieden werden. Diese Mischung wurde $10 \mathrm{~min}$ bei $95{ }^{\circ} \mathrm{C}$ im Thermomixer inkubiert. In der Zwischenzeit wurde der Laufpuffer $(50 \mathrm{ml})$ 
in einem Verhältnis von 1:20 mit destilliertem Wasser (950 ml) verdünnt. Der Zusammenbau der Western-Blot-Apparatur mit fertigen Polyacrylamidgelen, die Spülung der Laufplatte mit destilliertem Wasser und die Auffüllung des inneren und äußeren Kompartiments mit Laufpuffer folgten.

Nach 10 min wurden dann die Lauffächer mit dem Protein-Roti-Load-Gemisch befüllt. Das erste Fach wurde mit $5 \mu$ l Prostain-Protein-Ladder, der als Gewichtsmarker dient, befüllt. Die Proteinauftrennung nach Molekulargewicht und Ladung erfolgte zuerst bei $60 \mathrm{~V}$ für $15 \mathrm{~min}$, dann bei $150 \mathrm{~V}$ für $1 \mathrm{~h}$.

Im nächsten Schritt wurde das Gel auf eine Zellulosemembran zwischen in Laufpuffer getränkte Filtermembranen eingebracht und in den Trans-Blot-Turbo-Apparat gelegt. Der Transferpuffer bestand aus Transblot Turbo und Aqua bidest in einem Mischungs-verhältnis von 1:5. Die Proteine wurden dann bei $25 \mathrm{~V}$ und $1 \mathrm{Amp}$. über $30 \mathrm{~min}$ von dem Gel auf die Zellulosemembran übertragen. Daraufhin wurde die Membran ausgelöst, von Gelspuren bereinigt und in TBS-Tween gewaschen.

\begin{tabular}{|l|r|}
\hline \multicolumn{1}{|c|}{ TBS-Tween-Waschpuffer (2 I) } \\
\hline \multicolumn{1}{|c|}{ Agens } & Menge \\
\hline PBS & $200 \mathrm{ml}$ \\
\hline Tween 20 Detergent & $2 \mathrm{ml}$ \\
\hline Dest. $\mathrm{H}_{2} \mathrm{O}$ & $1798 \mathrm{ml}$ \\
\hline
\end{tabular}

\section{Tabelle 5: Zusammensetzung des TBS-Tween-Waschpuffer}

Zur Kontrolle des erfolgreichen Proteintransfers erfolgte die Anfärbung der Proteine auf der Membran mit Ponceau S. Der Farbstoff wurde danach mit aqua bidest entfernt.

Die Zellulosemembran wurde im Anschluss über $1 \mathrm{~h}$ in einem 5 prozentigen Milchsäurepuffer (10 ml TBS-Tween + 0,5 g Milchpulver) inkubiert, um unspezifische Antikörperbindungen gegen freie Proteinbindungsstellen zu verhindern. 


\subsubsection{Proteindetektion und Lichtmessung}

Nachdem der Milchsäurepuffer entfernt worden war, wurde die Primärantikörperlösung, (anti-N-Cadherin-Antikörper + $1 \%$ Milchsäurepuffer; 1:1000) auf die Membran gegeben und bei $4{ }^{\circ} \mathrm{C}$ über Nacht inkubiert. Es folgte ein dreimaliger Waschvorgang mit TBSTween über jeweils 10 min. Daraufhin wurde die Membran mit der Sekundäranti-körperlösung (anti-mouse-Antikörper + $1 \%$ Milchsäurepuffer; 1:1000) für $1 \mathrm{~h}$ bei RT versetzt. Der Sekundärantikörper bindet dabei spezifisch an den Primärantikörper. Nach einem abermaligen dreifachen Waschvorgang mit TBS-Tween über jeweils 5 min wurde 1,5 ml Western lightning plus ECL auf die Membran gegeben. Dies diente dazu, dass der sekundäre Antikörper mit HRP (Horseraddish-Peroxidase) konjugiert wurde. Letztgenanntes wurde mittels Chemielumineszenz visualisiert. Die emittierte elektromagneti-sche Strahlung wurde in einer Röntgenkassette sichtbar gemacht.

Um die Membran wieder verwenden zu können, wurden die Antikörperkomplexe mit einem speziellen Stripping-Puffer über 15 min abgelöst. Es folgte ein dreimaliger Waschvorgang mit TBS- Tween für jeweils $10 \mathrm{~min}$. Im Anschluss konnten dann weitere Proteinnachweise folgen.

\subsection{Immunhistochemie}

Das Tumorgewebe wurde in Formalin fixiert und in Paraffin eingebettet. Mit einem Schlittenmikrotom wurden $4 \mu \mathrm{m}$ dicke Schnitte angefertigt und auf Objektträger aufgelegt. Die Trocknung der Schnitte erfolgte im Wärmeschrank bei $40{ }^{\circ} \mathrm{C}$. Für die Deparrafinierung, die Rehydrierung und Epitopenwiederherstellung wurde der 3-in-1 procedure Buffer verwendet. Die endogene Peroxidase wurde mit $\mathrm{H}_{2} \mathrm{O}_{2}$ (über 5 min) geblockt. Anschließend wurden die Schnitte für $1 \mathrm{~h}$ bei RT mit dem anti-N-Cadherin- Antikörper inkubiert. Dieser wurde mit mittels Dako EnVision ${ }^{\mathrm{TM}}$ FLEX+ detection system detektiert und mit dem EnVision ${ }^{\mathrm{TM}}$ FLEX DAB + Chromogen visualisiert.

Die Gewebsschnitte wurden lichtmikroskopisch 8 min nach der Gegenfärbung mit Mayers Hämatoxylin begutachtet und hinsichtlich des Prozentsatzes positiv gefärbter Zellen und deren Färbeintensität, in Anlehnung an den immunoreactive staining score (IRS), analysiert (Felix Bremmer et al. 2012b). Beide Scores wurden im letzten Schritt miteinander multipliziert. So erhielt man einen vergleichbaren abschließenden Wert pro Gewebsschnitt. 


\begin{tabular}{|c|c|}
\hline \multicolumn{2}{|c|}{ Prozentsatz positiv gefärbter Zellen } \\
\hline Anteil positive Zellen (\%) & Score (Punkte) \\
\hline 0 & 0 \\
\hline$<10$ & 1 \\
\hline $10-50$ & 2 \\
\hline $51-80$ & 3 \\
\hline$>80$ & 4 \\
\hline
\end{tabular}

Tabelle 6: Prozentsatz positiv gefärbter Zellen

\begin{tabular}{|c|c|}
\hline \multicolumn{2}{|l|}{ Färbeintensität } \\
\hline Intensität & Score (Punkte) \\
\hline Negativ & 0 \\
\hline Leicht & 1 \\
\hline Mittel & 2 \\
\hline Stark & 3 \\
\hline
\end{tabular}

Tabelle 7: Färbeintensität

\begin{tabular}{|c|c|}
\hline \multicolumn{2}{|l|}{ Einteilung in Gruppen } \\
\hline Gesamtwert (Punkte) & Gruppe \\
\hline 0 & 1 \\
\hline $1-12$ & 2 \\
\hline $7-12$ & 3 \\
\hline
\end{tabular}

Tabelle 8: Immunhistochemischer Auswertungs-Score 


\subsection{Immunzytochemie}

Die Kultivierung und Behandlung der Zellen mit dem N-Cadherin-Antikörper erfolgte wie unter 2.2.3 beschrieben. Im Anschluss wurden die Zellen bei 1000 UpM über $10 \mathrm{~min}$ auf Objektträger zentrifugiert und über Nacht getrocknet. Daraufhin wurden sie $15 \mathrm{~min}$ mit Formalin fixiert und mit PBS gespült. Die Zellen wurden dann in PBS mit 0,25\% Triton X-100 inkubiert, um ihre Membran für den Farbstoff durchlässig zu machen. Die endogene Peroxidase wurde mit $\mathrm{H}_{2} \mathrm{O}_{2}$ (über 5 min) geblockt. Nachdem der Caspase-3Antikörper für $1 \mathrm{~h}$ appliziert worden war, wurden die Zellen erst 25 min mit dem sekundären Antikörper (anti mouse/rabbit, verbunden mit HRP) und dann noch 5 min mit dem DAB chromogen behandelt. Abschließend wurden die Proben mit Mayers Hämatoxylin gegengefärbt.

\subsection{Migrationsassay}

\subsubsection{Assay}

Bei der In-vitro-Migration wurden für die Zellanzucht ebenfalls 6-Well-Platten verwendet. 100000 oder 300000 Zellen wurden je nach Ziellinie pro Well ausgesät und mit Nährmedium auf 2 ml/Well verdünnt. Im Anschluss ließ man die Zellen im Brutschrank über 24 h anwachsen. Danach wurde das Nährmedium entweder durch siRNA-Medium (2,3 ml Nährmedium + $100 \mu$ l siRNA-Lösung), oder durch Antikörper- Medium (2 ml Nährmedium $+20 \mu 1 \mathrm{~N}$-Cadherin- oder Kontrollantikörper) ersetzt und für jeweils 48- oder 24 $\mathrm{h}$ inkubiert. Daraufhin wurden $7 \times 10^{4}$ dieser Zellen in Millicell $8.0 \mu \mathrm{m}$ hanging PET Inserts mit $10 \%$ FCS übertragen. Um einen Wachstumsgradienten zu erzeugen wurden die 24- Well- Kulturplatten mit $20 \%$ FCS befüllt. Es folgte eine 24- stündige Inkubationszeit im Brutschrank bei $37^{\circ} \mathrm{C}$. Anschließend wurden die migrierten Zellen mit Methanol für 3 min dehydriert, mit Eosin und Mayers Hämalaun für jeweils 3 min gegengefärbt und mit destilliertem Wasser gespült. Die Membran mit den darauf befindlichen Zellen wurde aus dem Insert herausgeschnitten und auf einen Objektträger in Öl gebettet (Abb. 3). 


\begin{tabular}{|l|r|}
\hline \multicolumn{2}{|c|}{ Mayers Hämalaun } \\
\hline \multicolumn{1}{|c|}{ Agens } & \multicolumn{2}{c|}{ Menge } \\
\hline Hämatoxylin & $50 \mathrm{~g}$ \\
\hline $\mathrm{K} \mathrm{Al}\left(\mathrm{SO}_{4}\right) 12 \mathrm{H} 2 \mathrm{O}$ & $0,2 \mathrm{~g}$ \\
\hline Natriumjodat & $30 \mathrm{~g}$ \\
\hline Chloralhydrat & $1 \mathrm{~g}$ \\
\hline Zitronensäure & 11 \\
\hline Aqua dest. & \\
\hline
\end{tabular}

Tabelle 9: Zusammensetzung von Mayers Hämalaun

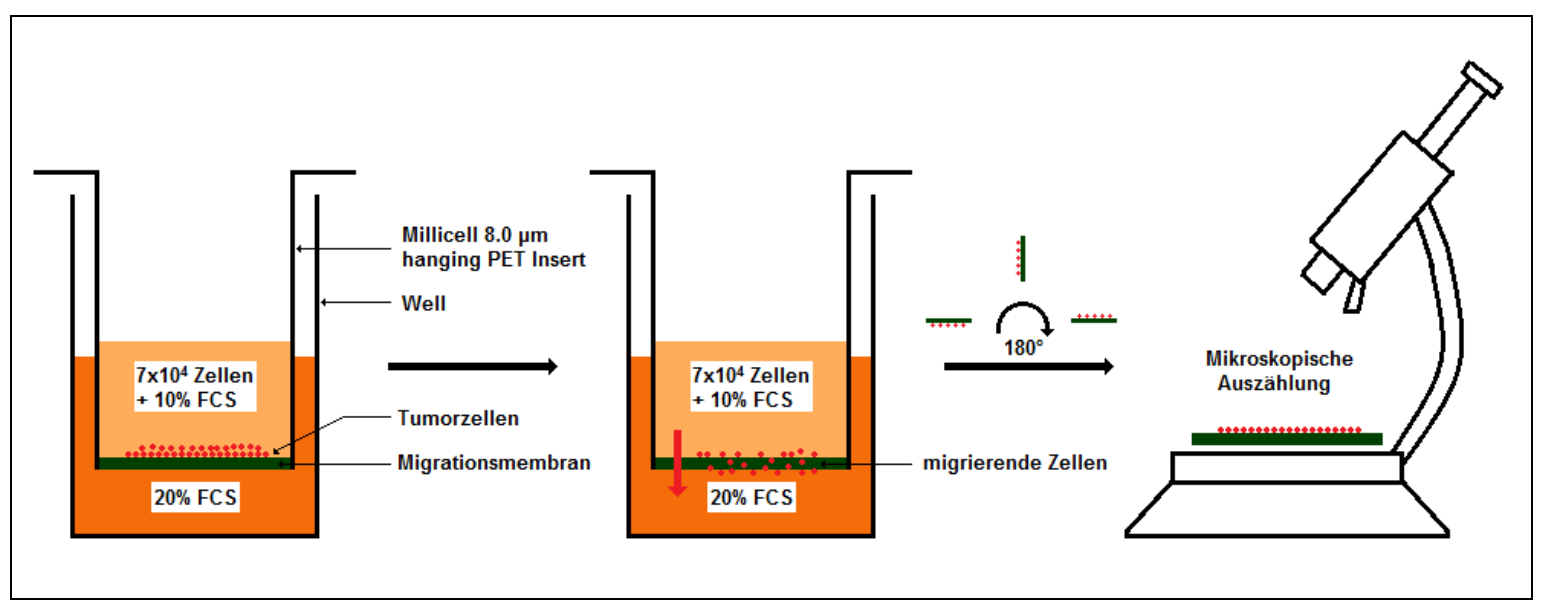

Abbildung 3: Migrationsassay

\subsubsection{Auswertung}

Als letzter Schritt wurden die Zellen lichtmikroskopisch ausgezählt. Das erfolgte bei 10facher Vergrößerung in fünf zufällig gewählten Gesichtsfeldern. Als migrierte Zellen wurden dabei nur blau gefärbte Zellkerne gezählt. 


\subsection{Invasionsassay}

\subsubsection{Assay}

Bei der Invasivitätsmessung wurden für die Zellanzucht 6-Well-Platten verwendet. 1x10 oder $3 \times 10^{5}$ Zellen wurden je nach Ziellinie pro Well ausgesät und mit Nährmedium auf 2 ml/Well verdünnt. Im Anschluss ließ man die Zellen im Brutschrank über $24 \mathrm{~h}$ anwachsen. Danach wurde das Nährmedium entweder durch siRNA-Medium (2,3 ml Nährmedium + $100 \mu 1$ siRNA-Lösung), oder durch Antikörper-Medium (2 ml Nährmedium + 20 $\mu \mathrm{l}$ N-Cadherin- oder Kontrollantikörper) ersetzt und für jeweils 48- oder $24 \mathrm{~h}$ inkubiert. Daraufhin wurden 70000 dieser Zellen in BioCoat Matrigel Invasion Chambers übertragen und mit 5\% FCS aufgefüllt. Um einen Wachstumsgradienten zu erzeugen wurden die 24-Well-Kulturplatten mit $20 \%$ FCS befüllt. Es folgte eine 48- stündige Inkubationszeit im Brutschrank bei $37{ }^{\circ} \mathrm{C}$. Anschließend wurden die Zellen wie in 2.6.1 gefärbt, die Membran mit den darauf befindlichen Zellen herausgeschnitten und auf Objektträger in Öl gebettet (Abb. 4).

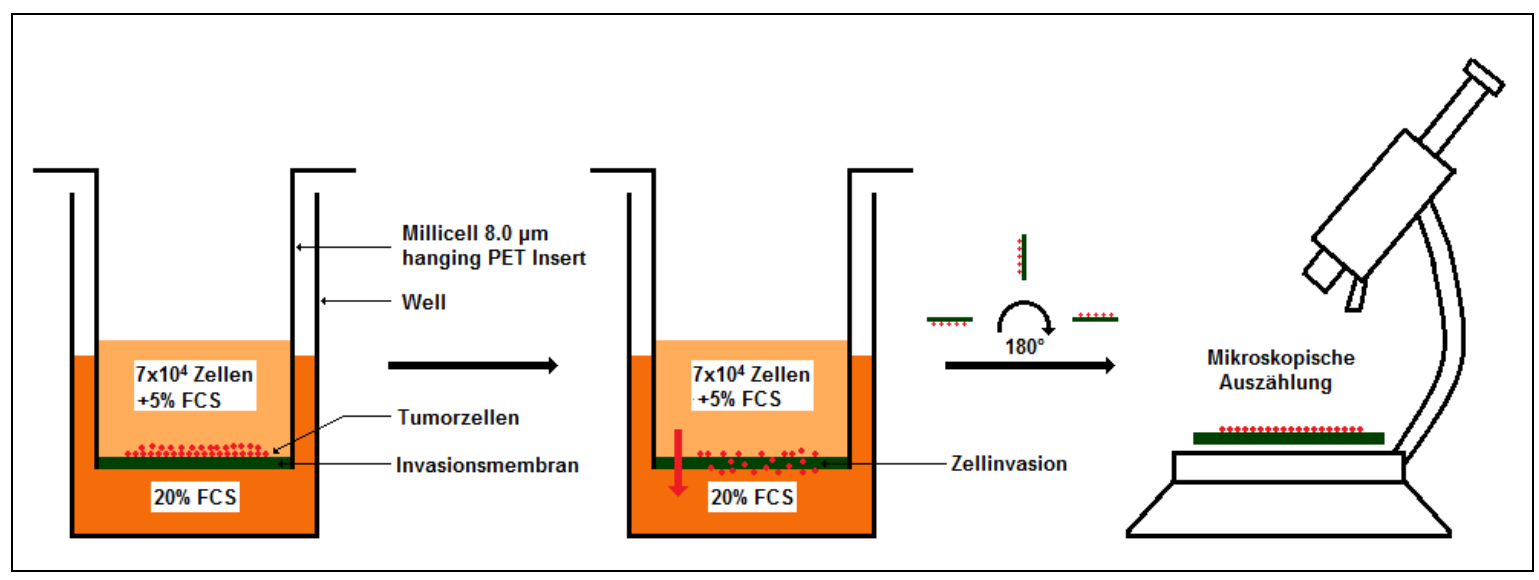

Abbildung 4: Invasionsassay

\subsubsection{Auswertung}

Die Auswertung erfolgte wie unter 2.6.2 beschrieben.

\subsection{Bestimmung der pERK/ ERK- Ratio}

300000 Zellen wurden pro Well ausgesät und mit Nährmedium auf 2 ml/Well verdünnt. Die Zellen wuchsen im Brutschrank über $24 \mathrm{~h}$ an. Danach wurde das Nährmedium durch 
siRNA-Medium (2,3 ml Nährmedium + $100 \mu$ l siRNA-Lösung) ersetzt. Nach 48 stündiger Inkubation wurde die Zellzahl mit dem Count and Viability Kit (siehe 2.2.2) bestimmt. Die Zellen wurden dann als Waschvorgang für 5 min bei $300 \mathrm{x}$ g zentrifugiert und das überschüssige Medium entfernt. Pro $1 \times 10^{6}$ Zellen wurden dann $500 \mu 1$ Assay Buffer und $500 \mu$ Fixation Buffer zugegeben und 5 min aus Eis inkubiert. Anschließend erfolgte wiederum ein Waschvorgang (siehe oben). Daraufhin wurden je 1000000 Zellen mit $1 \mathrm{ml}$ eisgekühltem Permeabilization Buffer versetzt und 5 min aus Eis inkubiert, um eine Durchlässigkeit der Zellmembranen zu erreichen. Nach einem weiteren Waschvorgang wurden jeweils $1 \times 10^{6}$ Zellen in $450 \mu$ l Assay Buffer resuspendiert und je $90 \mu 1$ pro Tube aliquotiert. In jeden Tube wurde $10 \mu$ l Antikörpermischung hinzugegeben.

Diese Lösung beinhaltete zwei Antikörper. Einen phospho-spezifischen Antikörper (Anti-phospho-ERK1/2 (Thr202/Tyr204,Thr185/typ187)-Phycoerythrin) und einen zweiten Antikörper, der das gesamte ERK detektierte (anti-ERK1/2-PECy5 konjugiert). Mittels dieser Antikörper konnte das Verhältnis zwischen phosphoryliertem ERK und der ERK-Gesamtmenge gemessen werden.

Die Tubes wurden daraufhin im Dunklen 30 min bei RT inkubiert. Nach einem weiteren Waschvorgang wurden $200 \mu \mathrm{l}$ Assay Buffer hinzugeben. Am Ende wurde die pERK/ ERK-Ratio durchflusszytometrisch mittels Muse Cell Analyzer bestimmt.

\subsection{Detektion apoptotischer Zellen}

Die Kultivierung und Behandlung der Zellen mit dem N-Cadherin-Antikörper erfolgte wie unter 2.2.4 beschrieben. Die Zellen wurden mittels Zentrifugation bei 1000 UpM über 10 min auf einen Objektträger transferiert und über Nacht getrocknet. Daraufhin wurden sie 15 min mit Formalin fixiert und mit PBS gespült. Um die Zellmembranpermeabilität für den Farbstoff zu erhöhen, wurden sie in PBS mit 0,25\% Triton X-100 inkubiert. Die endogene Peroxidase wurde mit $\mathrm{H}_{2} \mathrm{O}_{2}$ (über 5 min) geblockt. Nachdem der Caspase3Antikörper für $1 \mathrm{~h}$ appliziert worden war, wurden die Zellen erst 25 min mit dem sekundären Antikörper (anti mouse/rabbit, verbunden mit HRP) und dann noch 5 min mit dem DAB chromogen behandelt. Am Schluss wurden die Proben mit Mayers Hämatoxylin gegengefärbt und die apoptotischen Zellen unter dem Lichtmikroskop ausgezählt. 


\subsection{Bestimmung der pAKT/ AKT- Ratio}

Die Zellanzucht erfolgte wie unter $\mathbf{2 . 8}$ beschrieben. Das Kulturmedium wurde im Anschluss durch siRNA-Medium (2,3 ml Nährmedium + $100 \mu$ l siRNA-Lösung) ersetzt. Die weiteren Schritte erfolgten wie unter $\mathbf{2 . 8}$ dargestellt.

Die Antikörpermischung beinhaltete hier ebenfalls zwei Antikörper. Einen phospho-spezifischen Antikörper (Anti-phospho-Akt (Ser473) Alexa Flour555) und einen zweiten Antikörper, der das gesamte AKT detektierte (Anti-Akt, PECy5 konjugiert).

Die Tubes wurden daraufhin im Dunklen 30 min bei RT inkubiert. Nach einem weiteren Waschvorgang wurden $200 \mu$ l Assay Buffer hinzugeben. Am Ende wurde die pAKT/ AKT-Ratio mit dem Muse Cell Analyzer errechnet.

\subsection{Statistische Auswertung}

Die Auswertung sowohl der Proliferations-, Migrations- und Invasionsversuche als auch der Untersuchungen zugrundeliegender molekularer Mechanismen erfolgte u.a. mit Microsoft Excel. Die p-Werte wurden mit dem ungepaarten t-Test unter Zuhilfenahme der GraphPad Prism Software berechnet. Die statistische Signifikanz wurde mit $* \mathrm{p}<0.05 ; * * \mathrm{p}<0.01 ; * * \mathrm{p}<0.001$ dargestellt. Alle Experimente erfolgten in dreifacher Ausführung in Form von Triplikaten. 


\section{Ergebnisse}

\subsection{N-Cadherin-Expression in Keimzelltumoren}

Die Western-Blot-Analysen zeigten eine N-Cadherin-Expression in allen Zelllinien (NCCIT, NTERA-2, TCam-2) (Abb. 5). Hinsichtlich der Proteinquantität stellten sich gut sichtbare Unterschiede dar. So exprimierte TCam-2 sichtbar mehr N-Cadherin als NTERA-2 und NCCIT (Abb. 5). Die Cisplatin-resistenten Zelllinien (NCCIT-R, NTERA-2R) exprimierten das Protein ebenfalls (Abb. 6). Eine Quantitätsdifferenz im Vergleich zu NCCIT und NTERA bestand hier nicht (Abb. 6).

\subsection{N-Cadherin-Expression nach siRNA-Transfektion}

Unter der Transfektion mit siRNA gegen das N-Cadherin-Gen (siCDH2) zeigte sich eine deutlich herabgesetzte N-Cadherin-Expression in allen TGCT. Die relative Dichte der Western-Blot-Banden war signifikant reduziert (Abb. 7A-C). Der gleiche Effekt ließ sich bei den Cisplatin-resistenten Zelllinien ermitteln (Abb. 8A, B).

\subsection{N-Cadherin-Expression in Keimzelltumormetastasen}

Metastasen von 28 Patienten mit einem testikulären Keimzelltumor wurden auf die Expression des N-Cadherin-Proteins hin immunhistochemisch analysiert. Dabei sind jeweils oben die Gewebe in einer HE-Färbung, vergleichend zur unten liegenden N-CadherinFärbung abgebildet (Abb. 9-12). Tabelle 10 stellt die einzelnen histologischen Subtypen der untersuchten Metastasen dar. Alle Seminommetastasen exprimierten stark N-Cadherin ( $n=3$, Abb. 9). Zwei Metastasen von Dottersacktumoren $(n=5)$ exprimierten ebenfalls stark N-Cadherin (Abb. 10). Die meisten Gewebsareale in den Metastasen der reifen Teratome ( $\mathrm{n}=14)$ waren negativ für das Protein. Nur vereinzelte Regionen mit intestinalem Epithel und neuronalem Gewebe waren schwach positiv. Primitives neuroektodermales Gewebe und neuronales Gewebe in Metastasen unreifer Teratome $(n=4)$ waren stark positiv für N-Cadherin (Abb. 11). In zwei Metastasen embryonaler Karzinome konnte keine N-Cadherin-Expression nachgewiesen werden (Abb. 12). 


\begin{tabular}{|l|c|c|}
\hline Histologischer Subtyp & Anzahl & N-Cadherin-Färbung \\
\hline Seminom & 3 & 3 \\
\hline Dottersacktumor & 5 & 1 \\
\hline Reifes Teratom & 14 & 2 \\
\hline Unreifes Teratom & 4 & 0 \\
\hline Embryonales Karzinom & 2 & 2 \\
\hline
\end{tabular}

Tabelle 10: Histologische Subtypen der untersuchten Metastasen

\subsection{Proliferationsanalyse in GCT-Zelllinien}

\subsubsection{Nach siRNA-Transfektion}

Die Zellproliferation wurde anhand der absoluten Zellzahl 12-, 24-, 48- und $72 \mathrm{~h}$ nach siRNA-Transfektion gemessen. Bei NCCIT zeigte sich ein frühzeitiger Proliferationsabfall nach $12 \mathrm{~h}(\mathrm{p}<0,005)$, mit dem Maximum nach 24- und $48 \mathrm{~h}(\mathrm{p}<0,0005)$. Nach $72 \mathrm{~h}$ war keine signifikante Abweichung mehr feststellbar (Abb. 13A). Bei NTERA-2 und TCam-2 ließ sich ebenfalls eine signifikante Verminderung der Zellzahl beobachten, jedoch mit den Höchstwerten bei 48- und 72 h ( $p<0,005$ bei NTERA-2, $p<0,0005$ bei TCam-2) (Abb. 13B und Abb. 13C). Nach 12 und 24 h zeigte sich keine relevante Abweichung der Zellzahl bei NTERA-2 (Abb. 13B). Die Proliferation bei TCam-2 war nach $12(\mathrm{p}<0,05)$ und $24 \mathrm{~h}(\mathrm{p}<0,005)$ sichtbar reduziert (Abb. 13C). Bei NCCIT-R konnte zu allen Zeitpunkten eine statistisch signifikante Reduktion der Proliferation erkannt werden $(12 \mathrm{~h}(\mathrm{p}<0,005), 24 \mathrm{~h}(\mathrm{p}<0,05), 48 \mathrm{~h}(\mathrm{p}<0,0005), 72 \mathrm{~h}(\mathrm{p}<0,005))$ (Abb. 13D). Die Proliferation von NTERA-2R fiel nach $12 \mathrm{~h}(\mathrm{p}<0,005), 48 \mathrm{~h}(\mathrm{p}<0,005)$ und $72 \mathrm{~h}(\mathrm{p}<0,0005)$ signifikant ab. Nach 24 h konnte keine relevante Änderung gemessen werden (Abb. 13E).

\subsubsection{Nach Antikörper-Gabe}

Das Proliferationsverhalten der Zelllinien wurde anschließend unter der Proteinblockade mit dem monoklonalen Antikörper untersucht. Die Messungen erfolgten nach 1-, 12-, 24und 48 h. Dabei zeigte sich bei NCCIT ein hochsignifikanter Abfall der Proliferation nach $12 \mathrm{~h}(\mathrm{p}<0,0005), 24 \mathrm{~h}(\mathrm{p}<0,0005)$ und $48 \mathrm{~h}(\mathrm{p}<0,005)$. Nach einer Stunde ließ sich keine signifikante Wachstumsreduktion erkennen (Abb. 14A). Die Proliferation fiel bei 
NTERA-2 zu allen Zeitpunkten statistisch signifikant ab $(1 \mathrm{~h}(\mathrm{p}<0,05), 12 \mathrm{~h}(\mathrm{p}<0,005)$, $24 \mathrm{~h}(\mathrm{p}<0,05), 48 \mathrm{~h}(\mathrm{p}<0,05))$ (Abb. 14B). Gleiches konnte bei der Zelllinie TCam-2 beobachtet werden $(1 \mathrm{~h}(\mathrm{p}<0,005), 12 \mathrm{~h}(\mathrm{p}<0,0005), 24 \mathrm{~h}(\mathrm{p}<0,0005), 48 \mathrm{~h}(\mathrm{p}<0,0005))$ (Abb. 14C). Bei NCCIT-R zeigte sich eine signifikante Abnahme der Proliferation nach $12 \mathrm{~h}(\mathrm{p}<0,05)$ und $48 \mathrm{~h}(\mathrm{p}<0,05)$ (Abb. 14D), bei NTERA-2R nach $48 \mathrm{~h}(\mathrm{p}<0,05)$ (Abb. 14E). Zu den anderen Zeitpunkten konnte keine signifikante Proliferationsabnahme gemessen werden (Abb. 14D+E).

\subsection{Migrationsanalyse in GCT-Zelllinien}

\subsubsection{Nach siRNA-Transfektion}

Die Migration in NCCIT ( $<<0,0005)$, NTERA-2 $(\mathrm{p}<0,0005)$ und TCam-2 $(\mathrm{p}<0,05)$ war $48 \mathrm{~h}$ nach der Behandlung mit siRNA gegen $\mathrm{CDH} 2$ statistisch signifikant reduziert (Abb. 15 A-C). Außerdem zeigte sich eine gleichermaßen herabgesetzte Migration in Cisplatinresistenten Zelllinien NCCIT-R ( $p<0,0005)$ und NTERA-2R ( $<<0,0005)($ Abb. 15 D+E).

\subsubsection{Nach Antikörper-Gabe}

Das Migrationsverhalten von NCCIT, NTERA-2 und TCam-2 wurde ebenso nach der Blockade mittels monoklonalem Antikörper untersucht. Die Messung erfolgte nach $24 \mathrm{~h}$. Dabei ließ sich eine signifikant herabgesetzte Migration in allen drei Zelllinien (NCCIT $(\mathrm{p}<0,05)$, NTERA-2 $(\mathrm{p}<0,005)$ und TCam-2 $(\mathrm{p}<0,0005))$ nachweisen (Abb. 16 A-C). Leider konnten für die Cisplatin-resistenten Zelllinien NCCIT-R und NTERA-2R an dieser Stelle keine Ergebnisse notiert werden, da die Versuche auch nach wiederholter Ansetzung aus technischen Gründen nicht funktionierten.

\subsection{Invasionsanalyse in GCT-Zelllinien}

\subsubsection{Nach siRNA-Transfektion}

Die Invasivität der Zellinien NCCIT ( $\mathrm{p}<0,0005)$, NTERA-2 $(\mathrm{p}<0,0005)$ und TCam-2 $(\mathrm{p}<0,0005)$ war $48 \mathrm{~h}$ nach siRNA-Gabe signifikant herabgesetzt (Abb. 17A-C). Selbiges konnte nach der Behandlung mit siRNA gegen $\mathrm{CDH} 2$ in Cisplatin-resistenten Zelllinien NCCIT-R ( $p<0,0005)$ und NTERA-2R ( $<<0,0005)$ beobachtet werden (Abb. 17D+E). 


\subsubsection{Nach Antikörper-Gabe}

Die Invasivität von NCCIT $(\mathrm{p}<0,005)$, NTERA-2 $(\mathrm{p}<0,005)$ und TCam-2 $(\mathrm{p}<0,0005)$ konnte, nach Antikörper-vermittelter Blockade für 24 h, statistisch hochsignifikant reduziert werden (Abb. 18A-C). Leider konnten für die Cisplatin-resistenten Zelllinien NCCIT-R und NTERA-2R an dieser Stelle keine Ergebnisse notiert werden, da die Versuche auch nach wiederholter Ansetzung aus technischen Gründen nicht funktionierten.

\section{7 pERK/ ERK-Ratio nach siRNA-Transfektion}

Cisplatin-sensitive und Cisplatin-resistente Ziellinien wurden nach 48- stündiger Inkubation mit siRNA gegen CDH2 auf die pERK/ ERK-Ratio hin untersucht. Die Blockade führte zu einem signifikanten Anstieg des Quotienten in NCCIT ( $p<0,005)$, NTERA-2 ( $\mathrm{p}<0,0005)$, TCam-2 (p<0,005) NCCIT-R $(\mathrm{p}<0,0005)$ und NTERA-2R $(\mathrm{p}<0,005)($ Abb. 19A-E).

\subsection{Caspase-3-Aktivität nach Antikörper-Gabe}

Alle Ziellinien wurden hierzu über $48 \mathrm{~h}$ mit einem monoklonalen Antikörper gegen das $\mathrm{N}$-Cadherin-Protein vorbehandelt. In der sich anschließenden immunzytochemischen Analyse von Caspase-3 zeigte sich ein hochsignifikanter Anstieg der apoptotischen Zellen in allen Zelllinien ( $\mathrm{p}<0,0005)($ Abb. 20A-E).

\section{9 pAKT/ AKT-Ratio nach siRNA-Transfektion}

Darüber hinaus wurde, $48 \mathrm{~h}$ nach siRNA-Gabe gegen N-Cadherin, das pAKT-Level in den Zelllinien gemessen. Hierbei konnte in NCCIT, NCCIT-R und NTERA-2R keine Veränderung beobachtet werden $(\mathbf{A b b . 2 1 A + D + E ) , ~ w o h i n g e g e n ~ i n ~ N T E R A - 2 ~}(\mathrm{p}<0,005)$ und TCam-2 $(\mathrm{p}<0,05)$ ein signifikanter Abfall der Ratio erkennbar war (Abb. 21B+C). 


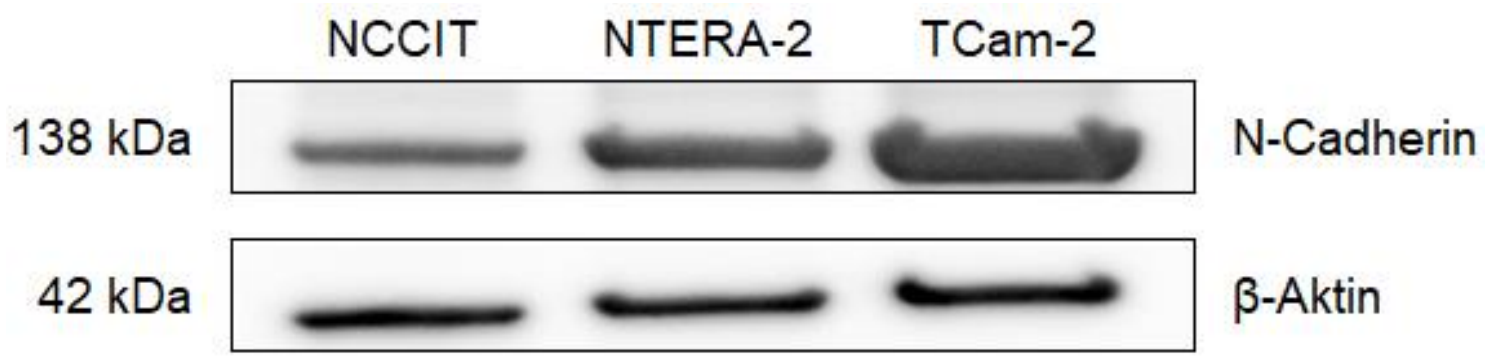

\section{Abbildung 5: N-Cadherin-Expression in Cisplatin-sensitiven GCT-Zellllinien}

Die Expression von N-Cadherin wurde mit Western-Blot-Analysen untersucht. Die Zelllinien NCCIT, NTERA-2 und TCam-2 exprimierten N-Cadherin. TCam-2 hatte eine sichtbar höhere Proteinexpression als NCCIT und NTERA-2.

A

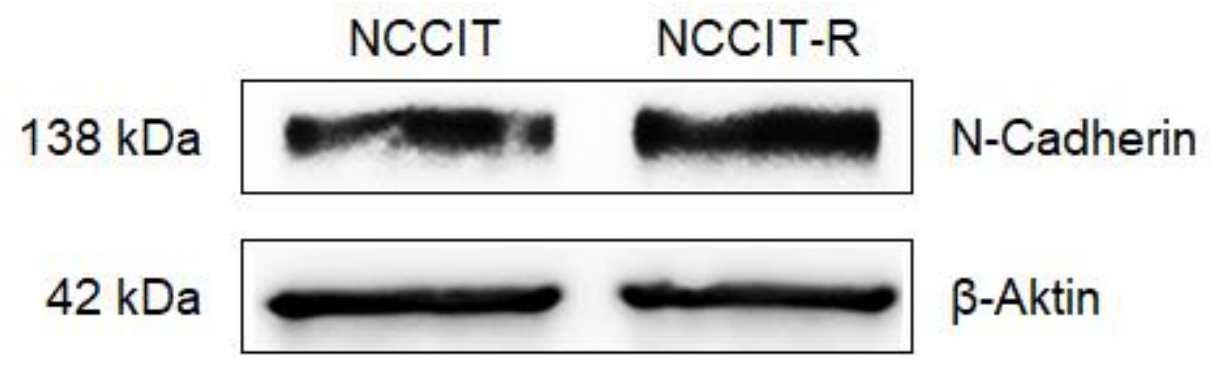

B

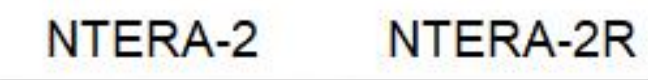

$138 \mathrm{kDa}$

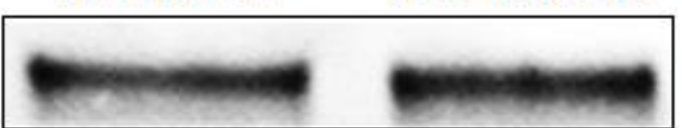

$\mathrm{N}-$ Cadherin

$42 \mathrm{kDa}$

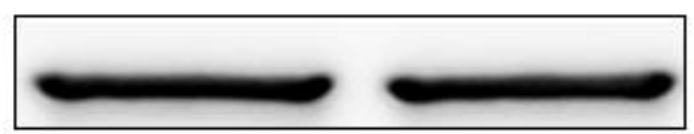

$\beta$-Aktin

\section{Abbildung 6: N-Cadherin-Expression in Cisplatin-resistenten GCT-Zellllinien}

Die Expression von N-Cadherin wurde mittels Western Blot untersucht. Die Zelllinien NCCIT-R (A) und NTERA-2R (B) exprimierten N-Cadherin. Hinsichtlich der Expressionshöhe waren keine Unterschiede zwischen den Cisplatin-sensitiven und -resistenten Zelllinien erkennbar (A+B). 


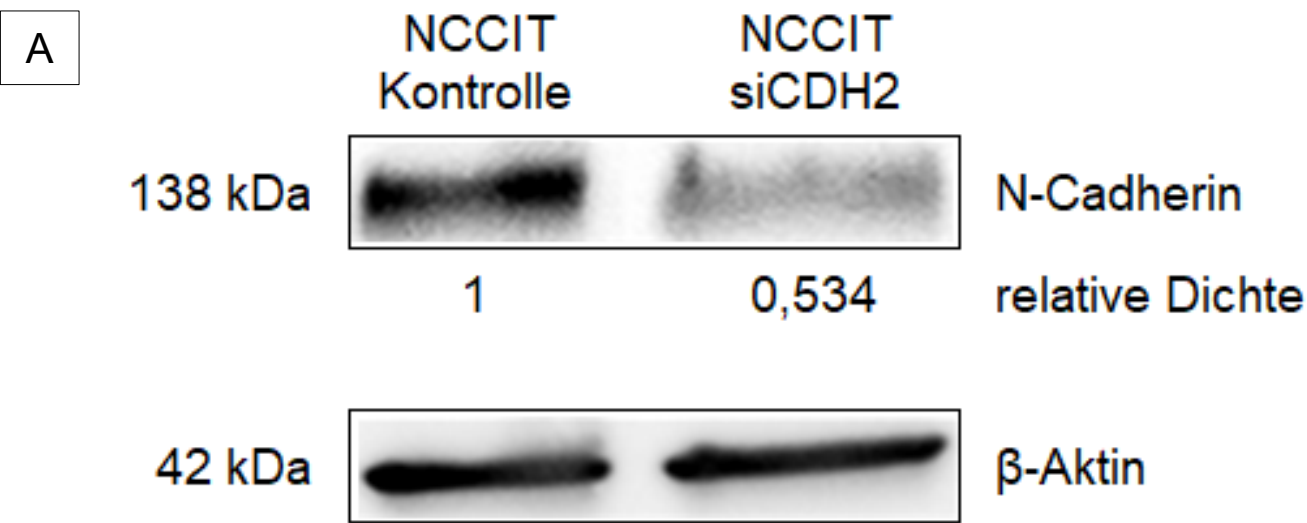

B

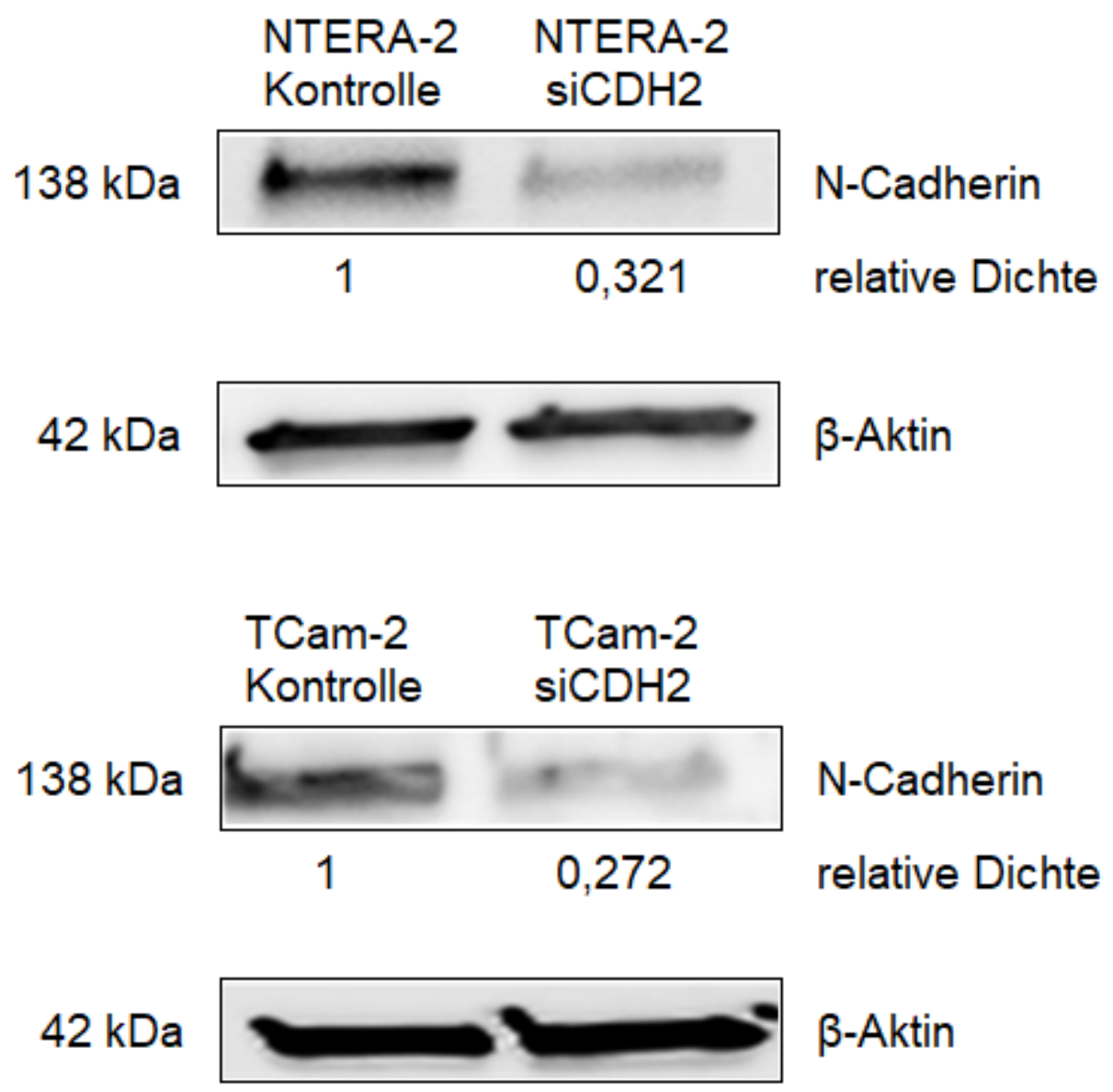

Abbildung 7: N-Cadherin-Expression in Cisplatin-sensitiven GCT-Zelllinien nach siRNA-Transfektion

Die Transfektion mit siRNA gegen das N-Cadherin-Gen (siCDH2) führte zu einer signifikanten Abnahme der N-Cadherin Expression in den Cisplatin-sensitiven TGCT-Zelllinien NCCIT (A), NTERA-2 (B) und TCam-2 (C). 
A

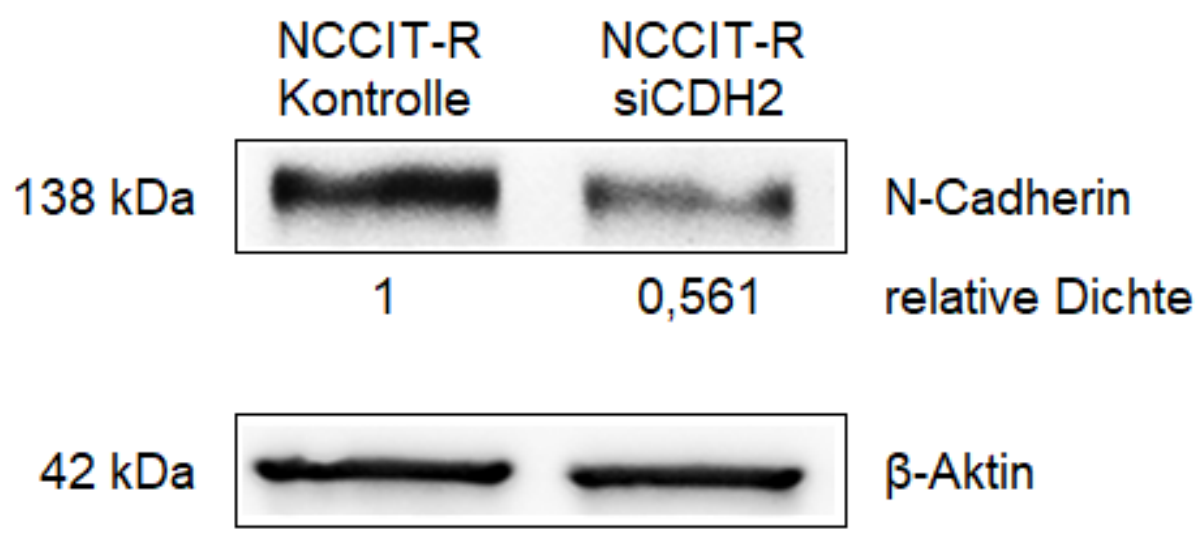

B

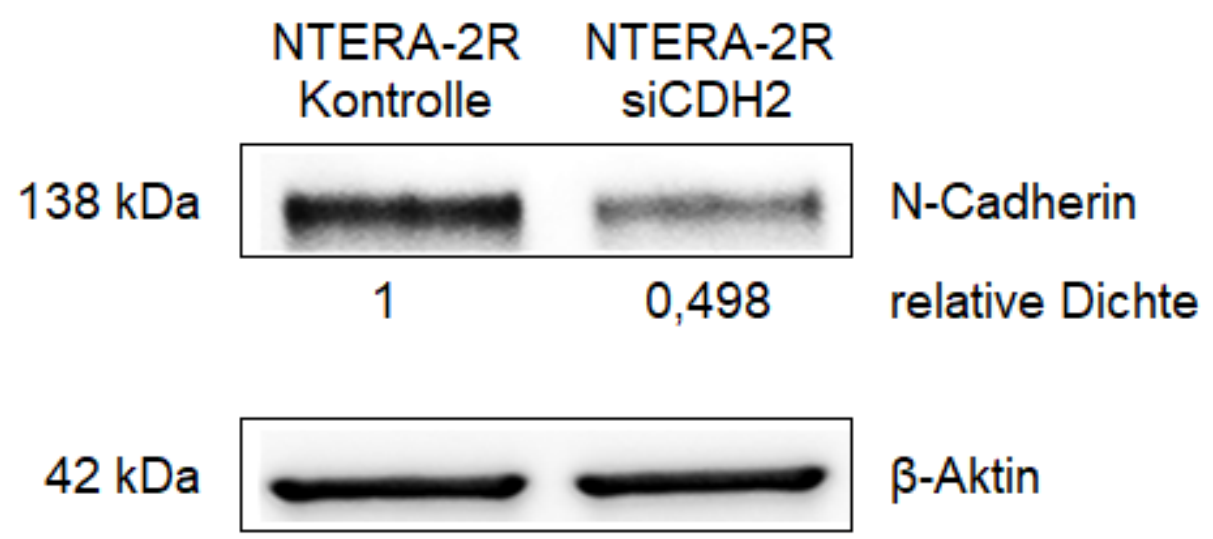

Abbildung 8: N-Cadherin-Expression in Cisplatin-resistenten GCT-Zelllinien nach siRNA-Transfektion

Die Transfektion mit siRNA gegen das N-Cadherin-Gen (siCDH2) führte zu einer signifikanten Abnahme der N-Cadherin-Expression in den Cisplatin-resistenten TGCT-Zelllinien NCCIT-R (A) und NTERA-2R (B). 

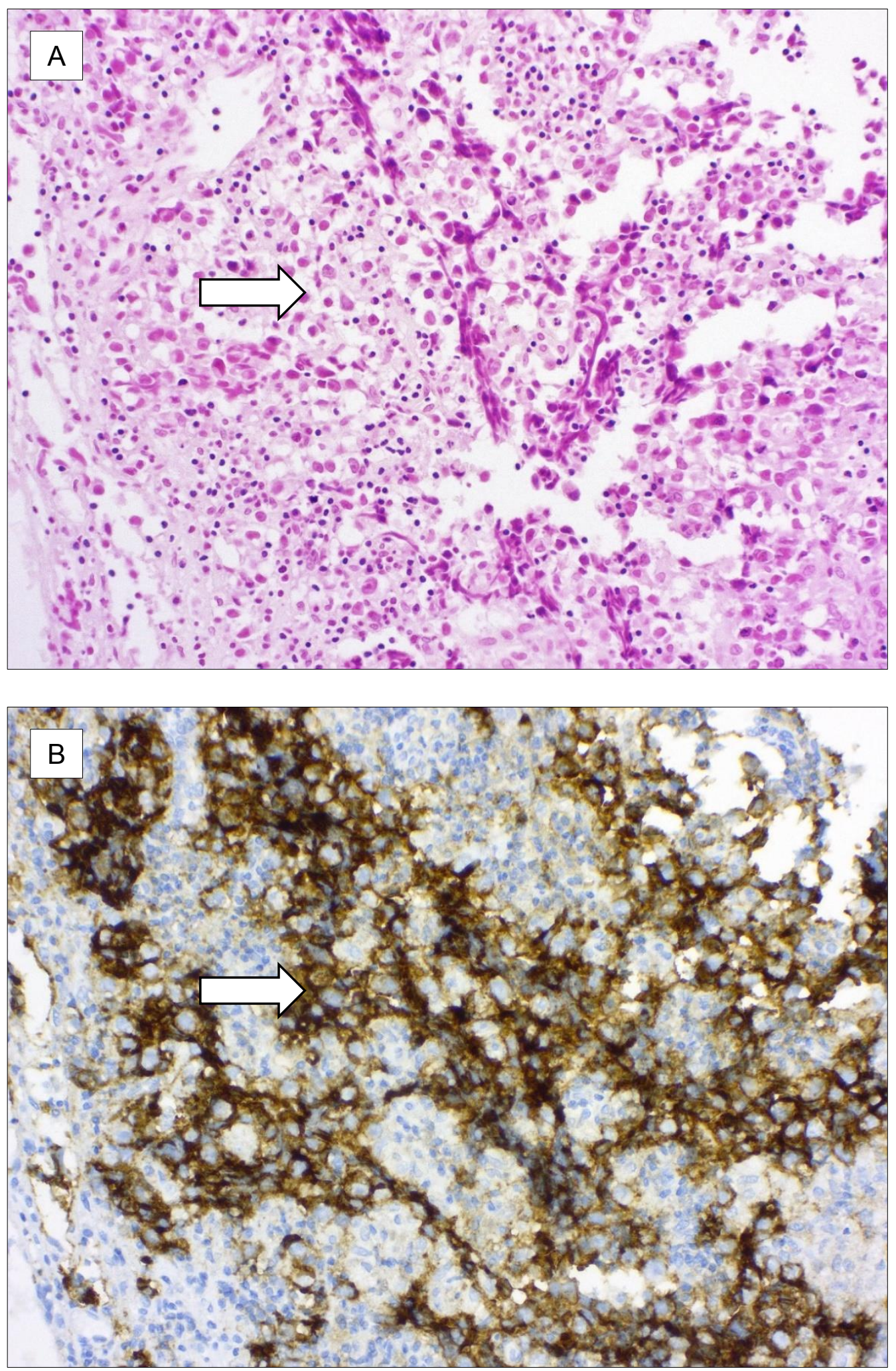

\section{Abbildung 9: N-Cadherin-Expression in der Metastase eines Seminoms}

Die Expression von N-Cadherin wurde immunhistochemisch untersucht. Die Tumorzellen $(\Longrightarrow$ ) exprimierten stark N-Cadherin (braune Signale) (A, HE, Vergrößerung x40; B, immunhistochemische Darstellung von N-Cadherin, Vergrößerung x40). 

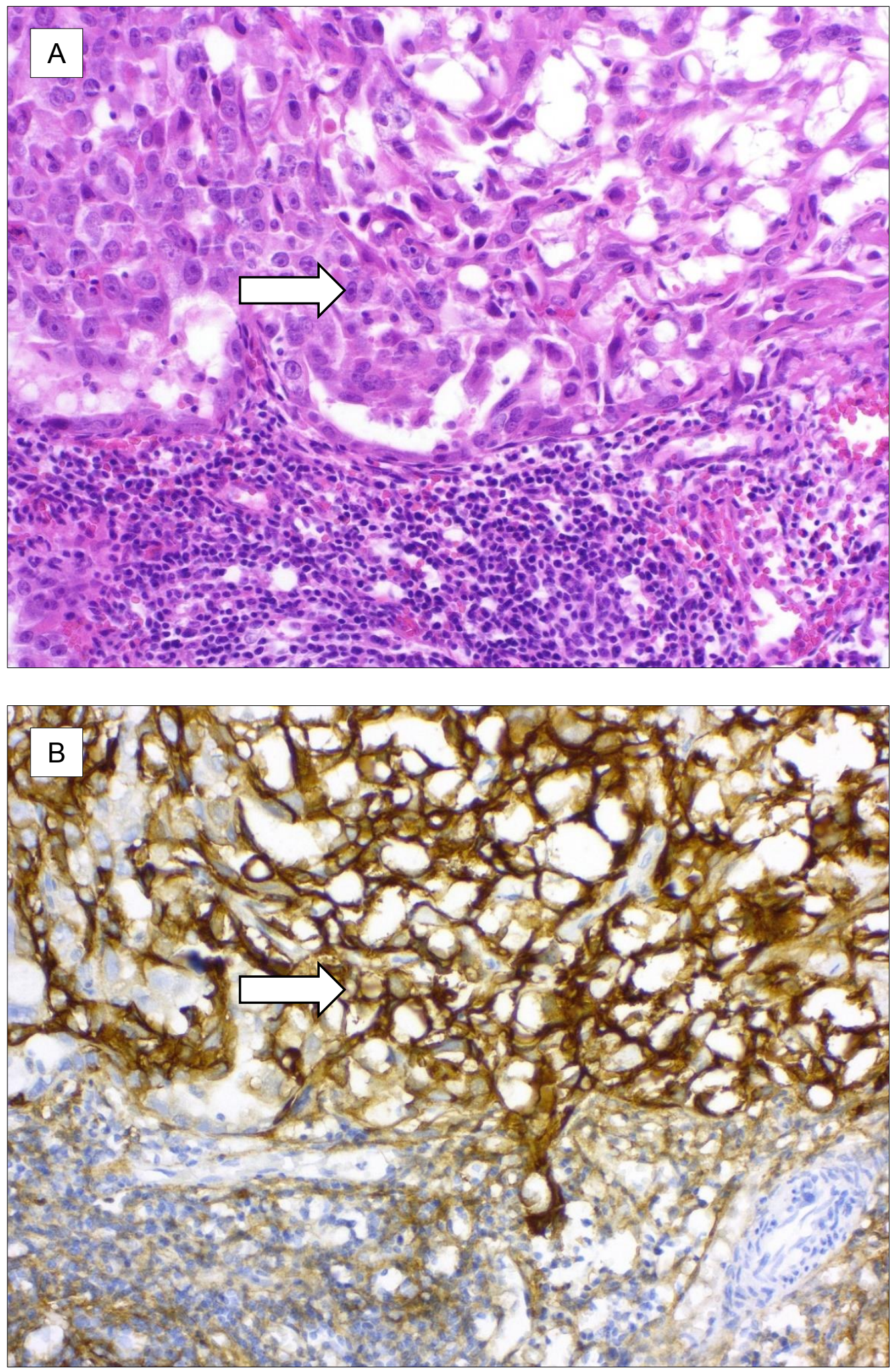

\section{Abbildung 10: N-Cadherin-Expression in der Metastase eines Dottersacktumors}

Die Expression von N-Cadherin wurde immunhistochemisch untersucht. Die Tumorzellen ( $\Longrightarrow$ ) exprimierten stark N-Cadherin (braune Signale) (A, HE, Vergrößerung x40; B, immunhistochemische Darstellung von N-Cadherin, Vergrößerung x40). 

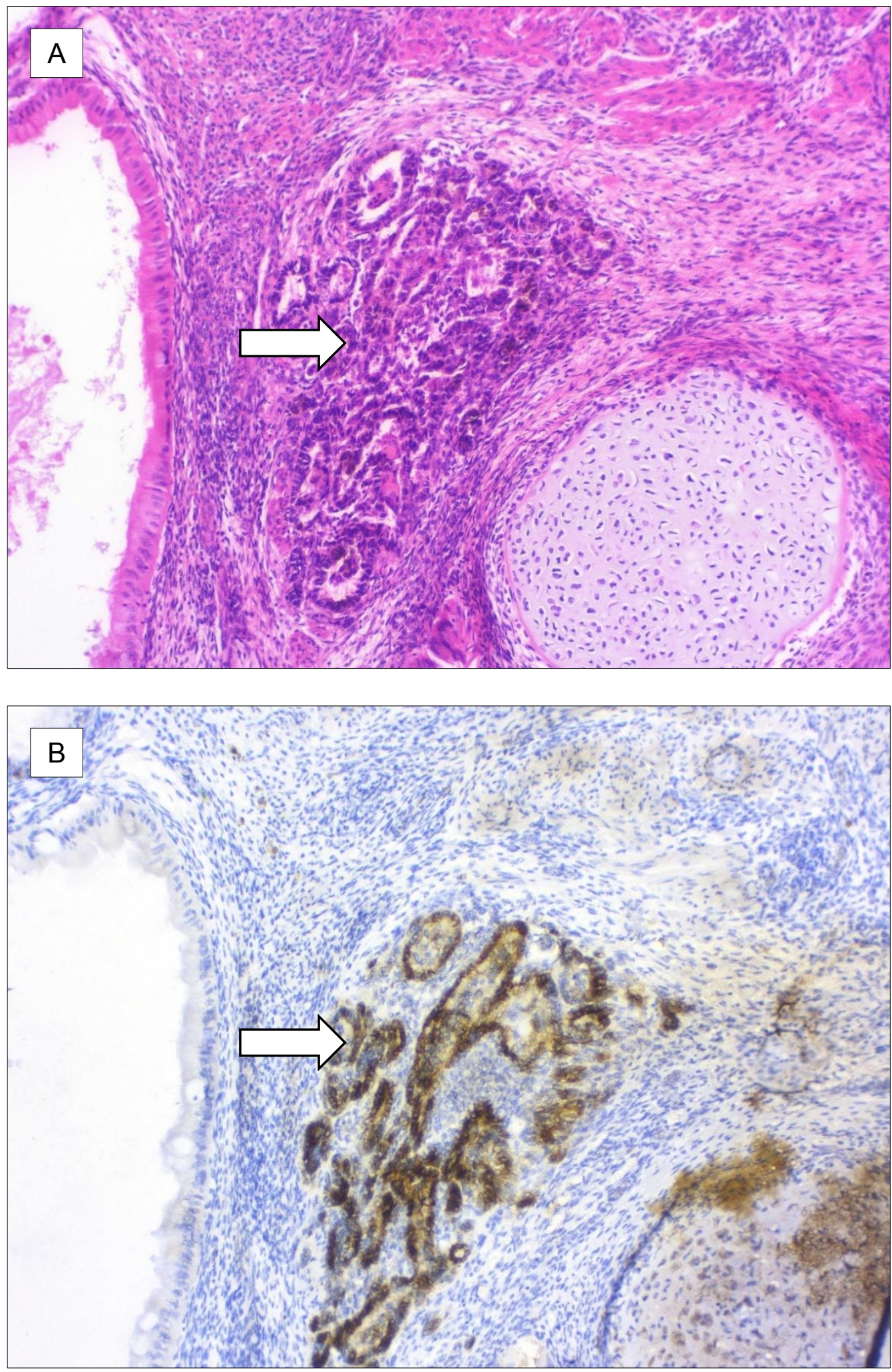

\section{Abbildung 11: N-Cadherin-Expression in primitivem neuroektodermalem Gewebe}

Die Expression von N-Cadherin wurde immunhistochemisch untersucht. Primitives neuroektodermales Gewebe ( $\Longrightarrow$ ) exprimierte N-Cadherin (braune Signale) (A, HE, Vergrößerung x20; B, immunhistochemische Darstellung von N-Cadherin, Vergrößerung $\mathrm{x} 20)$. 

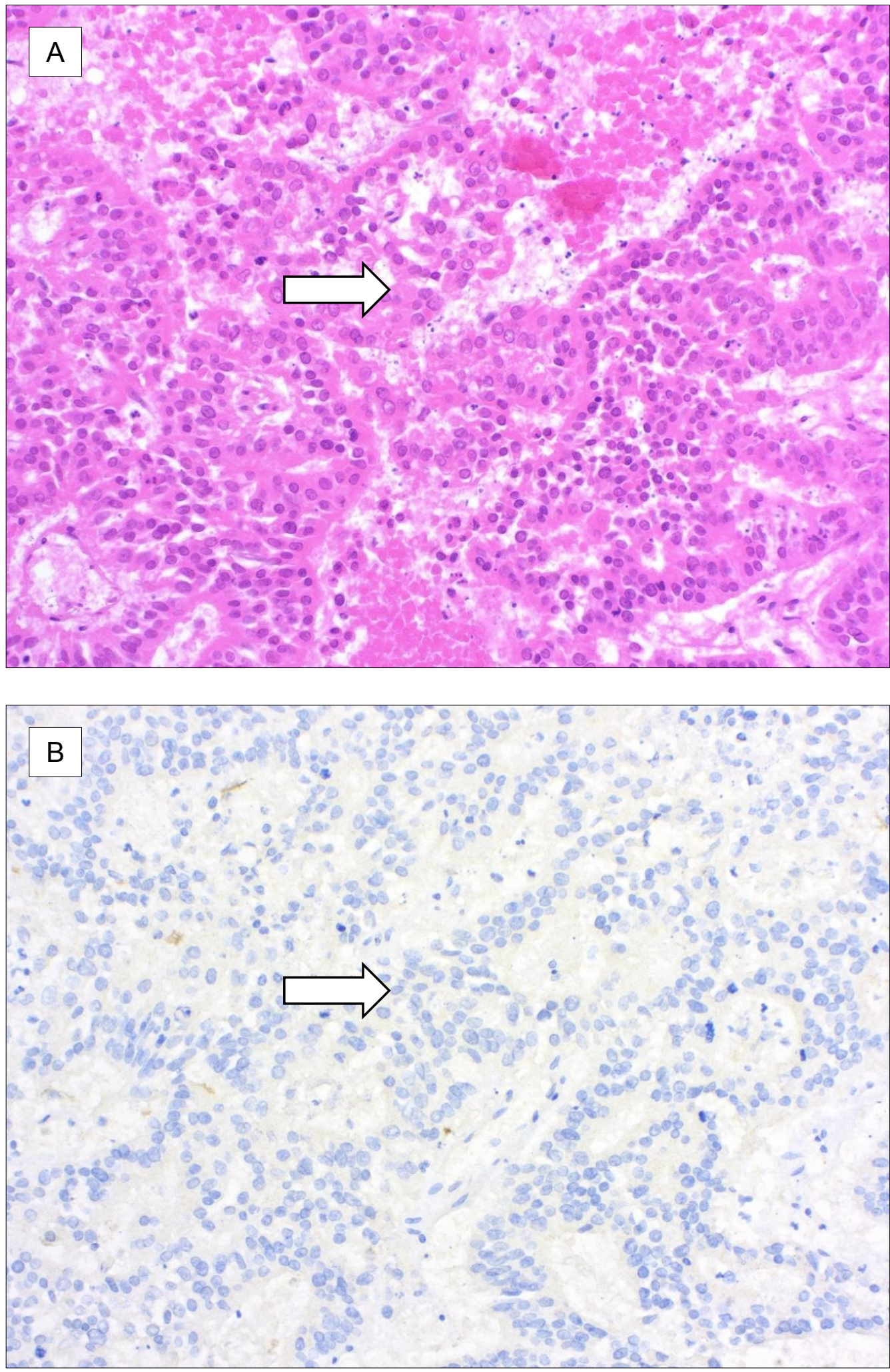

\section{Abbildung 12: N-Cadherin-Expression in der Metastase eines embryonalen Karzi- noms}

Die Expression von N-Cadherin wurde immunhistochemisch untersucht. Die Tumorzellen ( $(\overrightarrow{)})$ exprimierten kein N-Cadherin (A, HE, Vergrößerung x40; B, immunhistochemische Darstellung von N-Cadherin, Vergrößerung x40). 

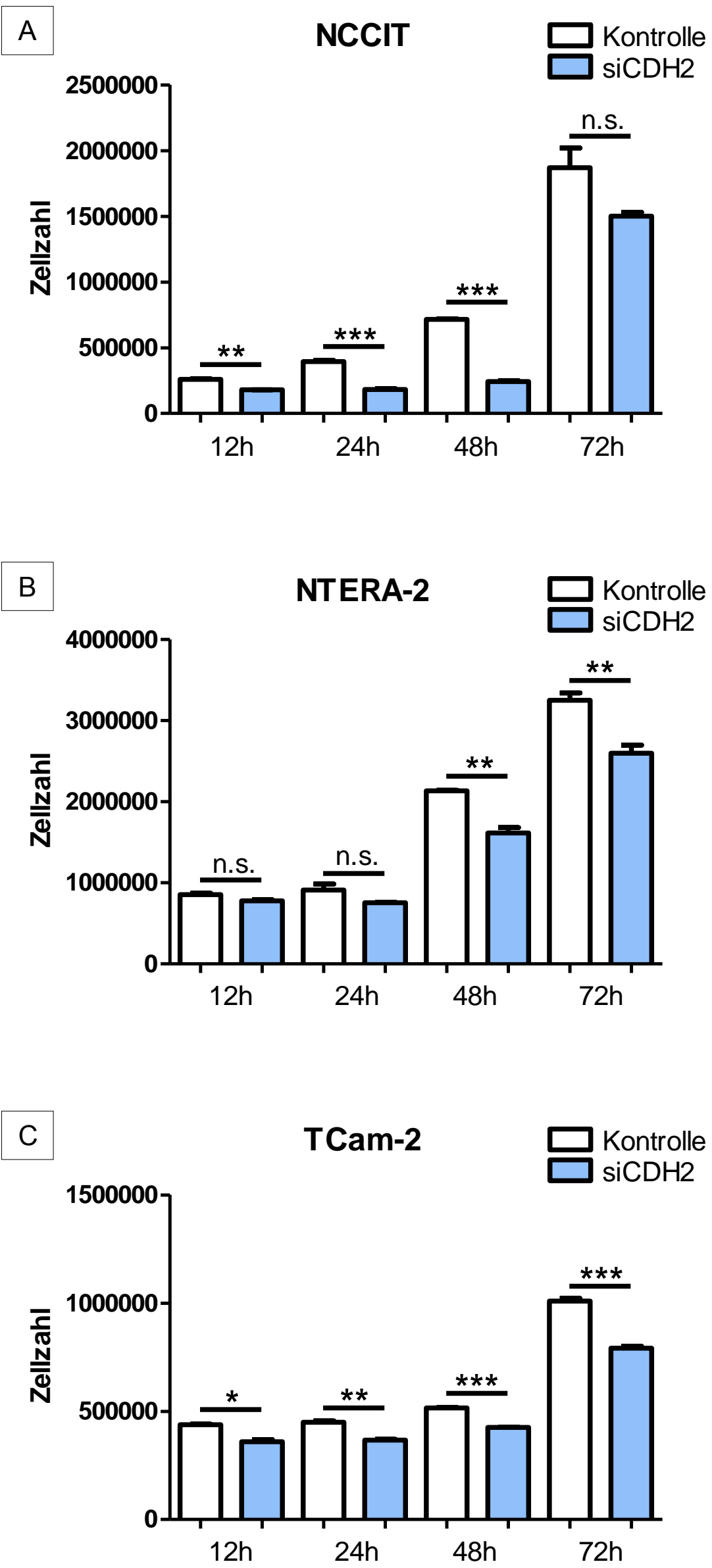


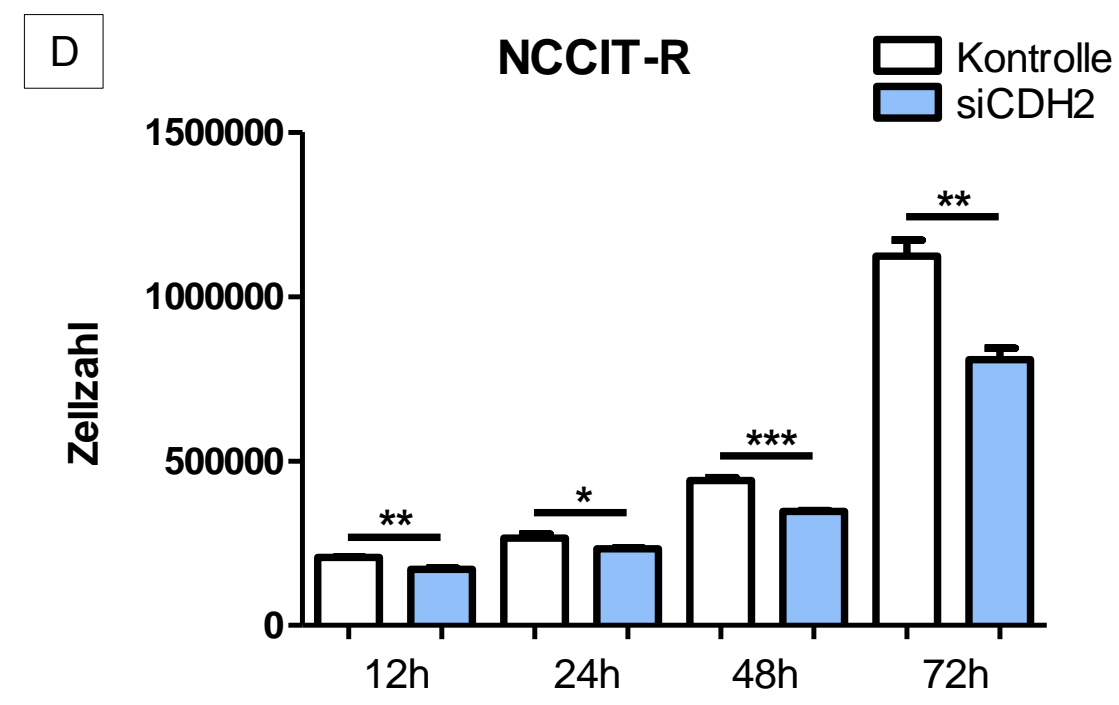

$\mathrm{E}$
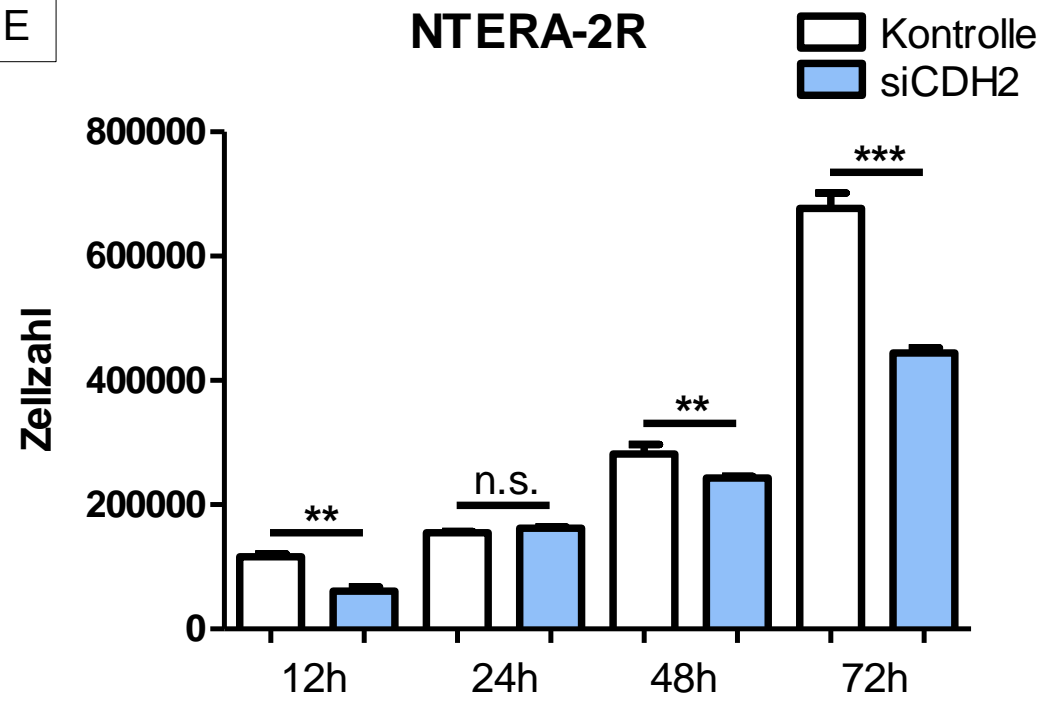

\section{Abbildung 13: Zellproliferation nach siRNA-Transfektion}

Das Zellwachstum wurde durchflusszytometrisch gemessen. Die Proliferation in der Zelllinie NCCIT war nach 12-, 24- und 48 h signifikant reduziert. Nach 72 h konnte keine Veränderung gemessen werden (A). Bei NTERA-2 war die Proliferation nach $48 \mathrm{~h}$ und 72 h signifikant reduziert. Nach 12 h und 24 h war keine signifikante Reduktion detektierbar (B). Die Proliferation von TCam-2 war zu allen Zeitpunkten (12 h, 24 h, 48 h und 72 h) statistisch signifikant reduziert (C). Die Proliferation von NCCIT-R war ebenfalls zu allen Zeitpunkten signifikant reduziert (D). In NTERA-2R war die Proliferation nach $12 \mathrm{~h}, 48 \mathrm{~h}$ und $72 \mathrm{~h}$ signifikant reduziert, nach $24 \mathrm{~h}$ war keine signifikante Abnahme messbar (E). (n.s. $=$ nicht signifikant, $*=p<0,05, * *=p<0,005, * * *=p<0,0005)$. 

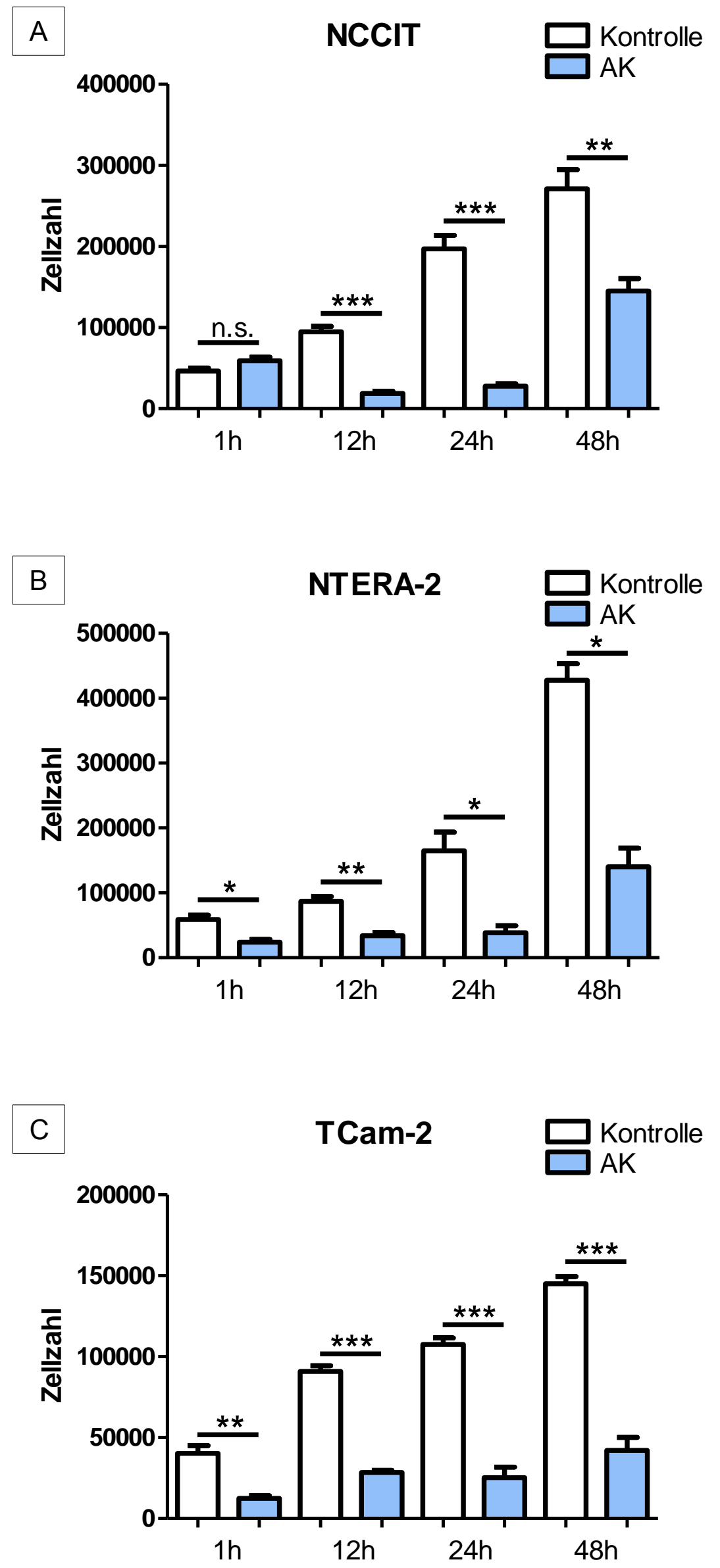

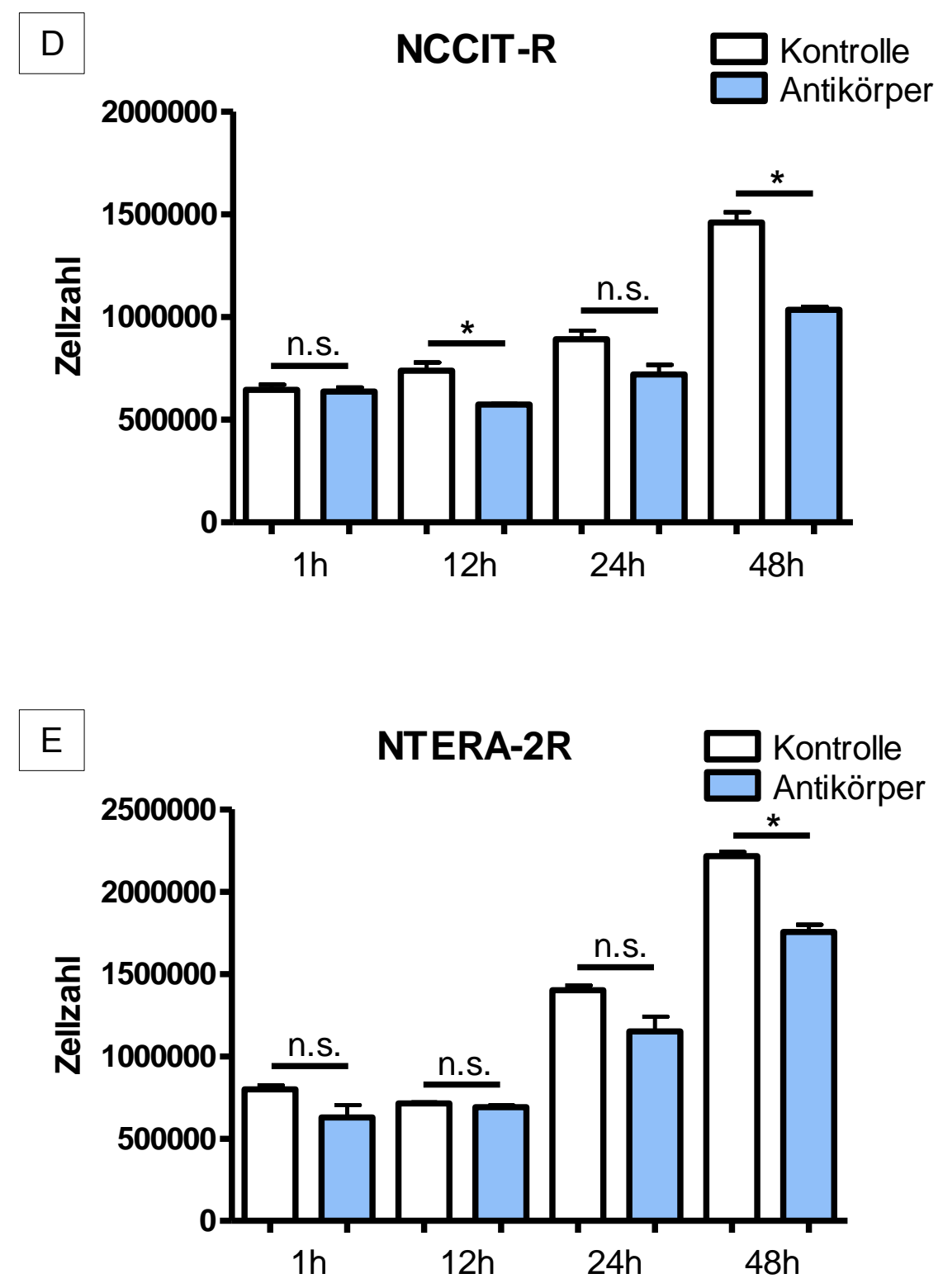

\section{Abbildung 14: Zellproliferation nach Antikörper-Gabe}

Die Zellzahlen wurden durchflusszytometrisch bestimmt. Die Proliferation in der Zelllinie NCCIT war nach 12-, 24- und 48 h signifikant reduziert. Nach 1 h konnte keine Veränderung gemessen werden (A). Bei NTERA-2 war die Proliferation nach 1 h, 12 h, 24 h und 48 h signifikant reduziert (B). Die Proliferation von TCam-2 war ebenfalls zu allen Zeitpunkten (1 h, 12 h, 24 h und 48 h) statistisch signifikant reduziert (C). In den Cisplatin-resistenten Zelllinien konnte eine signifikante Wachstumsabnahme bei NCCIT-R nach $12 \mathrm{~h}$ und $48 \mathrm{~h}(\mathbf{D})$, bei NTERA-2R nach 48 h (E) beobachtet werden (n.s. = nicht signifikant, $*=\mathrm{p}<0.05, * *=\mathrm{p}<0.005, * * *=\mathrm{p}<0.0005)$. 

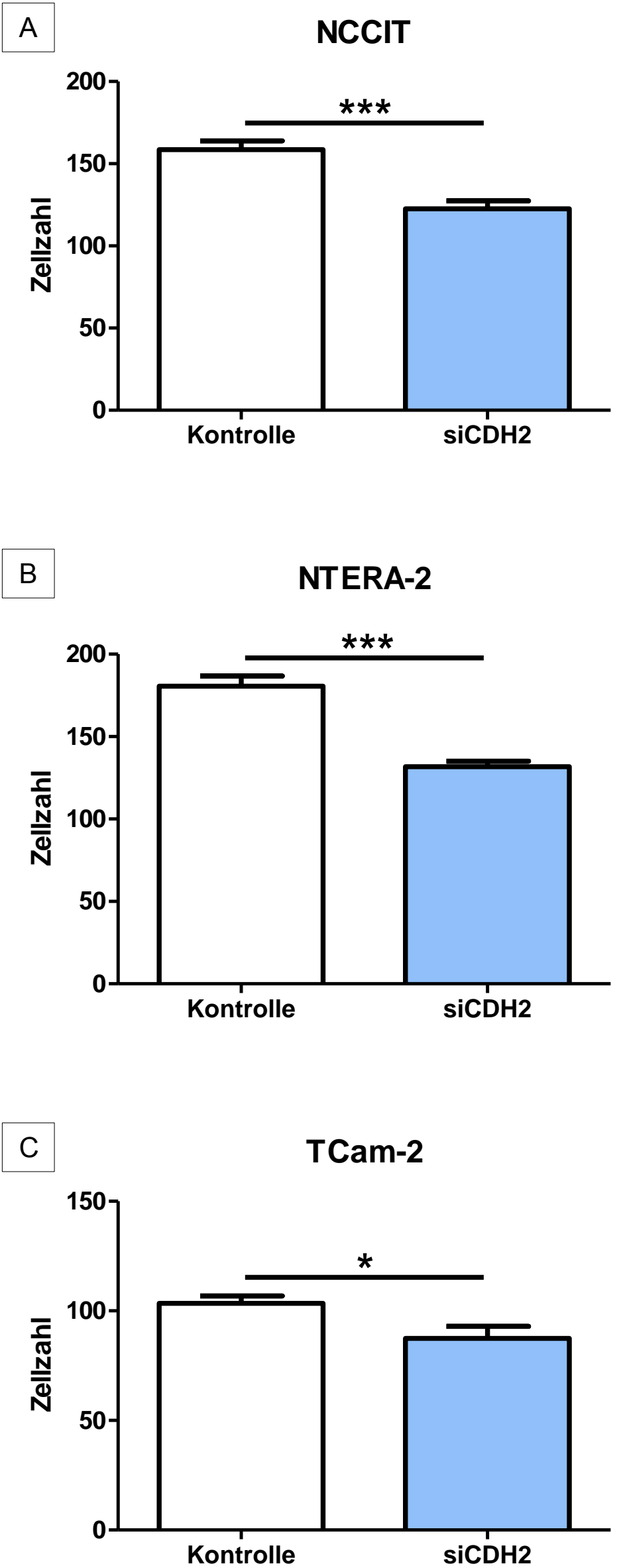

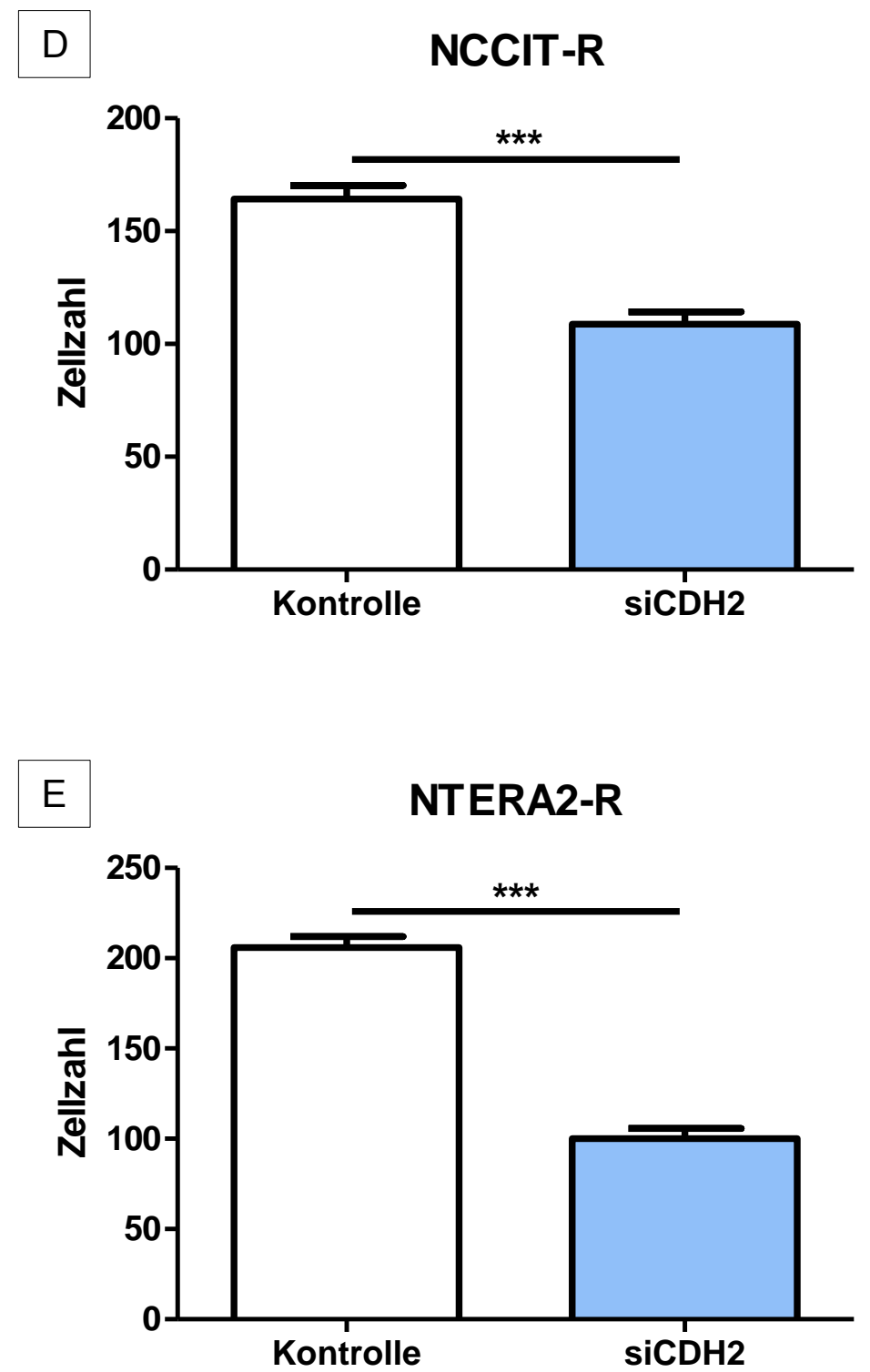

\section{Abbildung 15: Zellmigration nach siRNA-Transfektion}

Die Migration wurde mit dem Migrationsassay gemessen. Die Zellmigration von NCCIT (A), NTERA-2 (B), TCam-2 (C), NCCIT-R (D) und NTERA-2R (E) war nach 48 h signifikant reduziert. (n.s. $=$ nicht signifikant, $*=p<0,05, * *=p<0,005, * * *=p<0.0005)$. 

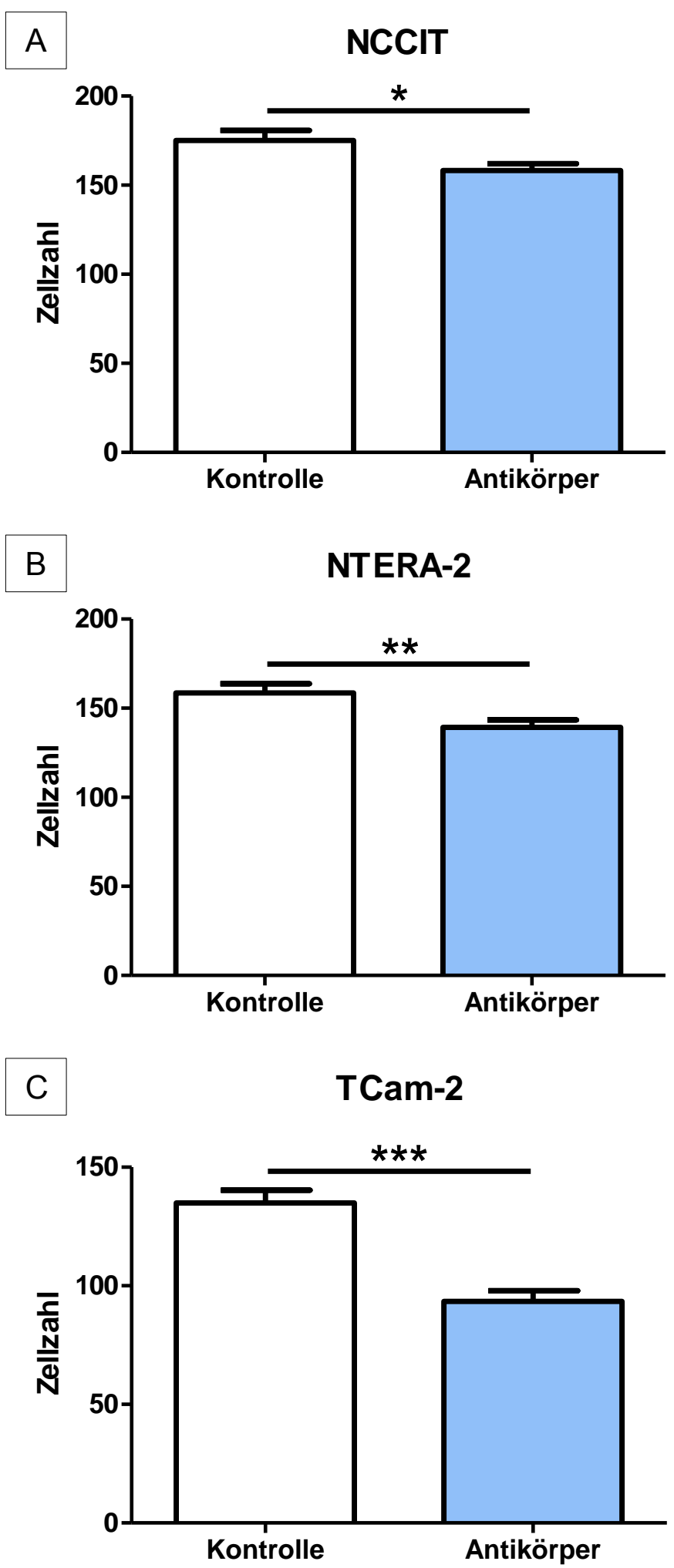

Abbildung 16: Zellmigration nach Antikörper-Gabe

Die Migration wurde mit dem Migrationsassay untersucht. Die Migration in den Zelllinien NCCIT (A), NTERA-2 (B) und TCam-2 (C) war 48 h nach Gabe des Blockadeantikörpers signifikant reduziert. (n.s. $=$ nicht signifikant, $*=p<0,05, * *=p<0,005$, ***= $\mathrm{p}<0,0005)$. 

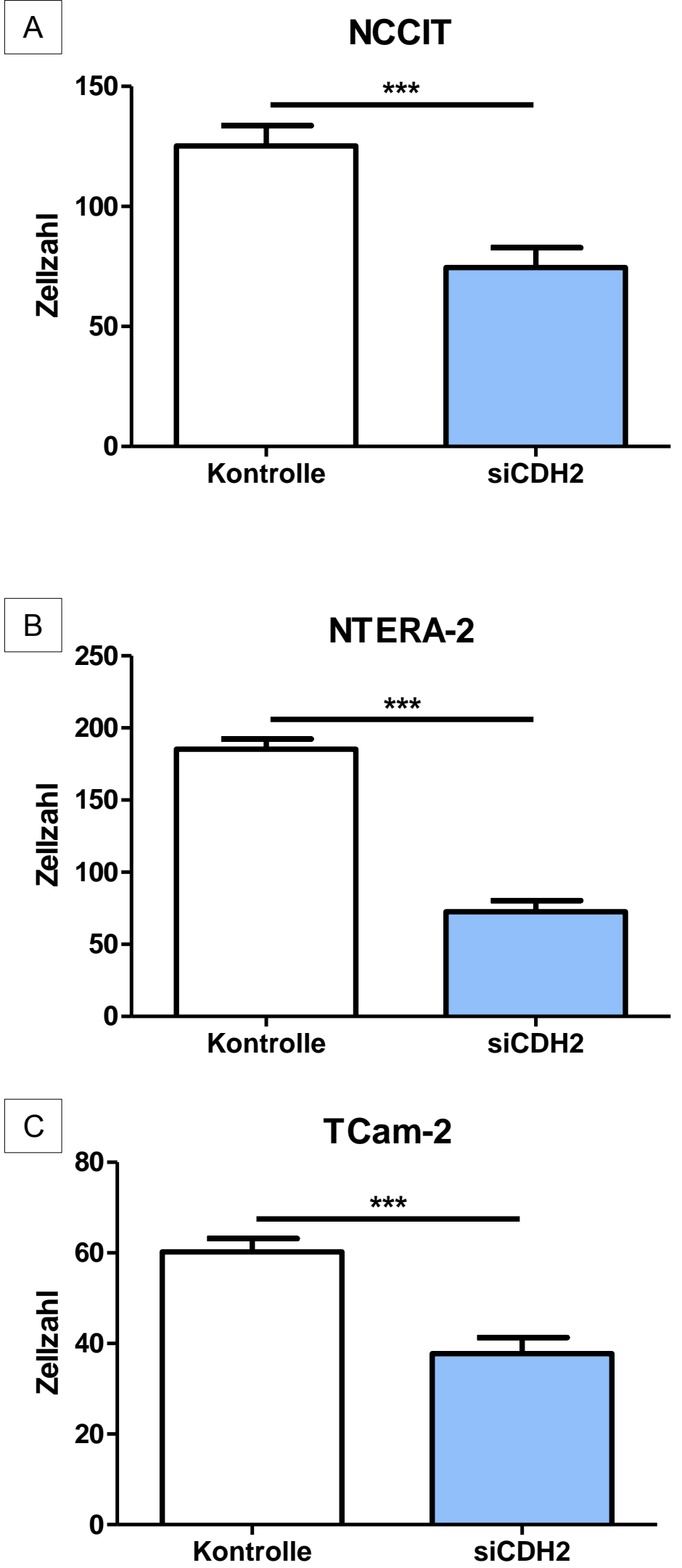

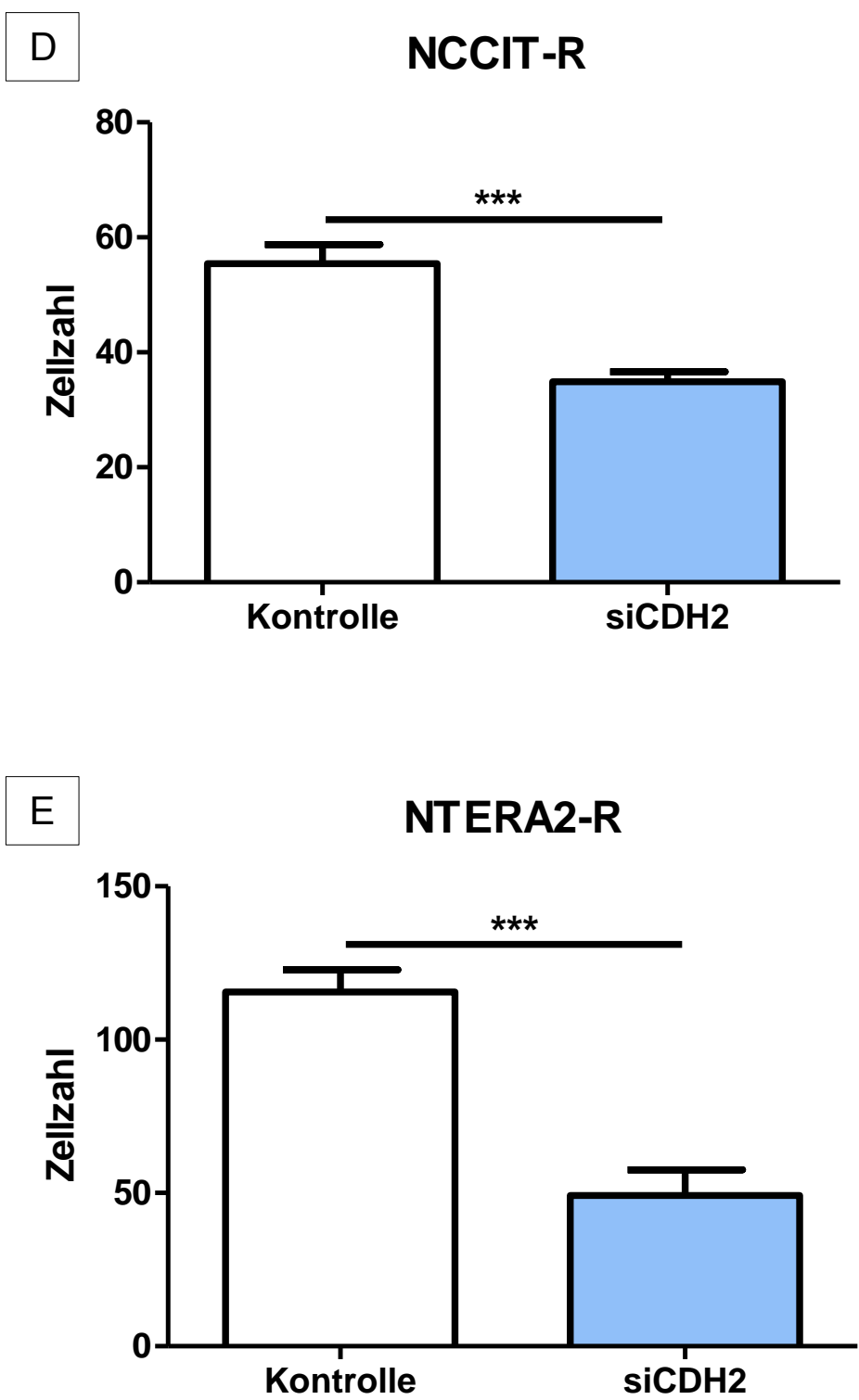

\section{Abbildung 17: Zellinvasion nach siRNA-Transfektion}

Die Invasion wurde mit dem Invasionsassay analysiert. Die Invasivität von NCCIT (A), NTERA-2 (B), TCam-2 (C), NCCIT-R (D) und NTERA-2R (E) war nach $48 \mathrm{~h}$ signifikant reduziert. (n.s. $=$ nicht signifikant, $*=p<0,05, * *=p<0,005, * * *=p<0,0005)$. 
A NCCIT
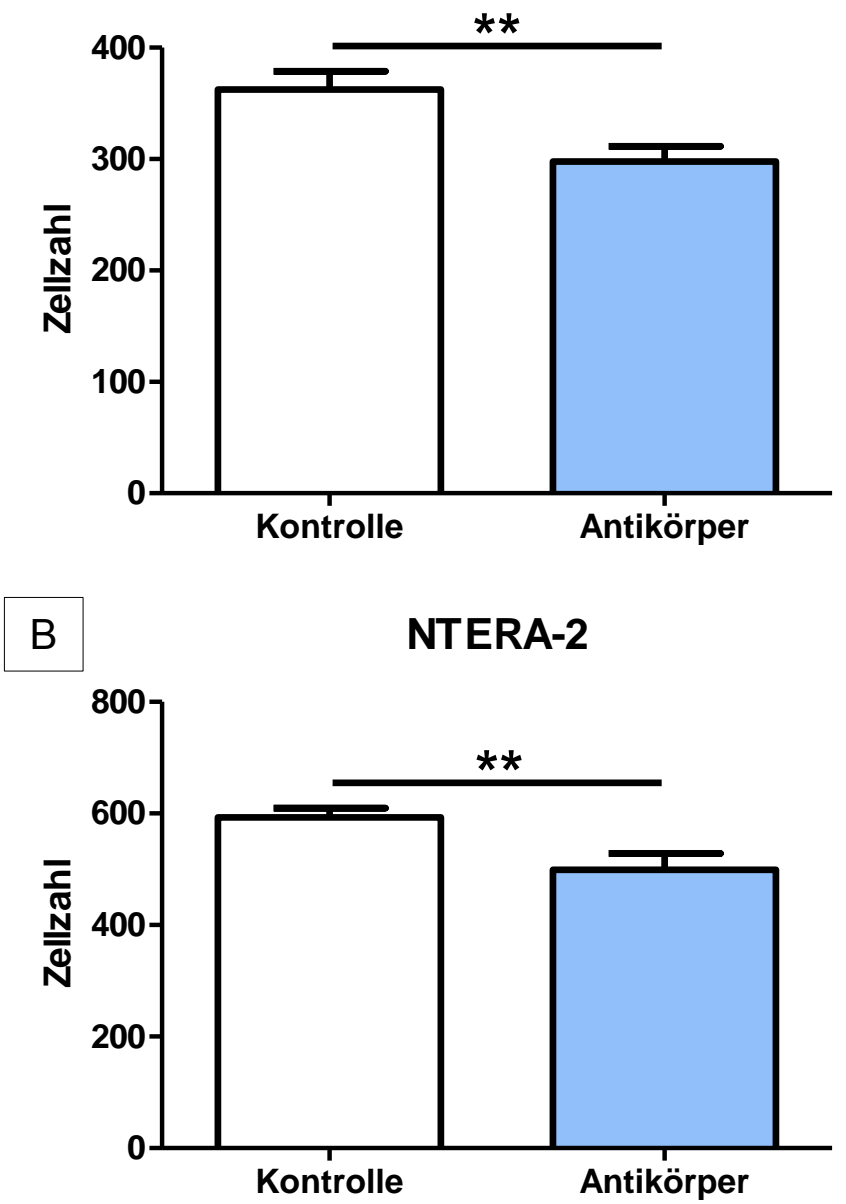

C TCam-2

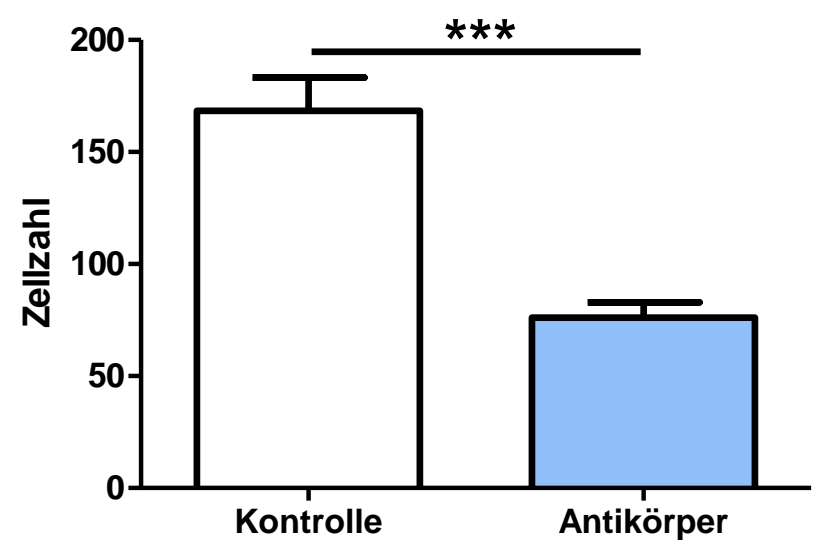

\section{Abbildung 18: Zellinvasion nach Antikörper-Gabe}

Die Zellinvasion wurde mit dem Invasionsassay untersucht. Die Invasivität von NCCIT (A), NTERA-2 (B) und TCam-2 (C) konnte - 48 h nach Gabe des spezifischen Antikörpers - signifikant inhibiert werden. (n.s. $=$ nicht signifikant, $*=p<0,05, * *=p<0,005$, $* * *=\mathrm{p}<0,0005)$. 

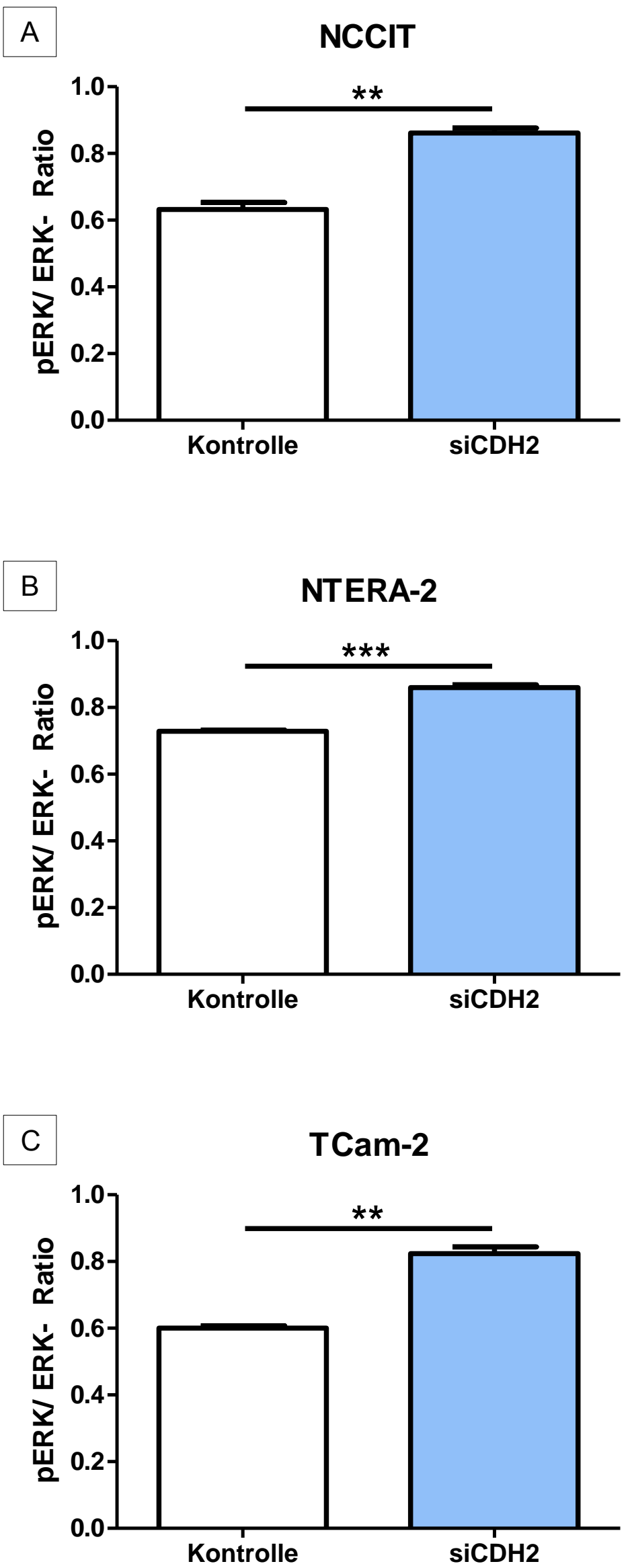

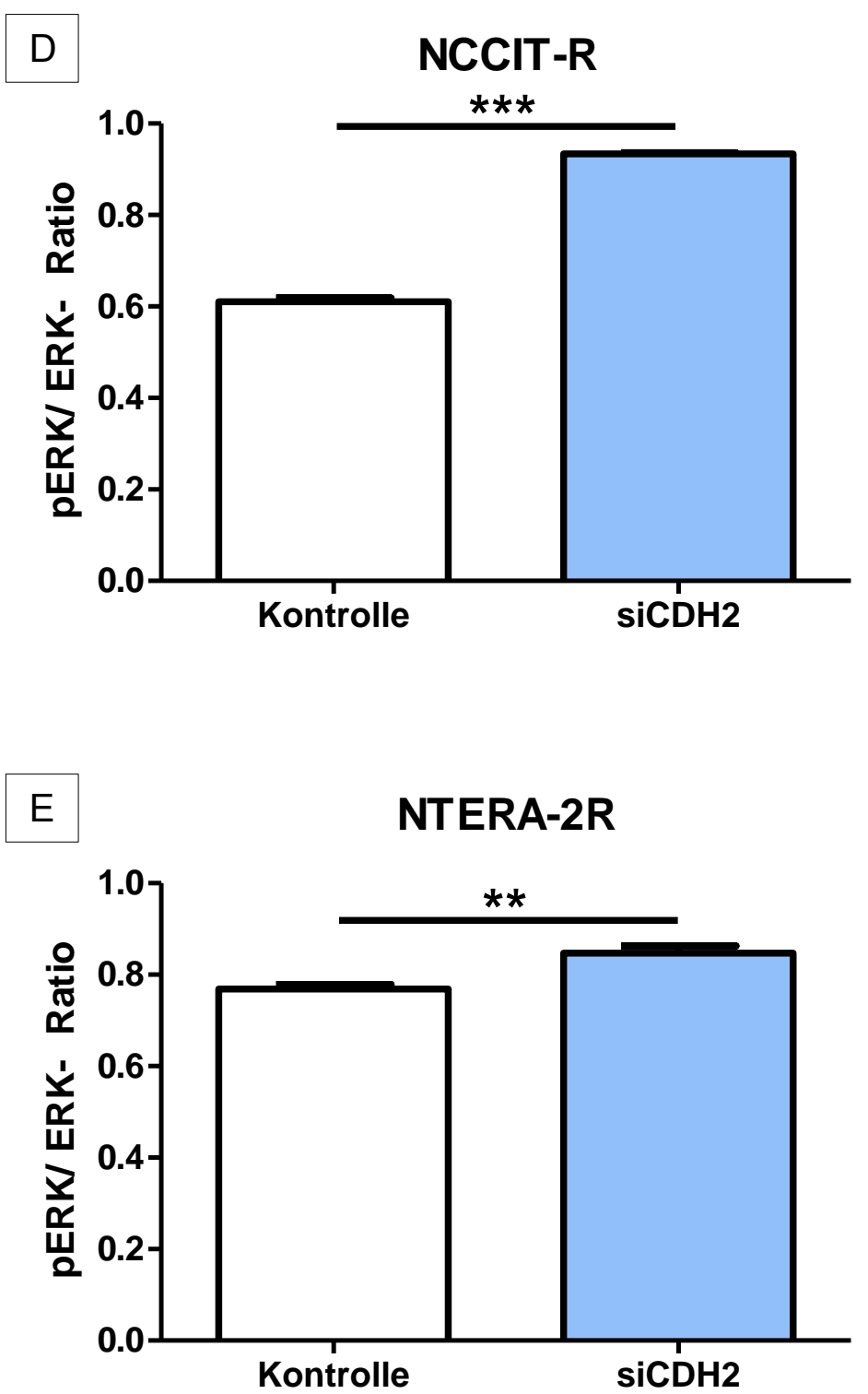

\section{Abbildung 19: pERK/ ERK-Ratio nach siRNA-Transfektion}

Die pERK/ ERK- Ratio wurde durchflusszytometrisch untersucht. 48 h nach siRNATransfektion zeigte sich ein statistisch signifikanter Anstieg des Quotienten in den Zelllinien NCCIT (A), NTERA-2 (B), TCam-2 (C), NCCIT-R (D) und NTERA-2R (E). (n.s. $=$ nicht signifikant, $*=p<0,05, * *=p<0,005, * * *=p<0,0005)$. 

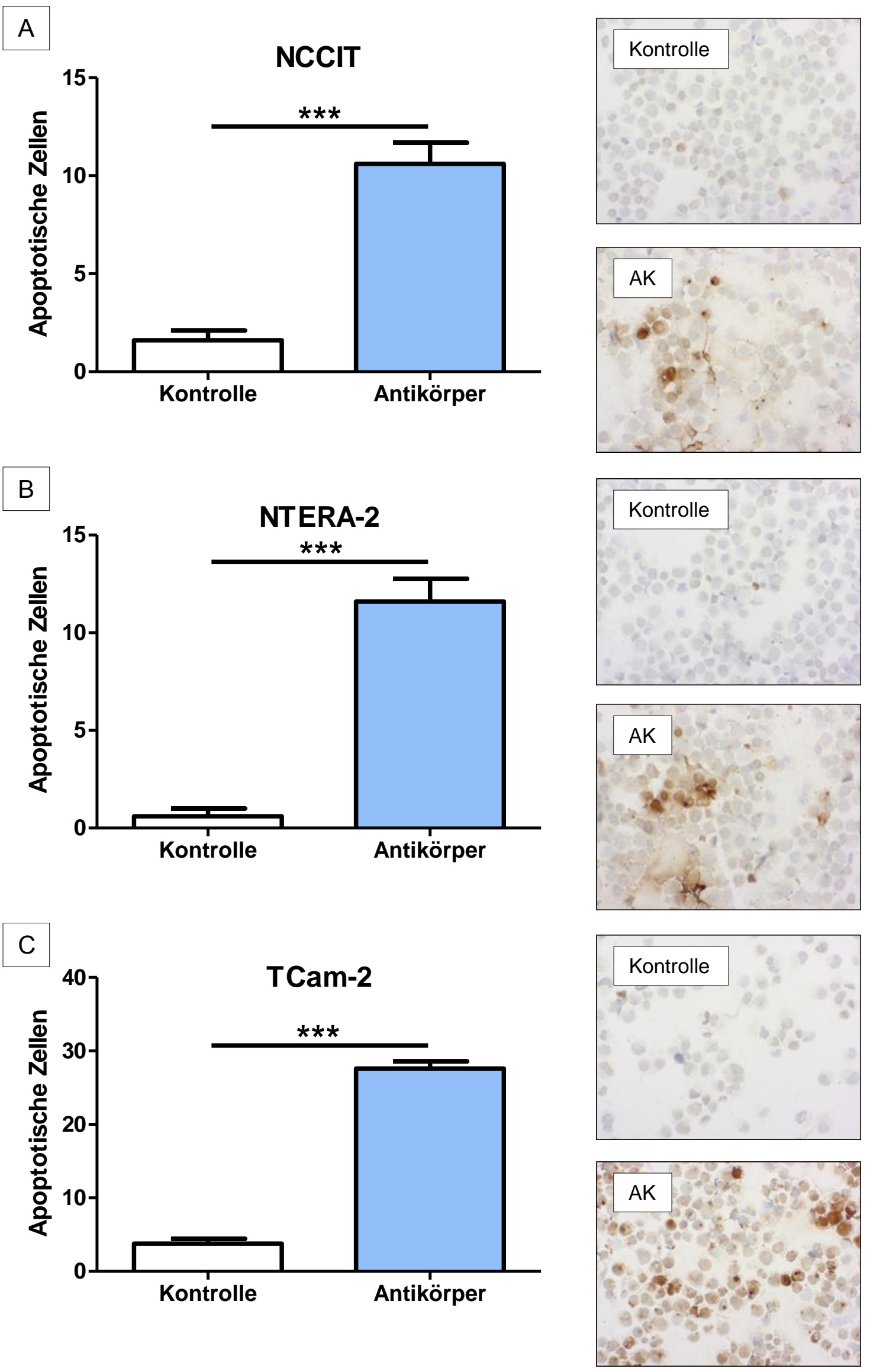

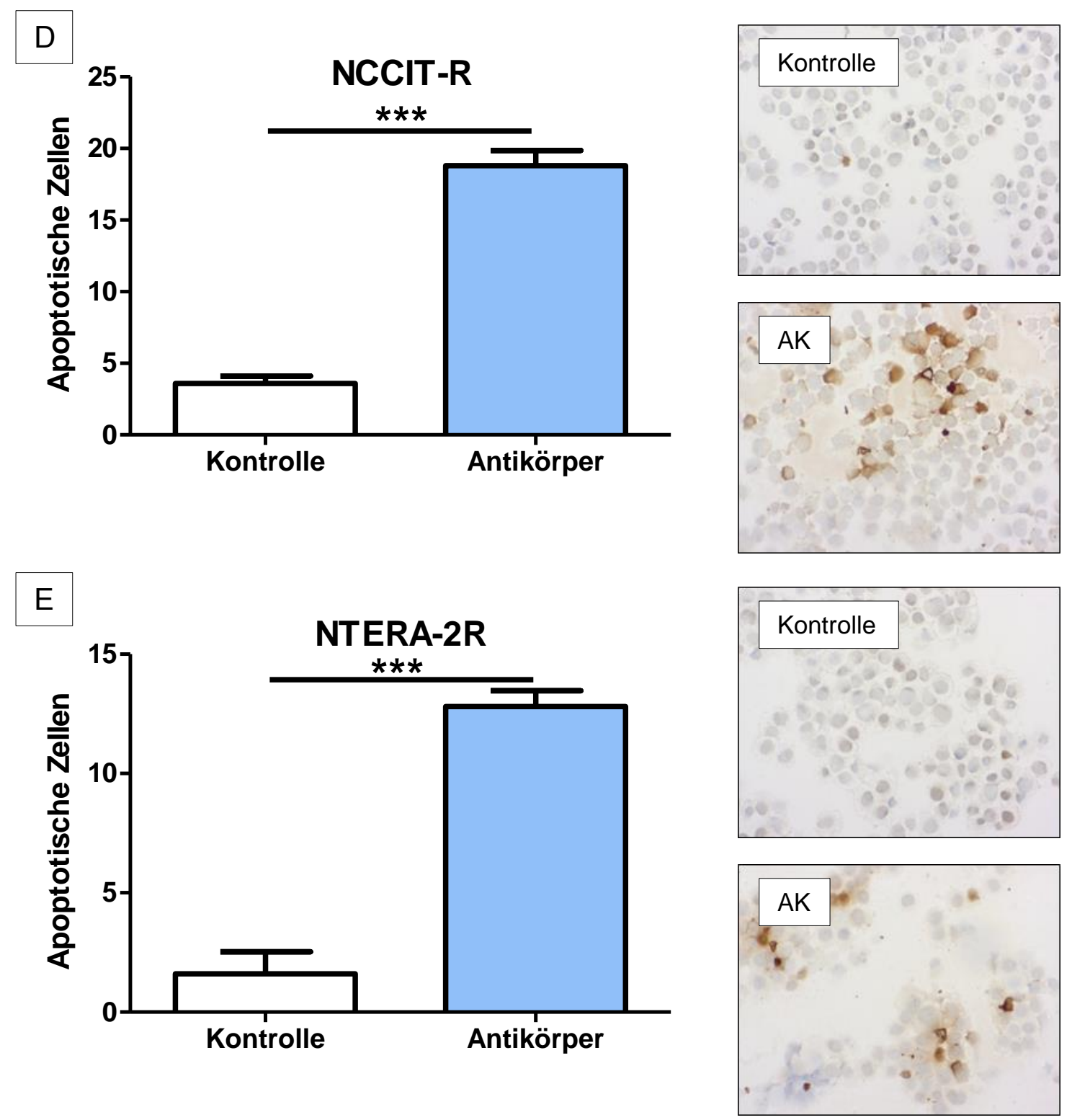

\section{Abbildung 20: Caspase-3-Aktivität nach Antikörper-Gabe}

Die Caspase-3-Aktivität wurde immunzytochemisch 48 h nach Gabe des Blockadeantikörpers untersucht. Bei den Keimzelltumorzelllinien NCCIT (A), NTERA-2 (B), TCam2 (C), NCCIT-R (D) und NTERA-2R (E) konnte ein signifikanter Anstieg apoptotischer Zellen beobachtet werden. (n.s. $=$ nicht signifikant, $*=\mathrm{p}<0,05, * *=\mathrm{p}<0,005, * * *=$ $\mathrm{p}<0,0005)$. 

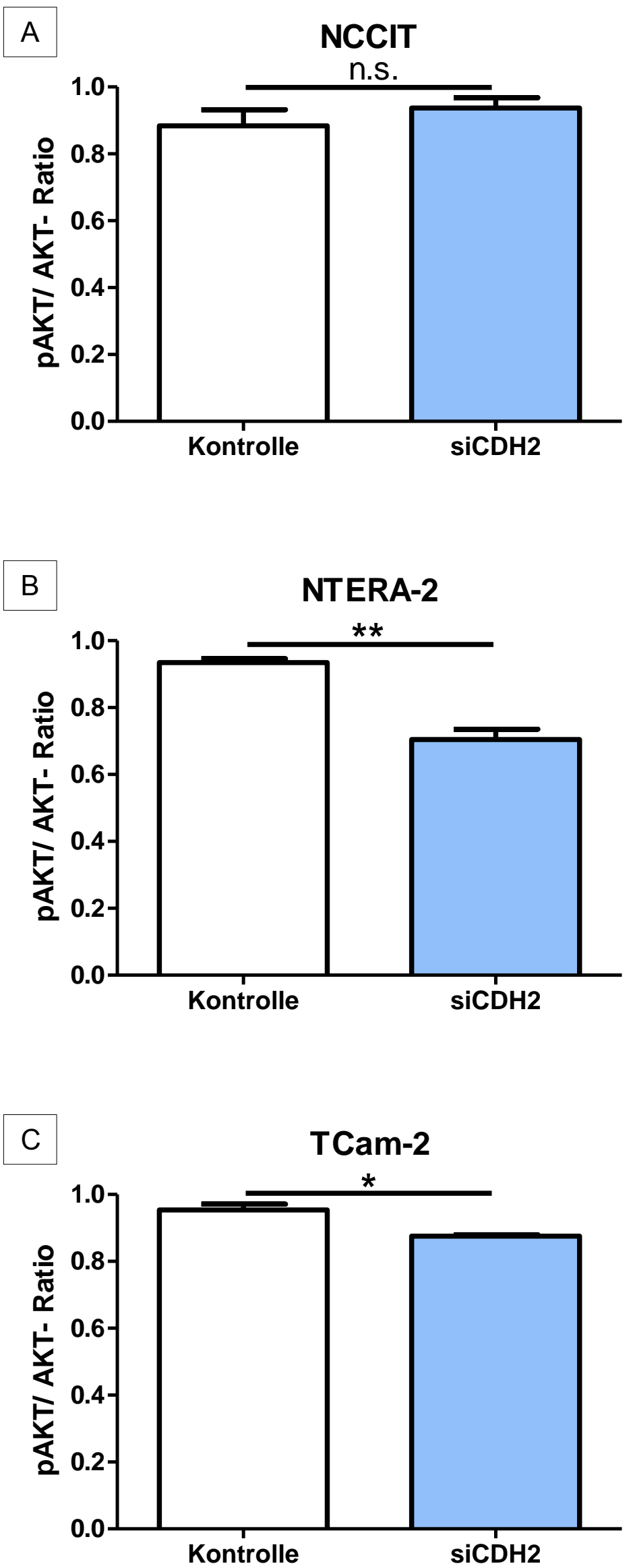

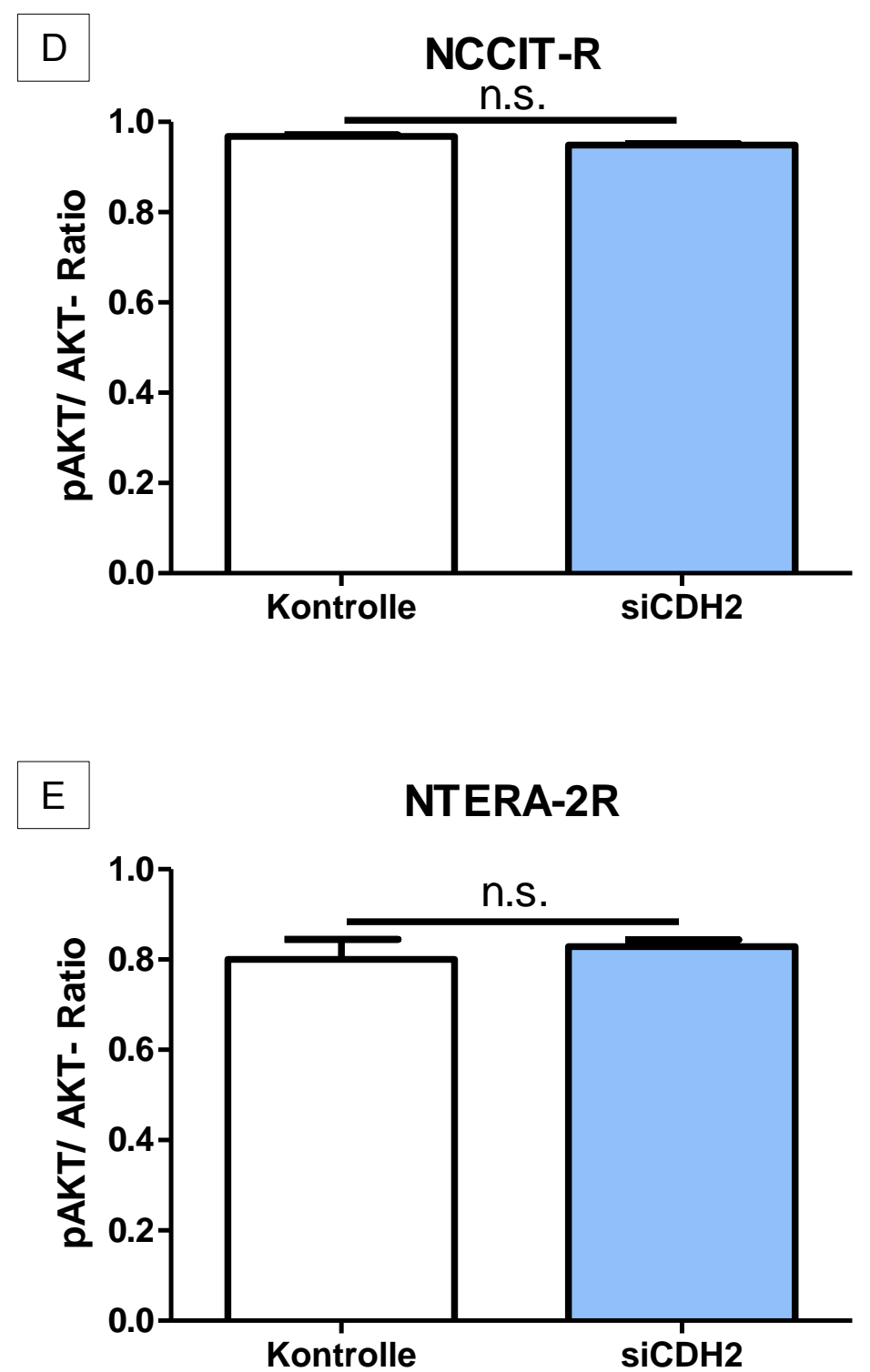

\section{Abbildung 21: pAKT/ AKT-Ratio nach siRNA-Transfektion}

Die pAKT/ AKT-Ratio wurde durchflusszytometrisch bestimmt. Die Cisplatin-sensitiven und -resistenten Zelllinien wurden $48 \mathrm{~h}$ mit siRNA vorbehandelt. In den Zellinien NCCIT (A), NCCIT-R (D) und NTERA-2R (E) zeigten sich keine Veränderungen des Quotienten, wohingegen er in NTERA-2 (B) $(\mathrm{p}<0,005)$ und TCam-2 $(\mathbf{C})(\mathrm{p}<0.05)$ signifikant gesenkt war. (n.s. $=$ nicht signifikant, $*=p<0,05, * *=p<0,005, * * *=p<0,0005)$. 


\section{Diskussion}

\subsection{N-Cadherin-Expression in TGCT}

Die Prognose maligner und metastasierter Tumore galt lange Zeit als infaust und ist auch nach heutigem medizinischem Standard - in den meisten Entitäten unvermindert schlecht. Insbesondere hohe Wachstumsraten, einhergehend mit einer schnellen Progression, bedingen bei Keimzelltumoren frühe Lymph- und Fernmetastasierungen (Di Pietro et al. 2005). Zum Diagnosezeitpunkt befinden sich bereits $25 \%$ der Patienten mit einem Seminom und bis zu 60\% der Patienten mit einem Nicht-Seminom in einem metastasierten Tumorstadium (Porcaro et al. 2002; Al Ghamdi und Jewett 2005). Die Einführung der Chemotherapie, insbesondere der Cisdiamminedichlorplatinum (Cisplatin, CDDP)basierten Hochdosischemotherapie (HDCT), änderte diese Prognose bei TGCT radikal. Heutzutage ist die Cisplatin-basierte HDCT ein Musterbeispiel für eine erfolgreiche und kurative Therapie eines metastasierten Tumors (Einhorn et al. 1990, 2002; Higby 1974). Ca. 80\% der Patienten werden aktuell mit dieser Initialtherapie geheilt (Beyer et al. 2013; Feldman et al. 2008).

Die Resultate einer Zweitbehandlung bei einem Rezidiv nach vorausgegangener HDCT sind hingegen enttäuschend. In einer Studie an 47 Patienten, die mit 66 Chemotherapien behandelt wurden, konnte nur noch eine Ansprechrate von weniger als 20\% ermittelt werden (Porcu et al. 2000). Neben den fehlenden Behandlungsmöglichkeiten in diesem Tumorstadium stellen die Akut- und Spätfolgen der Chemo-, aber auch der Radiotherapie ein weiteres gewichtiges Problem dar. Beide Therapien sind mit dem vermehrten Auftreten von soliden Zweittumoren vergesellschaftet (Travis et al. 2005). Zudem ist das Risiko für sekundäre Leukämien erhöht (Wierecky et al. 2005). Bei den Langzeitüberlebenden treten außerdem vermehrt kardiovaskuläre Erkrankungen auf (Huddart et al. 2003; van Den Belt-Dusebout et al. 2006; Zagars et al 2004). Das mit diesen assoziierte metabolische Syndrom kommt ebenfalls gehäuft vor (Haugnes et al. 2007). Darüber hinaus sind bei ca. $15-25 \%$ der Langzeitüberlebenden eine Nephrotoxizität, eine Ototoxizität und Raynaud-Phänomene festzustellen (Fosså et al. 2007; Zagars et al. 2004). Das Risiko eines Hypogonadismus liegt bei ca. 10-16\% (Huddart et al. 2005). Um zum einen diese hochtoxischen Effekte der Chemotherapie zu minimieren und zum anderen potente Behandlungsmöglichkeiten - besonders bei Rezidiven nach HDCT - zu schaffen, bedarf es der Entwicklung neuerer therapeutischer Optionen. Zugleich müssen auch die Mechanismen 
der Resistenzentwicklung genauer erforscht und besser verstanden werden (Jacobsen und Honecker 2015). Moderne therapeutische Überlegungen zielen deshalb vor allem auf die Entdeckung und Untersuchung molekularer Strukturen ab, die für eine spezifische Antikörper- oder Inhibitor-basierte Tumorbehandlung geeignet sind (Target- Therapie).

Da N-Cadherin in zahlreichen Tumorentitäten - unter anderem dem Mamma-, Pankreasund Prostatakarzinom sowie dem malignen Melanom - exprimiert wird und bei diesen eine entscheidende Rolle sowohl bei der Tumorzellproliferation als auch Metastasierung spielt, könnte es sich bei diesem Protein um genau so ein potentielles Zielmolekül mit therapeutischer Perspektive in TGCT handeln (Hazan et al. 2000; Li et al. 2001; Nalla et al. 2011; Sanders et al. 1999; Shintani et al. 2008; Tanaka et al. 2010).

Die WHO klassifiziert die malignen testikulären Keimzelltumoren in solche, die aus normalem Hodengewebe über die Zwischenstufe der testikulären intratubulären Keimzellneoplasie (GCNIS) entstehen und solche, die in keiner Beziehung zu dieser stehen. Die erste Gruppe ist dabei mit ca. 90\% deutlich größer als die zweite (Hanna und Einhorn 2014). Die GCNIS stellt damit eine weit verbreitete, diagnostisch und therapeutisch nutzbare wichtige Vorläuferläsion maligner Keimzelltumoren dar (Moch et al. 2016). In normalem Hodengewebe, in der GCNIS und in TGCT konnte die Expression von N-Cadherin nachgewiesen werden (Bremmer et al. 2012a). Dabei zeigte sich immunhistochemisch eine unterschiedliche Proteinexpression in den Keimzelltumor-Subtypen. Teratome, Seminome und Dottersacktumoren zeigten eine starke Expression des Adhäsionsmoleküls, wohingegen es in embryonalen Karzinomen und Chorionkarzinomen nicht angefärbt werden konnte (Bremmer et al. 2012a). Folglich stellt das Glykoprotein in der GCNIS wie auch in den meisten Keimzelltumoren ein potentielles Therapieziel dar.

Ein Ziel dieser Dissertationsarbeit war, aufbauend auf den oben genannten Forschungsergebnissen, die Expression von N-Cadherin in TGCT und analogen Zelllinien noch genauer zu analysieren. Mittels Western Blot konnte die Expression in den Cisplatin-sensitiven Zelllinien NCCIT, NTERA-2 und TCam-2 gezeigt werden (Abb. 5). Da NCCIT von einer pluripotenten Stammzelle eines Teratokarzinoms, TCam-2 von einem Seminom abstammt, konnten die Ergebnisse von Bremmer et al. - Seminome und Teratome exprimieren stark N-Cadherin - bestätigt werden (Bremmer et al. 2012a). Hingegen steht die nachgewiesene Expression des Proteins in der Zelllinie NTERA-2, die von einer pluripotenten Stammzelle eines embryonalen Karzinoms abstammt, in Widerspruch zu den Resultaten von Bremmer et al., dass embryonale Karzinome kein N-Cadherin exprimieren 
(Bremmer et al. 2012a). Demnach unterliegt die Expression des Proteins in embryonalen Karzinomen möglicherweise einer gewissen Variabilität, oder aber es besteht eine generelle Diskrepanz zwischen Zelllinie und in vivo gewonnenem Gewebe. Weitere Zellversuche und immunhistochemische Untersuchungen sollten hier Aufschluss bringen.

Eine deutliche Expression von N-Cadherin konnte auch in den Cisplatin-resistenten Ziellinien NCCIT-R und NTERA-2R festgestellt werden (Abb. 6). Differenzen bezüglich der Expressionsmenge zwischen den Cisplatin-sensitiven Zelllinien NCCIT und NTERA und den Cisplatin-resistenten Stämmen NCCIT-R und NTERA-2R konnten nicht gemessen werden. Diese Ergebnisse ermöglichten zum einen einen experimentellen Vergleich der Cisplatin-sensitiven und -resistenten Varianten in Hinblick auf die Rolle von N-Cadherin in der Proliferation, Migration und Invasion maligner TGCT, zum anderen konnte NCadherin als potentielles Zielmolekül für eine mögliche Second-line-Therapie, nach erworbener Cisplatin-Resistenz, identifiziert werden.

N-Cadherin konnte ebenso immunhistochemisch in allen untersuchten Seminom-Metastasen nachgewiesen werden (3/3). In 40\% der Metastasen eines Dottersacktumors verlief die Färbung positiv. Eine Proteinexpression konnte zudem in einer Metastase eines reifen- (1/14) sowie in zwei eines unreifen Teratoms (2/4) gezeigt werden. Metastasen von embryonalen Karzinomen exprimierten kein N-Cadherin (0/2) (Tab. 10). Zusammengefasst zeigt die immunhistochemische Analyse, mit Ausnahme des bereits oben diskutieren embryonalen Karzinoms, ein konkordantes Expressionsmuster von Metastasen und Primärtumoren sowie von In-vivo- und In-vitro-Zellpopulationen (Bremmer et al. 2012a, 2015a). Die Ergebnisse zeigen somit, dass N-Cadherin in fortgeschrittenen Tumorstadien als mögliches Zielmolekül in metastatischen Absiedlungen - insbesondere bei seminomatösen Keimzelltumoren - in Betracht käme. Unter diesem Gesichtspunkt sollte aber kritisch bedacht werden, dass teils überaus hohe Prozentzahlen der nichtseminomatösen Tumormetastasen keine Proteinexpression aufwiesen. 


\subsection{Proliferationsverhalten von GCT-Zelllinien nach N-Cadherin-Blo- ckade}

Die Tatsache, dass eine Störung der N-Cadherin-vermittelten Adhäsion in vitro und in vivo Apoptose induzieren kann, zeigt, dass das Protein bei der Proliferation und dem Überleben von Zellen eine wichtige Funktion innehat. Im physiologischen Kontext ist das Glykoprotein entscheidend für das Überleben der Kardiomyozyten und beeinflusst zudem die nachfolgende Herzentwicklung (Luo et al. 2001; Radice et al. 1997). Darüber hinaus ist es während der Osteogenese mitverantwortlich für die Adhäsion, die Differenzierung und das Überleben der Osteoblasten (Marie 2002). In Enterozyten stellt N-Cadherin einen wichtigen Überlebensfaktor dar, seine Inhibierung steigert die Apoptoserate (Hermiston und Gordon 1995). Außerdem fördert es das Überleben ovarieller Zellen und ist hier ebenfalls an der Apoptose beteiligt (Pon et al. 2005). Ein Antikörper gegen das Protein schwächt die Zellaggregation und steigert den programmierten Zelltod (Peluso 1997; Peluso et al. 1996). Gleiches zeigten Makrigiannakis et al. bei Granulosazellen (Makrigiannakis et al. 1999).

N-Cadherin, so demonstrieren zahlreiche Studien, verbessert auch bei Tumorzellen die Überlebensrate über eine Modulierung intrazellulärer Signalmoleküle und ist ebenso mitverantwortlich für erworbene Therapieresistenzen ( $\mathrm{Li}$ et al. 2001; Tanaka et al. 2010). Tanaka et al. wiesen bei dem Vergleich der Genexpressionslevel von androgenabhängigen- und kastrationsresistenten Prostatakrebszellen (CRPC) in Xenografts einen signifikanten Anstieg der N-Cadherin-Expression in den CRP-Zellen nach. Dementsprechend fehlte in hormonsensitiven Prostatakrebszelllinien eine Proteinexpression, wohingegen in kastrationsresistenten Zelllinien ein Nachweis erfolgte (Tanaka et al. 2010). Außerdem konnte ein ansteigendes Expressionsprofil bei dem Vergleich einer benignen Prostatahyperplasie mit hormonnaiven, hormonell vorbehandelten und CRP-Zellen gezeigt werden (Tanaka et al. 2010). Diese Beobachtungen unterstreichen, dass N-Cadherin bei Prostatakarzinomen eine wichtige Funktion in der Entwicklung von Kastrationsresistenzen einnimmt und dadurch bedingt auch mit einer schlechteren Prognose der Tumorerkrankung vergesellschaftet ist (Mariotti et al. 2007). Vergleichend dazu zeigte sich in unseren Analysen ein gleichartiges Expressionsmuster in Cisplatin-sensitiven und -resistenten Zelllinien (Abb. 5+6). Zumindest in vitro scheint N-Cadherin demnach in TGCT keine Rolle bei der Resistenzentwicklung zu spielen. Ob eine vermehrte Expression des Proteins mit einer negativen Prognose einhergeht, sollten weitere Experimente und Studien klären. 
Monoklonale Antikörper, gerichtet gegen die extrazelluläre Domäne des Proteins, führten bei Prostatakrebszellen zu einer Schwächung der Adhäsionsfähigkeit bei gleichzeitiger Reduktion der Proliferation (Tanaka et al. 2010). In vivo konnte gleichfalls eine Wachstumssuppression beobachtet werden, die sogar bei fortgeführter Behandlung zu einer langfristigen Reduktion des Zellüberlebens führte (Tanaka et al. 2010). Die Blockade des Proteins in Xenografts mit höherer Tumormasse verlangsamte das Zellwachstum signifikant und führte bei höheren Dosen zu teils vollständigen Remissionen (Tanaka et al. 2010). In klinischen Phase-I-Studien mit dem zyklischen Pentapeptid ADH-1 (ExherinTM), einem kompetitiven N-Cadherin-Antagonisten, konnte ebenfalls ein antitumoraler Effekt, u. a. in gynäkologischen und therapierefraktären soliden Tumoren nachgewiesen werden (Stewart et al. 2006; Perotti et al. 2009; Yarom et al. 2013). Ferner zeigte sich eine wachstumshemmende Wirkung des Inhibitors in Xenografts bei Brust-, Ovarial-, Kolon- und Lungenkarzinomen (Yarom et al. 2013). In Pankreaskarzinom- und Neuroblastomzelllinien inhibierte $\mathrm{ADH}-1$ die Zellproliferation über eine Apoptoseinduktion (Lammens et al. 2012; Shintani et al. 2008). Auch in malignen Melanomen konnte eine hohe Expression des Adhäsionsmoleküls sowohl in vitro als auch in vivo nachgewiesen werden (Sanders et al. 1999; Scott und Cassidy 1998; Hsu et al. 1996; Tang et al. 1994). Das Protein vermittelt hier die Aggregation der Melanomzellen sowie die Adhäsion an Fibroblasten und Endothelzellen (Li et al. 2001). Die Blockade mit einem monoklonalen Antikörper bewirkte, analog zu den anderen Tumorentitäten, eine signifikant reduzierte Überlebensrate der Krebszellen (Li et al. 2001).

In unseren Versuchen blockierten wir zum einen die mRNA-Translation über die Gabe von siRNA, zum anderen inhibierten wir das Molekül direkt mit einem monoklonalen Antikörper. Nach siRNA-Gabe kam es in allen untersuchten Cisplatin-sensitiven Zelllinien zu einer Reduktion der Proliferation. Drei Messungen ergaben dabei keine signifikanten Ergebnisse (NCCIT bei $72 \mathrm{~h}$ mit p>0,05 und NTERA-2 bei 12 h, $24 \mathrm{~h}$ mit p>0,05). Bei ähnlicher Proteinexpression in beiden Zelllinien (Abb. 5) könnte die mikroskopisch beobachtbare erhöhte Proliferation der NCCIT- im Vergleich zur NTERA-2- Zelllinie ursächlich für den zum letzten Messzeitpunkt aufgehobenen Hemmeffekt sein, wohingegen dieser bei NTERA-2, aufgrund der niedrigeren Wachstumsrate, erst nach $48 \mathrm{~h}$ sichtbar einsetzt. Passend dazu zeigt sich die wachstumshemmende Wirkung bei TCam-2 (höchste N-Cadherin- Expression, langsamste Teilungsrate) frühestmöglich und hält zu allen Zeitpunkten an. Die Proliferation von NCCIT-R war zu allen Zeitpunkten reduziert, 
bei NTERA-2R war die Wachstumsabnahme nur nach $24 \mathrm{~h}$ nicht signifikant. Die Blockade des Proteins mittels Antikörper zeigte ebenfalls eine Wachstumsreduktion in den Zelllinien. Unsere Ergebnisse belegen, dass N-Cadherin auch in testikulären Keimzelltumoren eine wichtige Funktion bei der Proliferation der Krebszellen einnimmt und eine Proteinhemmung eine signifikante Reduktion des Wachstums zur Folge hat. Der erfolgreiche Einsatz des spezifischen Antikörpers weist das Glykoprotein zudem als Molekül einer potenziellen zielgerichteten Krebstherapie aus.

Erste Hinweise darauf, welche molekularen Ursachen dem Proliferationsrückgang zugrunde liegen könnten, ergaben zytologische Beobachtungen. So zeigte die inhibierte Zellpopulation im Vergleich zur Kontrollgruppe massenhaft von der Kulturplatte abgeschwemmte und verstreut vorliegende, morphologisch avitale Krebszellen. Außerdem ließen sich die noch adhäsiven Zellen deutlich leichter mit Trypsin vom Plattenboden ablösen. Beides lässt vermuten, dass die Blockade N-Cadherin-vermittelter Zell-Zell- oder Zell-Platte-Adhäsionen, einhergehend mit Auflösung des Tumorzellverbandes und räumlicher Isolierung einzelner Tumorzellen, Apoptose induzieren könnte. Passend dazu protokollierten Koutsouki et al., dass die Blockade N-Cadherin abhängiger Zell-ZellKontakte in glattvenösen Gefäßmuskelzellen Apoptose induziert (Koutsouki et al. 2005). Vergleichbare Beobachtungen machten Tanaka et al. bei der histomorphologischen und immunhistochemischen Analyse inhibierter Prostatakrebszellen in Mausmodellen. Hier zeigten sich in der HE-Färbung flächige Tumorareale mit nekrotischen Veränderungen oder Zellverlust (Tanaka et al. 2010). Auch die Gabe von ADH-1 verursachte ausgedehnte Tumornekrosen (Shintani et al. 2008). Dass der Proliferationsindex (ki-67) im Vergleich zu nicht behandelten Tumoren signifikant reduziert war, weist zudem auf mindestens einen weiteren N-Cadherin- basierten Kontrollmechanismus des Wachstums hin (Tanaka et al. 2010). Die zugrundeliegenden molekularen Mechanismen wurden von uns daraufhin genauer untersucht (Abb. 19-21) und werden gesondert diskutiert (Kapitel 4.4). Trotzdem sollten ergänzende In-vivo-Versuche mit anschließender histomorphologischer Begutachtung des Gewebes weiteren Aufschluss bringen.

Die Tumoren könnten in diesem Fall auch auf induzierte Gefäßschädigungen und eine gestörte Angiogenese hin untersucht werden, die ebenfalls als wichtige Ursachen des Wachstumsrückgangs in Betracht kämen. Schon Tanaka et al. notierten eine geringere Vaskularisierung der Tumore (CD31- Färbung) nach Antikörper- Behandlung (Tanaka et al. 2010). Ergänzend postulierten Nalla et al. - ebenfalls in Prostatakrebszellen unter 
siRNA-vermittelter N-Cadherin-Blockade - ein um 45\% reduziertes Kapillarnetzwerk (Nalla et al. 2011). Klinische Studien mit ADH-1 zeigten ebenso Gefäßschäden wie Experimente mit Xenografs (Yarom et al. 2013). Die verminderte Gefäßdichte nach Proteininhibierung passt zu der Erkenntnis, dass N-Cadherin auch in Endothelzellen exprimiert wird und eine entscheidende Rolle bei der Ausreifung und Stabilisierung von Blutgefäßen und tumorassoziierten Gefäßneubildungen spielt (Gerhardt \& Betsholtz 2003; Mariotti et al. 2007). So resultierte aus der Neutralisation des Adhäsionsmoleküls während der Hirnentwicklung von Hühnern eine defekte Perizytenanhaftung an die Hirngefäße, in deren Folge es zu Hämorrhagien und einer fehlerhaften Vaskulogenese kam (Gerhardt et al. 2000). Eine Genblockade in Mäusen hatte sowohl eine gestörte Vaskularisierung des Embryos als auch des Dottersacks mit gesteigerter Letalität zur Folge (Luo und Radice 2005). Ergänzend zeigten Geiger et al., dass die Blockade von N-Cadherin bei Endothelzellen Apoptose induziert (Erez et al. 2004). Auch das Überleben venöser Gefäßmuskelzellen ist von N-Cadherin-vermittelten Zell-Zellkontakten abhängig (Koutsouki et al. 2005).

\subsection{Migrations- und Invasionsverhalten von GCT-Zelllinien nach N-Cad- herin-Blockade}

Bei der Metastasierung maligner Tumoren handelt es sich um einen komplexen, mehrstufigen und in großen Teilen noch unverstandenen Prozess. Basierend auf einer Reihe genetischer Alterationen, die mit einem veränderten Proteinexpressionsprofil - insbesondere der Zelladhäsionsmoleküle - einhergehen, kommt es zu einer erhöhten Motilität und Invasivität der Tumorzellen (Kang und Massague 2004). Zahlreiche Publikationen konnten dabei den Einfluss des Adhäsionsmoleküls N-Cadherin auf die Migration der Zellen belegen (Hazan et al. 2000; Li et al. 2001; Nieman et al. 1999; Qi J. et al. 2005; Suyama et al. 2002; Tanaka et al. 2010). Beim malignen Melanom fördert das Protein die interzelluläre Migration über den Kontakt mit Fibroblasten (Li et al. 2001). Außerdem zeigten Qi et al., dass das Molekül am Kontaktpunkt von Endothel- und Melanomzellen kumuliert ist und somit ebenso eine Schlüsselrolle bei der transendothelialen Migration einnimmt (Qi J. et al. 2005). Die Antikörper-vermittelte Blockade hemmte sowohl die interzelluläre als auch die transendotheliale Migration (Li et al. 2001; Sandig et al. 1997). Gleichsam wurde in N-Cadherin transfizierten, E-Cadherin positiven Brustkrebs- Zelllinien eine erhöhte Migration in Relation zur N-Cadherin-negativen Vergleichsgruppe gemessen 
(Hazan et al. 2000; Nieman et al. 1999). Darüber hinaus konnte eine höhere Adhäsion der Tumorzellen an das Gefäßendothel und damit mutmaßlich - analog zu den Melanomzellen - eine verbesserte transendotheliale Migration beobachtet werden (Hazan et al. 2000). Die Behandlung mit einem Antikörper gegen die endständige NH-Domäne des Moleküls senkte auch hier die Zellmigration (um bis zu 50\%) (Hazan et al. 2000). In Pankreaskarzinomzellen beobachtete man ebenfalls eine N-Cadherin abhängige Motilitätszunahme, die durch Applikation von ADH-1 erfolgreich inhibiert wurde (Shintani et al. 2008; Shintani et al. 2006). Unsere Experimente erbrachten übereinstimmende Ergebnisse. Die Migration war $48 \mathrm{~h}$ nach der Behandlung mit siRNA gegen $\mathrm{CDH} 2$ sowohl in den Cisplatin-sensitiven als auch -resistenten TGCT-Zelllinien signifikant reduziert (Abb. 15 A-E). Derselbe Effekt zeigte sich unter der Hemmung mit dem monoklonalen Antikörper (NCCIT $(\mathrm{p}<0,05)$, NTERA-2 $(\mathrm{p}<0,005)$ und TCam-2 $(\mathrm{p}<0,0005))($ Abb. 16 A-C). Es bleibt festzuhalten, dass N-Cadherin auch bei malignen Keimzelltumoren des Hodens maßgeblich an der Tumorzellmigration beteiligt ist. Ob es sich dabei um eine gesteigerte interzelluläre und oder transendotheliale Motilität der Zellen handelt und inwieweit NCadherin-exprimierende Fibroblasten oder Gefäßzellen am Prozess beteiligt sind, sollten weitere Versuche klären. Zudem sollten weitere Anstrengungen unternommen werden, die Inhibitionsexperimente mit dem monoklonalen Antikörper auch an den Cisplatin- resistenten Zelllinien erfolgreich durchführen zu können.

Ein direkter Zusammenhang zwischen N-Cadherin-Expression und gesteigerter Tumorinvasivität wurde ebenfalls in verschiedensten malignen Neoplasien beschrieben (Hazan et al. 2000; Islam et al. 1996; Nieman et al. 1999; Tanaka et al. 2010). So beobachteten Tanaka et al. eine mit gesteigertem Expressionslevel korrelierende erhöhte Invasivität bei N-Cadherin positiven Prostatakrebs- Zelllinien (Tanaka et al. 2010). Ergänzende in vivo Versuche mit subkutanen Tumorimplantaten erzielten gleichgerichtete Resultate. Neben einem muskelinvasiven Wachstum zeigte sich hier eine Tumoraussaat in distale Lymphknoten (Tanaka et al. 2010). Die Inhibierung des Adhäsionsmoleküls mit siRNA erbrachte folglich eine Reduktion der Tumorinvasivität (Tanaka et al. 2010). Ähnliche Ergebnisse zeigten sowohl die Analysen von Patienten mit Plattenepithelkarzinomen des Kopf- Halsbereiches und ektoper N-Cadherin- Expression als auch Versuche mit N-Cadherin positiven Brust- und Pankreaskrebs-Zelllinien (Hazan et al. 2000; Hazan et al. 1997; Islam et al. 1996; Nieman et al. 1999; Shintani et al. 2006). In unseren Experimenten kam es zu einem signifikanten Abfall der Tumorzellinvasion in Cisplatin-sensitiven und -resistenten Zelllinien (Abb. 17+18), womit bei TGCT ein Zusammenhang zwischen N- 
Cadherin Expression und gesteigerter Invasivität gezeigt werden konnte. Die antikörperbasierte Inhibition sowohl der Migration als auch der Invasion beweist außerdem, dass $\mathrm{N}$-Cadherin im Metastasierungsgeschehen maligner Keimzelltumore eine übergeordnete Rolle einnimmt und eine zielgerichtete Antikörper-Therapie diesen Prozess erfolgreich hemmen könnte. Anhaltspunkte für die zugrundeliegenden zellulären Mechanismen ergeben sich aus der geänderten Zellmorphologie und Proteinexpression, die in analogen Versuchsreihen beobachtet werden konnten. Schon Islam et al. zeigten 1996 an Plattenepithelkarzinomzelllinien des Kopf- Halsbereichs, dass die überwiegend N-Cadherin positiven, E-Cadherin negativen Tumorzellen ein gestreutes Wachstum mit Verlust durchgängiger Zell-Zellkontakte aufwiesen, wohingegen für die dominant E-Cadherin exprimierenden Zellen eine typisch squamöse Morphologie mit kontinuierlichen Adhäsionskontakten kennzeichnend war (Islam et al. 1996). 3 Jahre später fielen Nieman et al. ähnliche Unterschiede an Brustkrebszelllinien auf (Nieman et al. 1999). Bei Zellen mit E-Cadherin-Expression konnte ein epithelähnliches Wuchsmuster notiert werden, wohingegen bei N-Cadherin-Positivität eine fibroblastäre Morphologie mit Reduktion der Zellkontakte beschrieben wurde (Nieman et al. 1999). Dahingehende Experimente mit Pankreaskarzinomzellen reihten sich in gleicher Weise ein (Shintani et al. 2008). Darüber hinaus charakterisierten Tanaka et al. N-Cadherin positive Prostatakrebszellen nicht nur als abgeflacht und fibroblastär, sondern zeigten eine damit einhergehende Expression von Vimentin, bei Verlust von E-Cadherin (Tanaka et al. 2010). Insgesamt berichten die Autoren übereinstimmend von einer differenten Zellmorphologie, einhergehend mit einem geränderten Expressionsprofil, mit Verlust bzw. Alteration epithelialer Adhäsionsmoleküle (E-Cadherin, N-Cadherin), bei gleichzeitiger Hochregulation mesenchymaler Marker (Vimentin), die als Ergebnis eine erhöhte Metastasierungsneigung der Tumorzellen zur Folge haben. Diese auf genetischer- und Proteinebene stattfindende strukturelle Wandlung der Tumorzellen wird epitheliale-mesenchymale Transition (epithelial-mesenchymal transition (EMT)) genannt, wurde initial als funktionaler Prozess in der Embryogenese postuliert und gilt heutzutage als mitentscheidender Schritt zur Filialisierung maligner Tumoren (Yang und Weinberg 2008). Wegweisend ist dabei insbesondere die gesteigerte, oft sogar De-novo-Expression von N-Cadherin bei simultaner Herabregulierung von E-Cadherin (sog. „Cadherin-switch“). Der „Cadherin- Switch“ wurde in zahlreichen Tumoren - unter anderem in Mamma- und Prostatakarzinomen - nachgewiesen und trägt über die Zellablösung vom Primärtumor einerseits, über neu geschaffene Interaktionen 
mit Endothel-, Zell- und Matrixkomponenten des umgebenden Stromas andererseits, entscheidend zur Zellmigration, Invasion und damit Metastasierung bei (Hazan et al. 2004; Mariotti et al. 2007; Rosivatz et al. 2002; Sarrió et al. 2006; Yanagimoto et al. 2001). Demgemäß könnte N-Cadherin in TGCT - nach erfolgtem „Cadherin- Switch“ - als ein Katalysator der EMT fungieren und so die Motilität und Invasivität der Tumorzellen begünstigen. Folglich wäre nach Inhibition des Glykoproteins auch eine Umkehr des „Cadherin-switch“ mit gesteigerter Expression von E-Cadherin denkbar, der eine mesenchymale-epitheliale Transition (MET) mit Arretierung der Tumorzellen im Ursprungsverband bedingen würde. Die Beobachtung, dass invasive, fibroblastäre Karzinomzellen durch Transfektion mit E-Cadherin kodierender cDNA in einen nichtinvasiven Phänotyp transformiert wurden, untermauert diese Hypothese (Frixen et al. 1991). Ferner notierten Tanaka et al. - nach immunhistochemischer Gegenüberstellung inhibierter Prostatakarzinome mit unbehandelten Vergleichstumoren - zum einen eine geringere Anfärbbarkeit hinsichtlich Vimentin, zum anderen eine abgeschwächtere N-Cadherin Expression (Tanaka et al. 2010). Darüber hinaus zeigte eine klinische Phase-I-Studie mit dem NCadherin-Inhibitor ADH-1 eine Cadherin-Konversion (N-Cadherin-positiv/ E-Cadherinnegativ zu N-Cadherin-negativ/ E-Cadherin-positiv) in der Rebiopsie eines Chemotherapie-refraktären Plattenepithelkarzinoms des Ösophagus nach stattgehabter Applikation (Yarom et al. 2013). Weiterführende Versuche - u. a. mit dem Schwerpunkt eines morphologischen und immunhistochemischen Vergleichs N-Cadherin positiver- und negativer Zelllinien - sollten hier erfolgen. Der Inhibitor ADH-1 (ExherinTM) könnte zudem bei testikulären Keimzelltumoren eine alternative Behandlungsmethode neben der bereits in Aussicht gestellten Möglichkeit einer antikörperbasierten Target-Therapie gegen NCadherin - mit nachgewiesener Inhibition von Proliferation, Migration und Invasion darstellen. Auch die Invasionsexperimente mit den Cisplatin- resistenten Zelllinien unter dem Blockadeantikörper sollten abermals versucht werden. 


\subsection{Molekulare Mechanismen der N-Cadherin-vermittelten Proliferation in GCT-Zelllinien}

Ein weiteres Ziel dieser Arbeit war, die der N-Cadherin vermittelten Proliferation zugrundeliegenden molekularen Mechanismen zu erforschen. In der Literatur werden an dieser Stelle insbesondere zwei Signalwege beschrieben: Die MEK-ERK-Kaskade, ein Subtyp der Mitogen-activated protein kinase (MAPK)-Wege, und der Phosphoinositide 3-OH kinase/ protein kinase B (PI3K/ AKT)-Signalweg (Koutsouki et al. 2005; Li et al. 2001; Nalla et al. 2011; Schweyer et al. 2004). Die MAP-Kinase-Wege regulieren eine Vielzahl von Zellprozessen von der Proliferation und Differenzierung bis hin zur Apoptose (Qi M. 2005). Jeder MAPK-Weg besteht aus einer dreigeteilten Kinase-Kaskade, die eine MAPKinase-Kinase-Kinase (MAPKKK, MAP3K), eine MAP-Kinase-Kinase (MAPKK, MAP2K, MEK) und eine MAP-Kinase (MAPK) enthält (M. Qi M. 2005). Die Aktivierung der jeweiligen Kinasen erfolgt durch eine doppelte Phosphorylierung (Qi M. 2005). Einer der besten untersuchten MAPK-Wege ist die MEK-ERK-Kaskade. Über eine Aktivierung des Protoonkoproteins Ras kommt es in dieser zu einer Aktivierungskette von Raf, dann - über Phosphorylierung - von MEK1 / MEK2 (MAPKK) und ERK1 /ERK2 (MAPK) (Qi M. 2005). In eben diesem Signalweg notierten Nalla et al. eine gesteigerte Phosphorylierung von ERK nach N-Cadherin-Blockade (Nalla et al. 2011). Die Inhibition des Adhäsionsmoleküls führte auch in unseren Versuchen zu einem signifikanten Anstieg der pERK/ ERK-Ratio und damit zu einer verhältnismäßigen Zunahme des phosphorylierten ERK (Abb. 19). Ergänzend zeigten Schweyer et al., dass CDDP in TGCT- Zelllinien über eine Erhöhung des pMEK/ pERK-Levels eine Aktivierung der Effektorcaspase3 induziert (Schweyer et al. 2004). Caspasen sind aus Cystein und Asparat zusammengesetzte Proteasen, die in ihrer Gesamtheit eine sich verstärkende proteolytische Kaskade bilden, welche wiederum in der Spaltung bestimmter zellulärer Zielmoleküle und schließlich in der Apoptose mündet (Kumar 2007). Dabei werden Initiatorcaspasen am Beginn der Kaskade (u.a. Caspase-8 und -9) von Effektorcaspasen (u.a. Caspase-3) unterschieden (Kumar 2007). Da unsere Ergebnisse und Beobachtungen erstens einen Proliferationsrückgang nach N-Cadherin- Blockade, zweitens eine einhergehende Phosphorylierung/ Aktivierung von MEK/ ERK und drittens zytomorphologisch apoptotische Zellen zeigten (s. Abs. 4.2), untersuchten wir ebenfalls die Caspase-3-Aktivität. Hierbei konnte - nach antikörpervermittelter N-Cadherin-Inhibtion - eine immunzytochemisch deutlich erhöhte Anfärbbarkeit der Tumorzellen für Caspase-3 nachgewiesen werden (Abb. 20). In Prostatakarzinomen beobachteten Tanaka et al. nach Applikation eines Antikörpers gegen das 
Glykoprotein ebenfalls eine gesteigerte Caspase-3-Aktivität (Tanaka et al. 2010). Die Gabe von ADH-1 erzielte in Pankreaskrebszellen gleichartige Ergebnisse (Shintani et al. 2008). Die Daten lassen somit den Schluss zu, dass die Inhibition von N-Cadherin zuerst über eine Phosphorylierung und damit Aktivierung der MEK/ ERK-Kaskade, dann über die Aktivierung der Effektorcaspase-3 die Zellapoptose induziert und über diesen Mechanismus die Proliferation von TGCT- Zelllinien hemmt.

In verschiedensten Publikationen wurde außerdem der PI3K/ AKT-Signalweg im Zusammenhang mit dem Cadherin-vermittelten Zellwachstum beschrieben (Koutsouki et al. 2005; Li et al. 2001). Hier wirkt die Kinase PI3K über eine Phosphorylierung/ Aktivierung von AKT direkt auf die zellulären Apoptosemechanismen ein und macht die Zelle so resistent gegenüber apoptotischen Stimuli (Downward 2004). Koutsouki et al. postulierten, dass N-Cadherin über eine Aktivierung dieser Signalkaskade die Apoptose in glattmuskulären Gefäßzellen reduziert (Koutsouki et al. 2005). In Melanomzellen ging eine N-Cadherin-vermittelte Aktivierung von AKT mit einer Inaktivierung des proapoptotischen Proteins Bad und einer Stabilisierung des antiapoptotischen Proteins $\beta$ Catenin einher ( $\mathrm{Li}$ et al. 2001). Unsere Daten zeigten einen Abfall der pAKT/ AKT- Ratio in den Zelllinien NTERA-2 ( $\mathrm{p}<0,005)$ und TCam-2 ( $<<0.05)$, wohingegen die übrigen Zelllinien keine signifikanten Ergebnisse erbrachten (Abb. 21). Für das Wachstum von GCT-Zellen scheint der PI3K/ AKT-Signalweg damit keine übergeordnete Rolle zu spielen, könnte aber durchaus in Cisplatin-sensitiven Zelllinien eine Funktion in der Proliferation übernehmen. 


\section{Zusammenfassung}

Maligne Keimzelltumore des Hodens (Testicular germ cell tumors, TGCT) stellen bei jungen Männern zwischen dem 15. und 40. Lebensjahr die größte Gruppe solider und maligner Tumoren dar. Histologisch und unter klinisch-therapeutischen Gesichtspunkten wird zwischen den beiden großen Gruppen der Seminome (56\%) und Nicht-Seminome $(43 \%)$ unterschieden.

Bei Cadherinen handelt es sich um $\mathrm{Ca}^{2+}$-abhängige transmembranäre Glykoproteine, die zur Gruppe der Adhäsionsmoleküle gezählt werden. Das neurale Cadherin (N-Cadherin), erstmals im Mäusehirn identifiziert, hat im physiologischen Kontext bei der embryonalen Entwicklung, aber auch aus pathophysiologischer Perspektive beim Metastasierungsprozess maligner Tumoren eine wichtige Funktion inne.

Nachdem die Expression von N-Cadherin bereits in zahlreichen epithelialen- und mesenchymalen Tumoren beobachtet, seine Funktion in der Proliferation und dem Metastasierungsverhalten aufgezeigt werden konnte, wurde das Glykoprotein in den letzten Jahren auch in TGCT - einschließlich bekannter Vorläuferläsionen - nachgewiesen. Die Ergebnisse dieser Arbeit zeigten eine Expression des Proteins in allen untersuchten GCT-Zelllinien und damit erstmals auch in den Cisplatin- resistenten Zelllinien. In zahlreichen TGCT-Metastasen konnte N-Cadherin ebenfalls nachgewiesen werden.

In den Inhibitionsexperimenten von N-Cadherin mit siRNA und dem Blockadeantikörper zeigte sich eine signifikante Reduktion des Tumorwachstums. Gleichzeitig konnte eine Abnahme der Tumorzellmigration und -invasion notiert werden. Die Untersuchung der zugrundeliegenden molekularen Mechanismen ließ den Schluss zu, dass die Inhibition von N-Cadherin zuerst über eine Phosphorylierung und damit Aktivierung der MEK/ERK-Kaskade, dann über die Aktivierung der Effektorcaspase-3 die Zellapoptose induziert und über diesen Mechanismus das Wachstum von TGCT hemmt.

Zusammengefasst lässt sich folgern, dass GCT-Zelllinien und TGCT, einschließlich ihrer Metastasen, N-Cadherin exprimieren, die Gen- oder Proteinblockade zu einer Abnahme der Proliferation, Migration und Invasion der Tumorzellen führt und die Proliferationsreduktion über eine Aktivierung der MEK-ERK-Kaskade und Caspase 3 induziert wird. NCadherin könnte somit eine in Zukunft alternativtherapeutisch nutzbare Zielstruktur in TGCT - auch im metastasierten oder Rezidivstadium - darstellen. 


\section{Literaturverzeichnis}

Abutaily AS, Addis BJ, Roche WR (2002): Immunohistochemistry in the distinction between malignant mesothelioma and pulmonary adenocarcinoma: a critical evaluation of new antibodies. J Clin Pathol $\underline{55}$, 662-668

Akitaya T, Bronner-Fraser M (1992): Expression of cell adhesion molecules during initiation and cessation of neural crest cell migration. Dev Dyn 194(1), 12-20

Al Ghamdi AM, Jewett MA (2005): Stage I nonseminomatous germ cell tumors: the case for management by risk stratification. Can J Urol $\underline{12}, 62-65$

Angst BD, Marcozzi C, Magee AI (2001): The cadherin superfamily: diversity in form and function. J Cell Sci 114(4), 629-641

Atkin NB, Baker MC (1983): i(12p): Specific chromosomal marker in seminoma and malignant teratoma of the testis? Cancer Genet Cytogenet 10(2), 199-204

Banet N, Gown AM, Shih IeM, Kay Li Q, Roden RB, Nucci MR, Cheng L, Przybycin CG, Nasseri-Nik N, Wu LS (2015): GATA-3 expression in trophoblastic tissues: an immunohistochemical study of 445 cases, including diagnostic utility. Am J Surg Pathol 39(1), 101-108

Behnes CL, Hemmerlein B, Strauss A, Radzun HJ, Bremmer F (2012): N-cadherin is differentially expressed in histological subtypes of papillary renal cell carcinoma. Diagn Pathol $\underline{7}(1), 95$

Bergstrom R, Adami HO, Mohner M, Zatonski W, Storm H, Ekbom A, Tretli S, Teppo L, Akre O, Hakulinen T (1996): Increase in testicular cancer incidence in six European countries: a birth cohort phenomenon. J Natl Cancer Inst $\underline{88}(11)$, 727-733

Beyer J, Albers P, Altena R, Aparicio J, Bokemeyer C, Busch J, Cathomas R, CavallinStahl E, Clarke NW, Claßen J (2013): Maintaining success, reducing treatment burden, focusing on survivorship: Highlights from the third European Consensus Conference on Diagnosis and Treatment of Germ-Cell Cancer. Ann Oncol $\underline{24}(4), 878-888$

Bokemeyer C, Harstrick A, Schoffski P, Schmoll H, Poliwoda H (1992): Germ-cell tumors of the testis. The epidemiological and etiological aspects. Dtsch Med Wochenschr 117, 53(9), 1532-1537

Bosl GJ, Motzer RJ (1997): Testicular Germ -Cell Cancer. N Engl J Med 337(4), 242253 
Bremmer F, Hemmerlein B, Strauss A, Burfeind P, Thelen P, Radzun HJ, Behnes CL (2012a): N-cadherin expression in malignant germ cell tumours of the testis. BMC Clin Pathol 12(1), 19

Bremmer F, Thelen P, Pottek T, Behnes CL, Radzun HJ, Schweyer S (2012b): Expression and Function of the Vitamin D Receptor in Malignant Germ Cell Tumour of the Testis. Anticancer Res 32, 341-350

Bremmer F, Behnes CL Schweyer S (2014): Nichtseminomatöse Keimzelltumoren. Pathologe $\underline{35}(3), 238-244$

Bremmer F, Schallenberg S, Jarry H, Kuffer S, Kaulfuss S, Burfeind P, Thelen P, Radzun HJ, Ströbel P, Honecker F, Behnes CL (2015a): Role of N-cadherin in proliferation, migration, and invasion of germ cell tumours. Oncotarget $\underline{6}(32)$, 33426-33437

Bremmer F, Strobel P, Jarry H, Strecker J, Gaisa N, Straus A, Schweyer S, Radzun HJ, Behnes CL (2015b): CK19 is a sensitive marker for yolk sac tumours of the testis. Diagn Pathol $\underline{10}, 7$

Chia V, Quraishi SM, Devesa SS, Purdue MP, Cook MB, McGlynn KA (2002): International trends in the incidence of testicular cancer, 1973- 2002. Cancer Epidemiol Biomarkers Prev 19(5), 1151-1159

Cook MB, Akre O, Forman D, Madigan MP, Richiardi L, McGlynn KA (2010): A systematic review and meta-analysis of perinatal variables in relation to the risk of testicular cancer-experiences of the son. Int J Epidemiol 39(6), 1605-1618.

Dalgaard MD, Weinhold N, Edsgärd D, Silver JD, Pers TH, Nielsen JE, Jørgensen N, Juul A, Gerds TA, Giwercman A (2012): A genome-wide association study of men with symptoms of testicular dysgenesis syndrome and its network biology interpretation. J Med Genet $\underline{49}(1), 58-65$

De Wever O, Westbroek W, Verloes A, Bloemen N, Bracke M, Gespach C, Bruyneel E, Mareel M (2004): Critical role of N-cadherin in myofibroblast invasion and migration in vitro stimulated by colon-cancer-cell-derived TGF-beta or wounding. J Cell Sci 117(20), 4691-4703

Di Pietro A, Vries EG, Gietema JA, Spierings DC, de Jong S (2005): Testicular germ cell tumours : The paradigm of chemo-sensitive solid tumours. Int J Biochem Cell Biol $\underline{37}(12)$, 2437-2456

Downward J (2004): PI 3-kinase, Akt and cell survival. Semin Cell Dev Biol 15(2), 177 182

Einhorn LH (1990): Treatment of testicular cancer: a new and improved model. J Clin Oncol $\underline{8}(11), 1777-1781$. 
Einhorn LH (2002): Curing metastatic testicular cancer. Proc Natl Acad Sci U S A 99(7), $4592-4595$

Einhorn LH, Brames MJ, Juliar B, Williams SD (2007): Phase II study of paclitaxel plus gemcitabine salvage chemotherapy for germ cell tumors after progression following high-dose chemotherapy with tandem transplant. J Clin Oncol 25(5), 513-516

Ekbom A, Akre O (1998): Increasing incidence of testicular cancer--birth cohort effects. APMIS $\underline{106}(1), 225-231$

El Sayegh TY, Kapus A, McCulloch CA (2007): Beyond the epithelium: Cadherin function in fibrous connective tissues. FEBS Lett 581(2), 167-174

Enewold L, Zhou J, Devesa SS, Erickson RL, Zhu K, McGlynn KA (2011): Trends in Testicular Germ Cell Tumors Among U.S. Military Servicemen, 1990-2003. Mil Med 176(10), 1184-1187

Erez N, Zamir E, Gour BJ, Blaschuk OW, Geiger B (2004): Induction of apoptosis in cultured endothelial cells by a cadherin antagonist peptide: involvement of fibroblast growth factor receptor-mediated signalling. Exp Cell Res 294(2), 366378

Feldman DR, Bosl GJ, Sheinfeld J, Motzer RJ (2008): Medical Treatment of Advanced Testicular Cancer. JAMA 299(6), 672-684

Fosså SD, Chen J, Schonfeld SJ, McGlynn KA, McMaster ML, Gail MH, Travis LB (2005): Risk of contralateral testicular cancer: A population-based study of 29515 U.S. Men. J Natl Cancer Inst 97(14), 1056-1066

Fosså SD, Gilbert E, Dores GM, Chen J, McGlynn KA, Schonfeld S, Storm H, Hall P, Holowaty E, Andersen A (2007): Noncancer causes of death in survivors of testicular cancer. J Natl Cancer Inst 99(7), 533-544

Frixen UH, Behrens J, Sachs M, Eberle G, Voss B, Warda A, Löchner D, Birchmeier W (1991): E-cadherin-mediated cell-cell adhesion prevents invasiveness of human carcinoma cells. J Cell Biol 113(1), 173-185

Gerhardt RH, Betsholtz C (2003): Endothelial-pericyte interactions in angiogenesis. Cell Tissue Res $\underline{314}(1), 15-23$

Gerhardt RH, Wolburg H, Redies C (2000): N-cadherin mediates pericytic-endothelial interaction during brain angiogenesis in the chicken. Dev Dyn 218(3), 472-479

Gumbiner BM (2005): Regulation of cadherin-mediated adhesion in morphogenesis. Nat Rev Mol Cell Biol $\underline{6}(8), 622-634$

Hanna NH, Einhorn LH (2014): Testicular Cancer - Discoveries and Updates. N Engl J Med 371(21), 2005-2016 
Haugnes HS, Aass N, Fosså SD, Dahl O, Klepp O, Wist EA, Svartberg J, Wilsgaard T, Bremnes RM (2007): Components of the metabolic syndrome in long-term survivors of testicular cancer. Ann Oncol 18 (2), 241-248

Hazan RB, Kang L, Whooley BP, Borgen PI (1997): N-cadherin promotes adhesion between invasive breast cancer cells and the stroma. Cell Adhes Commun $\underline{4}(6)$, $399-411$

Hazan RB, Phillips GR, Qiao RF, Norton L, Aaronson SA (2000): Exogenous expression of $\mathrm{N}$-cadherin in breast cancer cells induces cell migration, invasion, and metastasis. J Cell Biol 148(4), 779-90

Hazan RB, Qiao R, Keren R, Badano I, Suyama K (2004): Cadherin switch in tumor progression. Ann N Y Acad Sci 1014, 155-163

Hemminki K, Chen B, Schettler T, Assinder SJ (2006): Familial risks in testicular cancer as aetiological clues. Int J Androl 29(1), 205-210

Hermiston ML, Gordon JI (1995): In vivo analysis of cadherin function in the mouse intestinal epithelium: Essential roles in adhesion, maintenance of differentiation, and regulation of programmed cell death. J Cell Biol 129(2), 489-506

Higby D (1974): Diamminodichloroplatinum in the chemotherapy of testicular tumors. J Urol 112(1), 100-104

Hoei-Hansen CE, Holm M, Rajpert-De Meyts E, Skakkebaek NE (2003): Histological evidence of testicular dysgenesis in contralateral biopsies from 218 patients with testicular germ cell cancer. J Pathol 200(3), 370-374

Hsu MY, Wheelock MJ, Johnson KR, Herlyn M (1996): Shifts in cadherin profiles between human normal melanocytes and melanomas. J Investig Dermatol Symp Proc 1 (2), 188-194

Huddart RA, Norman A, Shahidi M, Horwich A, Coward D, Nicholls J, Dearnaley DP (2003): Cardiovascular disease as a long-term complication of treatment for testicular cancer. J Clin Oncol 21(8), 1513-1523

Huddart RA, Norman A, Moynihan C, Horwich A, Parker C, Nicholls E, Dearnaley DP (2005): Fertility, gonadal and sexual function in survivors of testicular cancer. Br J Cancer 93(2), 200-207

Hyafil F, Babinet C, Jacob F (1981): Cell-cell interactions in early embryogenesis: a molecular approach to the role of calcium. Cell $\underline{26}, 447-454$

Islam S, Carey TE, Wolf GT, Wheelock MJ, Johnson KR (1996): Expression of N-cadherin by human squamous carcinoma cells induces a scattered fibroblastic phenotype with disrupted cell-cell adhesion. J Cell Biol 135(6), 1643-1654 
Jacobsen C, Honecker F (2015): Cisplatin resistance in germ cell tumours: Models and mechanisms. Andrology $\underline{3}(1), 111-121$

Jacobsen R, Bostofte E, Engholm G, Hansen J, Olsen JH, Skakkebaek NE, Moller H (2000): Risk of testicular cancer in men with abnormal semen characteristics: cohort study. BMJ $\underline{321}$ (7264), 789-792

Kang Y, Massague J (2004): Epithelial-Mesenchymal Transitions : Twist in Development and Metastasis. Cell 118(3), 277-279

Kashima T, Nakamura K, Kawaguchi J, Takanashi M, Ishida T, Aburatani H, Kudo A, Fukayama M, Grigoriadis AE (2003): Overexpression of cadherins suppresses pulmonary metastasis of osteosarcoma in vivo. Int J Cancer 104(2), 147-154

Kim SH, Jen WC, De Robertis EM, Kintner C (2000): The protocadherin PAPC establishes segmental boundaries during somitogenesis in Xenopus embryos. Curr Biol 10(14), 821-830

Koutsouki E, Beeching CA, Slater SC, Blaschuk OW, Sala-Newby GB, George SJ (2005): N-Cadherin - Dependent Cell - Cell Contacts Promote Human Saphenous Vein Smooth Muscle Cell Survival. Arterioscler Thromb Vasc Biol 25(5), 982-988

Krege S, Beyer J, Souchon R, Albers P, Albrecht W, Algaba F, Bamberg M, Bodrogi I, Bokemeyer C, Cavallin-Ståhl E (2008a): European Consensus Conference on Diagnosis and Treatment of Germ Cell Cancer: A Report of the Second Meeting of the European Germ Cell Cancer Consensus group (EGCCCG): Part I. Eur Urol 53(3), 478-496

Krege S, Beyer J, Souchon R, Albers P, Albrecht W, Algaba F, Bamberg M, Bodrogi I, Bokemeyer C, Cavallin-Ståhl E (2008b): European Consensus Conference on Diagnosis and Treatment of Germ Cell Cancer: A Report of the Second Meeting of the European Germ Cell Cancer Consensus Group (EGCCCG): Part II. Eur Urol 53(3), 497-513

Kumar S (2007): Caspase function in programmed cell death. Cell Death Differ 14(1), $32-43$

Lammens T, Swerts K, Derycke L, de Craemer A, de Brouwer S, de Preter K, Van Roy N, Vandesompele J, Speleman F, Philippé J (2012): N-Cadherin in neuroblastoma disease: Expression and clinical significance. PLoS ONE $\underline{7}(2), 1-8$

Li G, Satyamoorthy K, Herlyn M (2001): N-Cadherin-mediated Intercellular Interactions Promote Survival and Migration of melanoma cells. Cancer Res 61(9), 38193825

Luo Y, Ferreira-Cornwell MC, Baldwin HS, Kostetskii I, Lenox JM, Lieberman M, Radice GL (2001): Rescuing the N-cadherin knockout by cardiac-specific expression of N- or E-cadherin. Development 128(4), 459-69 
Luo Y, Radice GL (2005): N-cadherin acts upstream of VE-cadherin in controlling vascular morphogenesis. J Cell Biol 169(1), 29-34

Makrigiannakis A, Coukos G, Christofidou-solomidou M, Gour BJ, Radice GL, Blaschuk O, Coutifaris C (1999): N-Cadherin-Mediated Human Granulosa Cell Adhesion Prevents Apoptosis A Role in Follicular Atresia and Luteolysis? Am J Pathol 154(5), 1391-1406

Marie PJ (2002): Role of N-Cadherin in bone formation. J Cell Physiol 190(3), 297-305

Mariotti A, Perotti A, Sessa C, Rüegg C (2007): N-cadherin as a therapeutic target in cancer. Expert Opin Investig Drugs 16(4), 451-465

McGlynn KA, Trabert B (2012): Adolescent and adult risk factors for testicular cancer. Nat Rev Urol 9(6), 339-349

McGlynn KA, Devesa SS, Sigurdson AJ, Brown LM, Tsao L, Tarone RE (2003): Trends in the incidence of testicular germ cell tumors in the United States. Cancer 97(1), 63-70

Moch H, Cubilla AL, Humphrey PA, Reuter VE, Ulbright TM (2016): The 2016 WHO Classification of Tumours of the Urinary System and Male Genital Organs-Part A: Renal, Penile, and Testicular Tumours. Eur Urol 70(1), 93-105.

Møller H (1989): Decreased testicular cancer risk in men born in wartime. J Natl Cancer Inst $\underline{81}(21), 1668-1669$

Nalla AK, Estes N, Patel J, Rao JS (2011): N-cadherin mediates angiogenesis by regulating monocyte chemoattractant protein-1 expression via PI3K/Akt signaling in prostate cancer cells. Exp Cell Res $\underline{317}(17), 2512-2521$

National Cancer Institute (2014): Cancer Stat Facts: Testicular cancer. National Cancer Institute, Surveillance, Epidemiology and End Results Program. (http://seer.cancer.gov/statfacts/html/testis.html)

Nieman MT, Prudoff RS, Johnson KR, Wheelock MJ (1999): N-cadherin promotes motility in human breast cancer cells regardless of their E-cadherin expression. $\mathrm{J}$ Cell Biol 147(3), 631-644

Peluso JJ (1997): Putative mechanism through which N-cadherin-mediated cell contact maintains calcium homeostasis and thereby prevents ovarian cells from undergoing apoptosis. Biochem Pharmacol 54(8), 847-853

Peluso JJ, Pappalardo A, Trolice MP (1996): N-cadherin-mediated cell contact inhibits granulosa cell apoptosis in a progesterone-independent manner. Endocrinology $\underline{137}(4), 1196-1203$

Peralta Soler A, Knudsen KA, Tecson-Miguel A, McBrearty FX, Han AC, Salazar H (1997): Expression of E-cadherin and $\mathrm{N}$-cadherin in surface epithelial-stromal 
tumors of the ovary distinguishes mucinous from serous and endometrioid tumors. Hum Pathol 28 (6), 734-739

Perotti A, Sessa C, Mancuso A, Noberasco C, Cresta S, Locatelli A, Carcangiu ML, Passera K, Braghetti A, Scaramuzza D (2009): Clinical and pharmacological phase I evaluation of ExherinTM (ADH-1), a selective anti-N-cadherin peptide in patients with N-cadherin-expressing solid tumours. Ann Oncol 20(4), 741745

Pon YL, Auersperg N, Wong AS (2005): Gonadotropins Regulate N-cadherin-mediated Human Ovarian Surface Epithelial Cell Survival at Both Post-translational and Transcriptional Levels through a Cyclic AMP / Protein Kinase A Pathway. J Biol Chem 280(15), 15438-15448

Porcu P, Bhatia S, Sharma M, Einhorn LH (2000): Results of treatment after relapse from high-dose chemotherapy in germ cell tumors. J Clin Oncol 18 (6), 1181-1186

Pötter E, Bergwitz C, Brabant G (1999): The cadherin-catenin system: Implications for growth and differentiation of endocrine tissues. Endocr Rev 20(2), 207-239

Qi J, Chen N, Wang J, Siu C (2005): Transendothelial Migration of Melanoma Cells Involves N-Cadherin-mediated Adhesion and Activation of the $\beta$-Catenin Signaling Pathway. Mol Biol Cell 16(9), 4386-4397

Qi M (2005): MAP kinase pathways. J Cell Sci 118(16), 3569-3572

Radice GL, Rayburn H, Matsunami H, Knudsen KA, Takeichi M, Hynes RO (1997): Developmental defects in mouse embryos lacking N-cadherin. Dev Biol $\underline{181}(1), 64-78$

Rodriguez E, Mathew S, Reuter V, Ilson DH, Bosl GJ, Chaganti RSK (1992): Cytogenetic analysis of 124 prospectively ascertained male germ cell tumors. Cancer Res $\underline{52}(8), 2285-2291$

Rodriguez E, Houldsworth J, Reuter VE, Meltzer P, Zhang J, Trent JM, Bosl GJ, Chaganti RS (1993): Molecular cytogenetic analysis of i(12p)-negative human male germ cell tumors. Genes Chromosomes Cancer $\underline{8}(4): 230-236$

Rosen A, Jayram G, Drazer M, Eggener SE (2011): Global trends in testicular cancer incidence and mortality. Eur Urol 60(2), 374-379

Rosivatz E, Becker I, Specht K, Fricke E, Luber B, Busch R, Höfler H, Becker KF (2002): Differential expression of the epithelial-mesenchymal transition regulators snail, SIP1, and twist in gastric cancer. Am J Pathol 161(5), 1881-1891

Samaniego F, Rodriguez E, Houldsworth J, Murty VV, Ladanyi M, Lele KP, Chen QG, Dmitrovsky E, Geller NL, Reuter V (1990): Cytogenetic and molecular analysis of human male germ cell tumors: chromosome 12 abnormalities and gene amplification. Genes Chromosomes Cancer 1(4), 289-300 
Sanders DS, Blessing K, Hassan GA, Bruton R, Marsden JR, Jankowski J (1999): Alterations in cadherin and catenin expression during the biological progression of melanocytic tumours. Mol Pathol 52(3), 151-157

Sandig M, Voura EB, Kalnins VI, Siu CH (1997): Role of cadherins in the transendothelial migration of melanoma cells in culture. Cell Motil Cytoskeleton 38 (4), 351364

Sarrió D, Moreno-Bueno G, Sánchez-Estévez C, Bañón-Rodríguez I, Hernández-Cortés G, Hardisson D, Palacios J (2006): Expression of cadherins and catenins correlates with distinct histologic types of ovarian carcinomas. Hum Pathol 37(8), 1042-1049

Schweyer S, Soruri A, Meschter O, Heintze A, Zschunke F, Miosge N, Thelen P, Schlott T, Radzun HJ, Fayyazi A (2004): Cisplatin-induced apoptosis in human malignant testicular germ cell lines depends on MEK/ERK activation. Br J Cancer $\underline{91}(3), 589-598$

Scott GA, Cassidy L (1998): Rac1 Mediates Dendrite Formation in Response to Melanocyte Melanoma Model. J Invest Dermatol 111(2), 243-250

Shen SS, Ro JY: General concepts, Germ cell tumors. In: Amin MB, Tickoo SK (Hrsg.): Diagnostic pathology. Genitourinary. 2. Auflage; Elsevier, Salt Lake City 2016a, 748-755

Shen SS, Ro JY: Seminoma. In: Amin MB, Tickoo SK (Hrsg.): Diagnostic pathology. Genitourinary. 2. Auflage; Elsevier, Salt Lake City 2016b, 762-769

Shen SS, Ro JY: Embryonal Carcinoma. In: Amin MB, Tickoo SK (Hrsg.): Diagnostic pathology. Genitourinary. 2. Auflage; Elsevier, Salt Lake City 2016c, 770- 775

Shintani Y, Hollingsworth MA, Wheelock MJ, Johnson KR (2006): Collagen I promotes metastasis in pancreatic cancer by activating c-Jun NH2-terminal kinase 1 and up-regulating N-cadherin expression. Cancer Res 66(24), 11745-11753

Shintani Y, Fukumoto Y, Chaika N, Grandgenett PM, Hollingsworth MA, Wheelock M J, Johnson KR (2008): ADH-1 suppresses N-cadherin-dependent pancreatic cancer progression. Int J Cancer 122(1), 71-77

Skakkebaek NE, Rajpert-De Meyts E, Main KM (2001): Testicular dysgenesis syndrome: an increasingly common developmental disorder with environmental aspects. Hum Reprod 16(5), 972-978

Stemmler MP (2008): Cadherins in development and cancer. Mol Biosyst $\underline{4}(8), 835-850$

Stewart DJ, Jonker DJ, Goel R, Goss G, Maroun JA, Cripps CM (2006): Final clinical and pharmacokinetic (PK) results from a phase I study of the novel $\mathrm{N}$-cadherin $(\mathrm{N}-\mathrm{cad})$ antagonist, Exherin $(\mathrm{ADH}-1)$, in patients with refractory solid tumors stratified according to N-cad expression. J Clin Oncol 24, 3016 
Suyama K, Shapiro I, Guttman M, Hazan RB (2002): A signaling pathway leading to metastasis is controlled by N-cadherin and the FGF receptor. Cancer Cell $\underline{2}(4)$, 301-314

Takeichi M (1995): Morphogenetic roles of classic cadherins. Curr Opin Cell Biol 7(5), 619-627

Tanaka H, Kono E, Tran CP, Miyazaki H, Yamashiro J, Shimomura T, Fazli L, Wada R, Huang J, Vessella RL (2010): Monoclonal antibody targeting of N-cadherin inhibits prostate cancer growth, metastasis and castration resistance. Nat Med $\underline{16}(12), 1414-1420$

Tang A, Eller MS, Hara M, Yaar M, Hirohashi S, Gilchrest BA (1994): E-cadherin is the major mediator of human melanocyte adhesion to keratinocytes in vitro. J Cell Sci 107( Pt 4), 983-992

Travis LB, Fosså SD, Schonfeld SJ, McMaster ML, Lynch CF, Storm H, Hall P, Holowaty E, Andersen A, Pukkala E (2005): Second cancers among 40576 testicular cancer patients: Focus on long-term survivors. J Natl Cancer Inst 97(18), 1354-1365

Van Den Belt-Dusebout AW, Nuver J, de Wit R, Gietema JA, Ten Bokkel Huinink WW, Rodrigus PT, Schimmel EC, Aleman BM, van Leeuwen FE (2006): Long-term risk of cardiovascular disease in 5-year survivors of testicular cancer. J Clin Oncol 24(3), 467-475

Westergaard T, Olsen JH, Frisch M, Kroman N, Nielsen JW, Melbye M (1996): Cancer risk in fathers and brothers of testicular cancer patients in Denmark. A population-based study. Int J Cancer 66(5), 627-631

Wheelock MJ, Shintani Y, Maeda M, Fukumoto Y, Johnson KR (2008): Cadherin switching. J Cell Sci $\underline{121}(\mathrm{Pt} 6), 727-735$

Wierecky J, Kollmannsberger C, Boehlke I, Kuczyk M, Schleicher J, Schleucher N, Metzner B, Kanz L, Hartmann JT, Bokemeyer C (2005): Secondary leukemia after first-line high-dose chemotherapy for patients with advanced germ cell cancer. J Cancer Res Clin Oncol 131(4), 255-260

Yanagimoto K, Sato Y, Shimoyama Y, Tsuchiya B, Kuwao S, Kameya T (2001): Coexpression of $\mathrm{N}$-cadherin and alpha-fetoprotein in stomach cancer. Pathol Int $\underline{51}(8), 612-618$

Yang J, Weinberg RA (2008): Review Epithelial-Mesenchymal Transition : At the Crossroads of Development and Tumor Metastasis. Dev Cell 14(6), 818-829

Yarom N, Stewart D, Malik R, Wells J, Avruch L, Jonker DJ (2013): Phase I clinical trial of exherin (ADH-1) in patients with advanced solid tumors. Curr Clin Pharma$\operatorname{col} \underline{8}(1), 81-88$ 
Zagars GK, Ballo MT, Lee AK, Strom SS (2004): Mortality after cure of testicular seminoma. J Clin Oncol 22(4), 640-647

Zhang C, Berney DM, Hirsch MS, Cheng L, Ulbright TM (2013): Evidence supporting the existence of benign teratomas of the postpubertal testis: a clinical, histopathologic, and molecular genetic analysis of 25 cases. Am J Surg Pathol 37(6), 827-835 


\section{Danksagung}

Herrn PD Dr. Felix Bremmer möchte ich für den Themenvorschlag dieser Arbeit danken. Er hat mich stets bei allen wissenschaftlichen Fragestellungen unterstützt. Nicht zuletzt sein Engagement sowie das beständige Interesse an den Fortschritten der Untersuchungen haben maßgeblich zum Gelingen dieser Arbeit beigetragen.

Den Professoren P. Ströbel und H.-J. Radzun danke ich für die Bereitstellung des Arbeitsplatzes sowie aller nötigen Materialien.

Mein Dank gilt auch allen Mitarbeitern des Zentrums Pathologie und besonders Herrn Stefan Küffer, der mir bei allen durchgeführten Untersuchungen dieser Arbeit immer mit Rat und Tat zur Seite stand.

Ebenfalls möchte ich mich bei Herrn PD. Paul Thelen für die immer wieder hilfreichen Ratschläge bei wissenschaftlichen Fragestellungen bedanken.

Dank sagen möchte ich auch bei Herrn Prof. P. Burfeind und Frau PD. Dr. rer. nat. Kaulfuß, die mir stets hilfreiche Ratschläge bei der Durchführung meiner Laborarbeiten gegeben haben. 